\title{
$8 F$
}

507

. N8
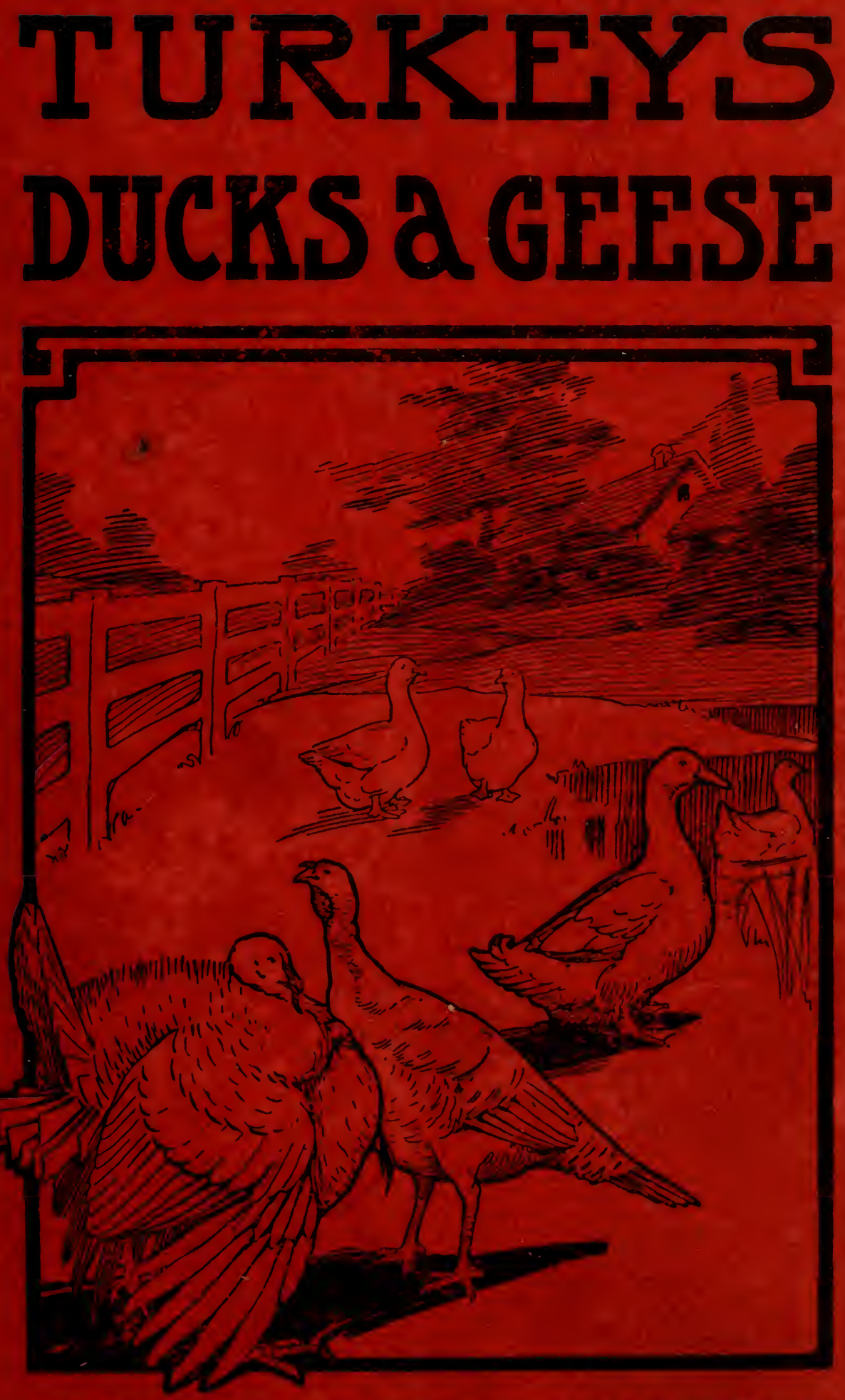

WEBB PUBBLISHING CO.,ST.PAUL,MINN. 


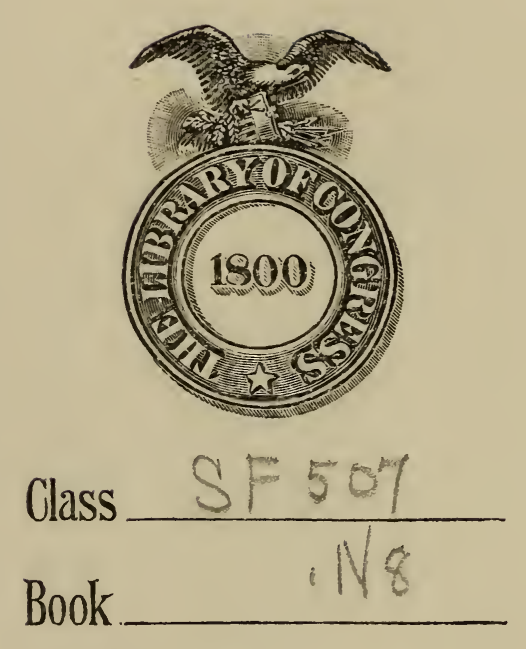

\section{Copyrightt No.}

COPYRIGHT DEPOSIT. 






\section{Turkeys, Ducks and Geese}

A Book of the Latest, Most Complete and Reliable Information on Breeding,

Hatching, Rearing, Fattening,

Developing, Showing and Selling for

Pleasure and Profit

By H. A. NOURSE and others.

\section{FULLY ILLUSTRATED}

Price Fifty Cents

WEBB PUBLISHING COMPANY

St. Paul, Minnesota 


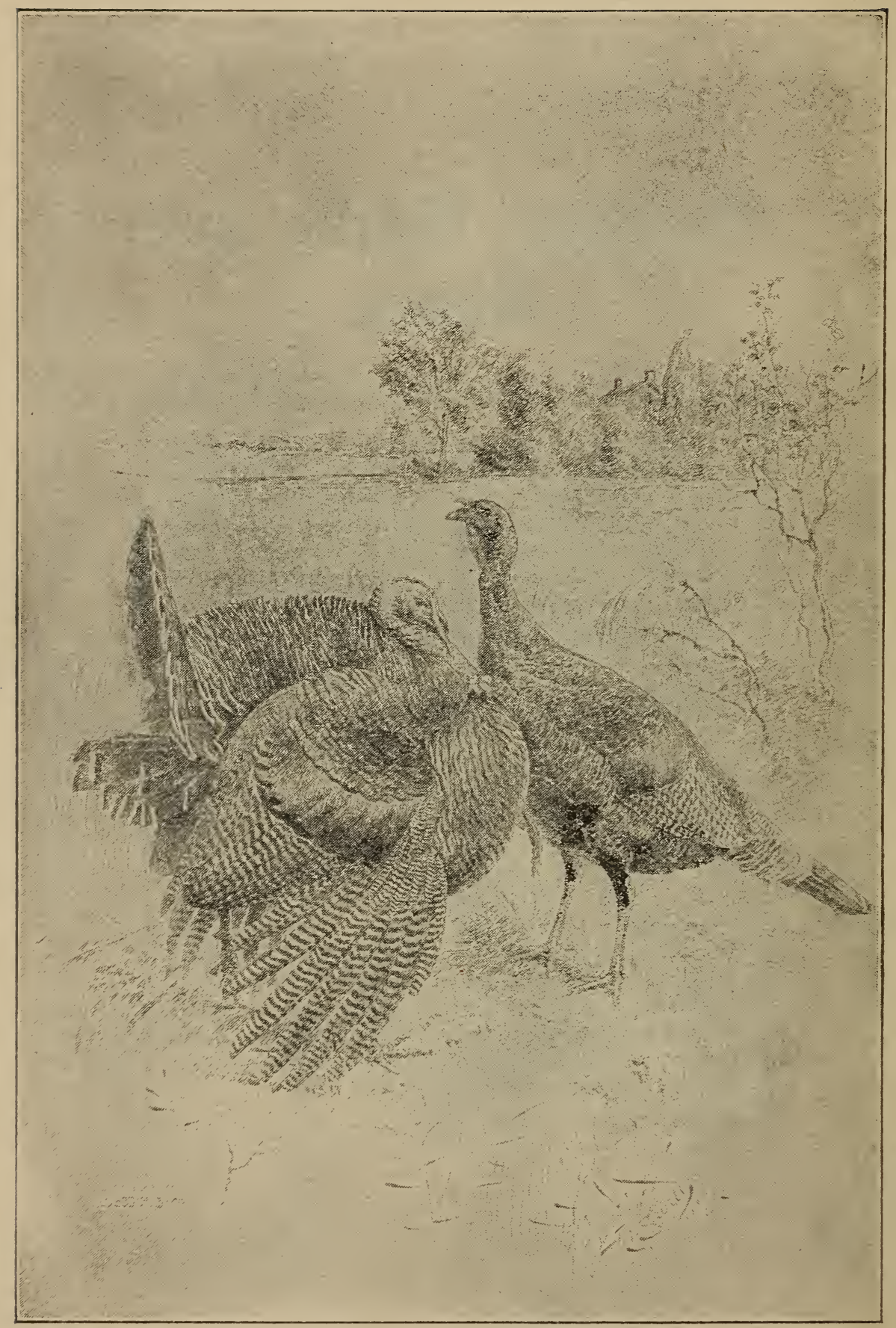

Standard-Bred Bronze Turkeys. 


\section{BREEDS OF TURKEYS.}

\section{The Principal Varieties and Their Chief Characteristics, Size, Popularity and Availability for Different Uses.}

\section{By H. A. Nourse.}

Among all the varieties of turkeys, the best known are, arranged in the order of their size, Bronze, Narragansett, Buff, Slate, Black and White. The Bronze also stands first in popularity by a very wide margin, with the White Holland second and the Narragansett third.

The Bronze variety, because of its extreme size and brilliancy of color, principally, has outstripped the other varieties until probably three-fourths of all the turkeys marketed in America each season are either thoroughbred Pronze or grades in which the Bronze blood predominates. Turkeys of this breed have been regarded as more healthy and vigorous than those of other breeds, but if there is any real difference, it is due to the fact that being so much more widely bred there is less danger that they will suffer from inbreeding. It is generally conceded, however, that any rariety which is properly bred and cared for, care being taken to breed from none but strong specimens, will soon be free from any inherent weakness or disability.

The White Holland, the only pure white breed, while the smallest of the Standard varieties, according to the Standard weights, is being bred to as large size as some of the heavier varieties by many breeders. This has never been a market breed, its size not being sufficient to make it most profitable for that purpose. It has, however, come into much favor for home consumption where the smaller carcass is sufficient for the ordinary family.

The Bronze, Narragansett, White Holland, Black and Slate turkeys breed very true to color and form and it is 
seldom that any decidedly off-colored specimens are found, even when very large flocks are raised. This fact cannot be said of the Buff variety, which really has no good claim on the name "Buff." The color usually shades from almost white in the primaries and secondaries of wings to reddish chestnut on the wing bows and backs.

One other variety may be classed as pure-bred, namely the Bourbon Reds, which are very much like the Buff in appearance except that, being allowed to have the more stable color red, they are better able to breed out the white.

The American Wild turkey, which still exists in some parts of the country, is grown to some extent in captivity and is used now and then to cross on the pure-bred varieties to improve the stamina. Those which are grown in captivity seldom get larger than the pure-bred White Holland, and the effect of crossing them with the larger Bronze and Narragansett breeds is usually to reduce the size somewhat.

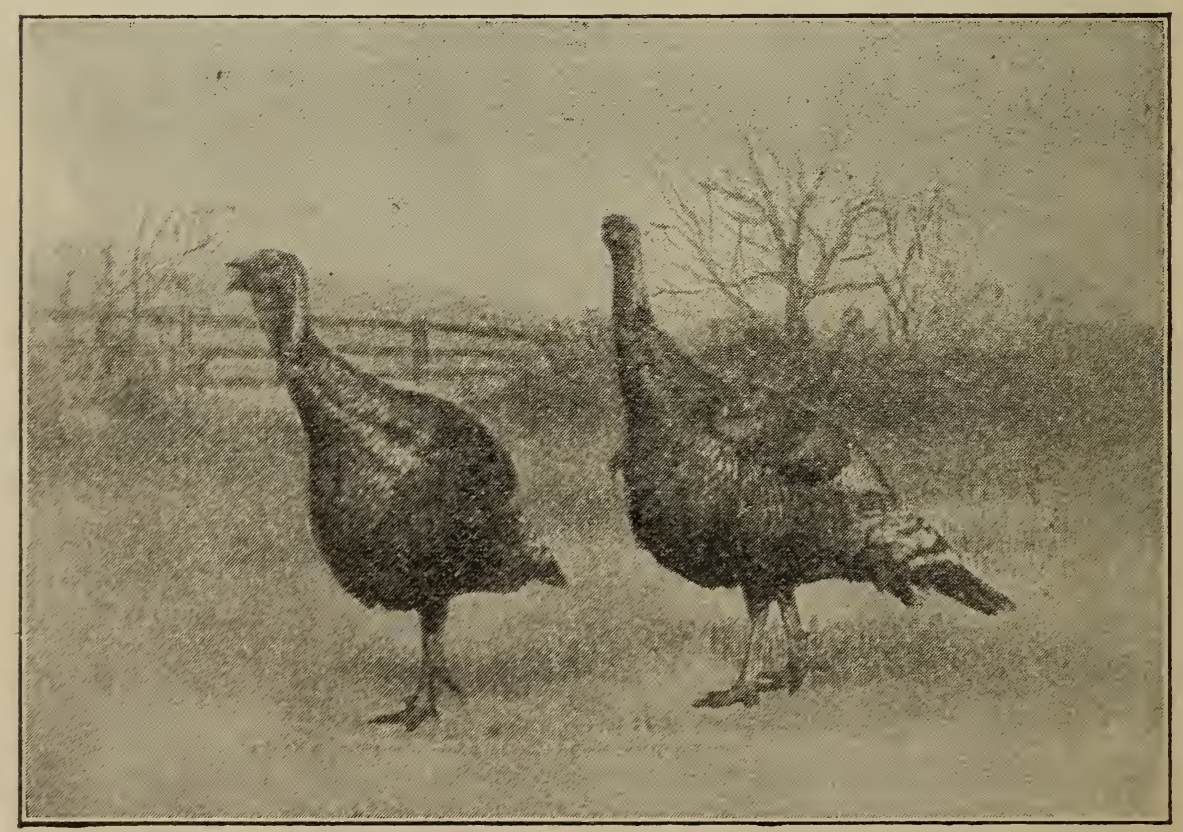

'Two Well-Developed Young Bronze Turkey Toms. 


\section{THE BRONZE TURKEY.}

\section{The Most Popular Breed-Points on Breeding-The Correct Shape and Color Described.}

\section{By Geo. D. Holden.}

Of all American turkeys the Bronze is the largest, and is more extensively bred than any other variety, and forms the largest classes at our poultry shows; in fact, at many shows one will see only the Bronze represented, the other varieties being shown mainly at our state and county fairs by those breeders who make a business of traveling from one fair to another with carload lots of the different varieties of poultry. The extent to which they are bred and their place of prominence at our best shows is proof enough that they are the favorite breed of turkeys in this country. In England the Bronze turkey was introduced to build up and improve the English turkey, and proved of wonderful benefit to them in the way of increased size and vigor of constitution. In looking over the flocks of turkeys throughout the farming districts one will find the blood of the Bronze in strong evidence. But few flocks will be found that do not show a trace of it, and from that they grade up to the thoroughbred Bronze.

\section{Selecting Breeding Stock.}

In the selecting of breeding stock one should aim to use those birds that are fully matured, as from such the roung stock will be of larger size and greater vigor than that from young and immature birds. A cock of from two to four years of age, with hens of from one to three years of age, will give A1 results, much better, as a general thing, than younger stock. Turkeys will often breed well up to five and six years of age. One should not look for excessive weight in breeding stock, but rather for good sized 
frame and vigorous constitution. An overfat bird is seldom a good breeder. One male bircl is sufficient for a good sized flock of females, the number varying somewhat according to the rigor of the male bird. Turkeys do not bear confinement well and require plenty of range and are, therefore, more easily raised on farms than when the range is limited to small enclosures. On a farm they will range at will. pick up much of their living and utilize much that would otherwise go to waste.

Turkey chicks are very delicate and tender for the first six weeks or two months of their existence, or up until the time they begin to "shoot the red," as it is termed, which is the development of the red protuberances upon the neck and throat. After this time they become hardy and vigorous and will stand almost any conditions of climate, but up until that time care must be exercised to keep them from getting damp or chilled; they will not stand the effects of a heavy rain storm, and damp quarters are almost certain to prove fatal to them. If their quarters are dry and comfortable and they are not allowed to remain out in rain storms, they will get along very well.

\section{Required Shape and Color.}

The rich colors of the Bronze turkey are such that it easily takes first rank as an exhibition bird, and as we have stated, forms the largest classes at our poultry shows. In shape a turkey should be of good sized frame, long in body, deep through the center, and with sufficient flesh to round the body out well, and to give to the breast that broad, deep and full appearance demanded by the Standard, with back rising from the neck in a curving line to about the center of back and then descending in a graceful curve to the tail. The wings should be large and powerful, folded smoothly and carried well up on the sides, with thighs long and stout, and shanks large and strong. Such a turkey would easily carry standard weight and not be overfat. 
In color the neck and breast should be a light, brilliant bronze, with body a beautiful black shaded with bronze, but not as rich or decided in character as that of the breast. The fluff black, each feather ending in a wide black and bronze band with a narrow edging of white or gray. The surface

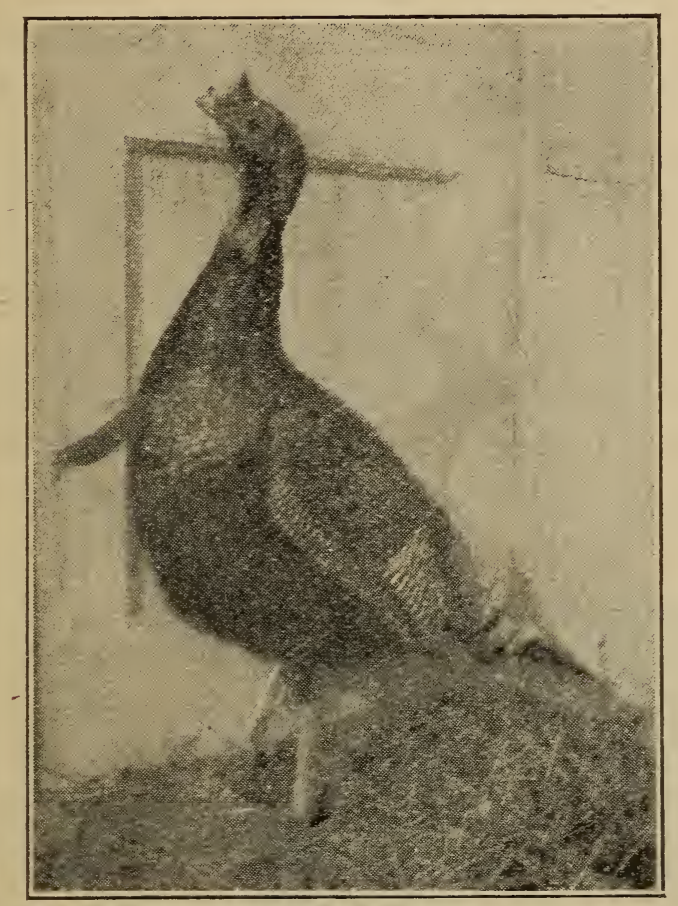

A Prize-Winning Bronze Turkey of wings should be of a bronze character. The wing coverts should be a rich bronze with a black band at the end. The primaries should be evenly and distinctly barred across with parallel bars of black and white extending the entire length of the feather. The tail must be black in ground color, penciled with narrow bands of light brown and ending with a black band edged with white or gray-with tail coverts similar in color to that of the breast, but not so rich and decided in character. This is the color of the male and the female is similar in color, except not so brilliant and clearly defined with the edging of the feathers a dull white or gray.

The usual defects in the color of the plumage of the Bronze turkey. lies in the weakness of the bronze, and in the lack of white edging where it is required, and in the barring or the penciling of the tail and tail coverts. The bronze must be rich and decided in color, and not of a dead faded appearance. And in wings the barring must be regu- 
lar and even in the primaries. And the tail well-penciled well down to the base, with a good broad, bronze bar at the end with a wide edging of white. The tail is often lacking in penciling or else marked with white or gray penciling instead of brown, and often lacling the bronze bar at the end with the white edging.

It takes richness of color and colors well defined to produce a good exhibition plumage on the male turkey, and this, in connection with good shape and sufficient weight, completes an exhibition male, one that should score high. The exhibition female is very similar in shape and color, but with the color demands not so exacting as in the male. From A1 stock there should not be much trouble in producing a quality sufficient to show up well in the show room, as the Bronze turkey seems to breed truer to color than the majority of the parti-colored varieties of fowls. They are the favorite turkeys and are deserving of their popularity.

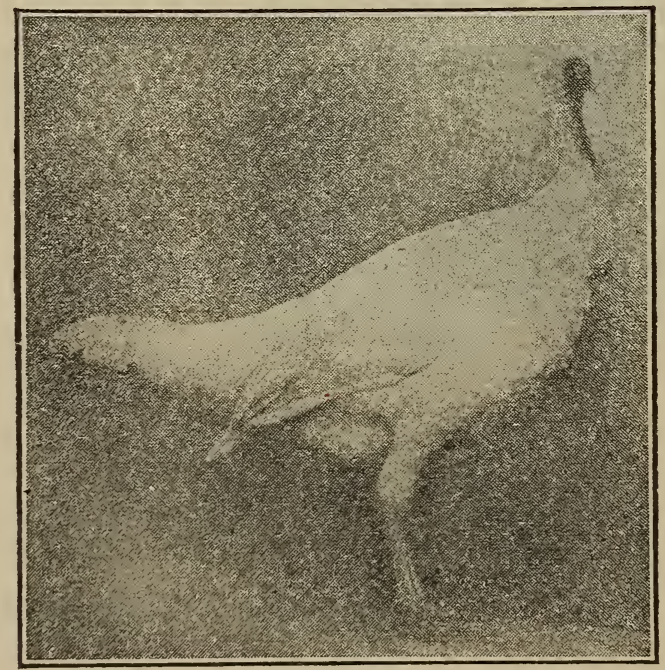

Winning White Holland l'urkey. 


\section{WHITE HOLLAND TURKEYS.}

\section{This Breed Stands Second in Popularity in America and Has Many Characteristics Which Recommend It-The Only Pure White Breed.}

\section{By H. A. Nourse.}

The White Holland, as its name signifies, is pure white so far as its plumage goes. The head and adjuncts and the legs and feet show the only color, with the exception of the beard, which is the tassel-like growth of coarse hair which hangs from the middle part of the breast and is a fine.black. This does not appear to any great extent in young birds but is found in the mature males.

It is rather more domestic in its habits than the Bronze and other larger varieties of turkeys, ustally preferring to stay in the vicinity of the buildings rather than to range widely in search of natural food. This characteristic makes the breed better adlapted for farmers and others living in reasonably thickly settled territory, where the wanderings of other varieties would probably result in trouble with neighbors or loss of turkeys, or both.

The old belief that white specimens are more tender and lack stamina has no application in this case. The White Hollands that are from strong stock and are properly hatched and reared are as strong and vigorous as any turkeys. On account of their more domestic habits they are more rapidly fattened and their white plumage gives them opportunity to dress off in an attractive manner if the work is well done. Their smaller size gives them an especial value for the tables of small families. 


\section{BREEDING TURKEYS.}

\section{"Like Begets Like" is a Safe Rule to Follow in Breeding Turkeys-No Double Mating System is Employed- Vigor and Stamina Are Very Important.}

\section{By H. A. Nourse.}

In the work of breeding turkeys the simpiest rules apply. The complex double mating systems, used for the production of show males and females in some of the varieties of Standard-bred fowls, have no place in turkey breeding and turkey raisers are to be congratulated upon the fact. Turkeys breed much truer to conformation and color than do Standard fowls and the best mating is the one which contains both males and females of the highest excellence - provided all are strong and vigorous. Vigor and stamina are absolutely necessary and to maintain both frequent adding of new blood from a different line of breeding is necessary. None of the systems of inbreeding which have proved successful for domestic fowls have produced anything but disappointment when applied to turkeys.

Outcrossing, however, will not alone maintain the strength of the individuals of the flock. The environment and care, not to mention the feeding, must be right and be comparatively near that intended by nature, or the flock will deteriorate rapidly. As nature intended the turkey to live principally in the open air and subsist largely on the food of the fields, namely vegetable growths, bugs and worms, turkeys do not take kindly to confinement, as a rule, and if successive generations are kept in yards the size and vigor will decrease.

In view of these facts, which long experience has brought out, the best mating to make is the one which includes none but strong, vigorous birds, not too closely re- 
lated, and each possessing, so far as may be, the highest excellence of shape and color, or the shape and color which conform most closely to the descriptions in the American Standard of Perfection. Very large birds are not very oftcn the best of breeders and very small ones should not be bred from. The safe rule is to select those on the larger side of medium.

\section{TURKEY GULTURE.}

General Care of Old and Young-Mating and BreedingHatching and Rearing-Fresh Air Coops-Killing the Lice-Prevention of Disease.

\section{By A. T. Titus.}

The first essential to success in turkey breeding is vigor in the parent stock. I prefer hens of standard weight, with broad heads, large feet and legs, good length of body and -two years old and over, as a turkey hen, if never allowed to get fat, will continue to be useful up to five years or even to six or seven years of age. Never discard a good hen as long as she lives and lays. With such hens I prefer a younger mate, a good type of his breed, having a broad masculine head, heavy ear carunculations and wattles, large feet, long, stout shanks, and upright carriage, as these are indications of vigor and of large size at maturity. For best results breeding stock should never be allowed to become fat, as I am firmly convinced that a turkey once fat never again regains its former vigor. Beginners in turkey breeding are often misled by such a statement as the following: "Young stock for sale from hens weighing 24-32 lbs. and a 52-lb. tom." A hen weighing 32 lbs. does not often lay fertile eggs and a $52-1 \mathrm{~b}$. tom is usually equally impotent. After the flock has been mated it should have free range or a large inclosure. 
How many females to mate with one tom is a matter of opinion. While one vigorous tom will head a flock of twenty hens with good results, I do not consider a flock of more than ten hens to be a profitable venture. Even with a flock of ten hens, I would recommend a reserve tom so that in case of accident to the head of the flock early in the breeding season, you would have a tom to take its place. It is not necessary to confine the reserve tom as the more vigorous one will be the recognized, unclisputed head of the flock.

\section{Feeding the Breeders.}

The hens should be well fed on the grains of the farmwheat, oats, barley and corn, the latter sparingly, or infertile eggs will result from the hens being overfat. The tom should be well fed. If you depend on his getting sufficient food fed with the flock, he is likely to be underfed. He needs an extra ration of corn claily. In addition to the above the flock needs vegetable food, grit and charcoal in early spring, and especially a little meat food, not much. A heap of old plaster from buildings is also good.

We set our first eggs under common hens. We like to set about three hens at about the same time on eight to eleven turkey eggs according to size of the hen, and as soon as a turkey hen is ready to sit, we give her eighteen to twenty eggs. When the time for the hens to hatch arrives, we remove the turks as hatched and give them to the turkey hen in the evening, removing her eggs and giving them to other hens to be hatched. A good turkey mother will raise a brood of twenty-five to thirty poults.

\section{Nests for Sitters.}

Barrels containing a little clean straw placed on their sides in the orchard, among trees, or in other secluded places, secured so they cannot roll, and with a hole in the lowest part to prevent water accumulating, will tempt turkey hens to nest there. The barrel makes a first class nest for setting a turkey hen. It is a good plan to gather in the 
turkey eggs every evening, leaving a hen's egg or a glass or wooden egg in the nest so as not to discourage the hen, and put them in a cool place, preferably a dry cellar and partially turn each egg daily.

Ten days before hatching time treat the sitting hens for lice. Dust them thoroughly with insect powder, repeating same on the twenty-sixth day to free the hen from lice at hatching time.

If vour turkey hen is quiet you may remove the shells from the nest at hatching time, and sometimes it is desirable to remove the poults also; but if the hen is nervous don't disturb her until she is ready to leave the nest.

\section{Feeding the Poults.}

We water the poults when twenty-four hours old, using a very shallow dish for the purpose. An old sardine can answers this purpose well. When they are thirty-six hours old-forty-eight hours will not hurt-we feed them a ration of clean sand, charcoal and egg shell pulverized fine. A few hours later we feed them what they will readily eat of milk curd well pressed until it crumbles readily or a standard brand of chick feed. The latter is more convenient and safer. Dry rolled oats is good feed.

Before feeding, if the weather is warm, we take the turkey hen and poults from the nest and quietly carry them to a grassy place ten to twenty rods from the buildings, where we have already prepared a board pen made of three I2-inch boards 8 feet long fastened securely in form of a triangle. We place the poults in the pen and water them, then quietly place the hen in the pen and come away. As the poults cannot get out the hen will stay in until the poults can get out. Then we let the hen care for them. About four or five o'clock in the afternoon we drive the hen near the buildings, allowing her to brood the flock in the open, near the buildings for protection from shunks and other enemies. While in the pen we keep fresh water before them always 
and feed sparingly as before directed about three times a day. - A good rule in feeding is to feed poults half as much as they will eat, as the little gluttons will eat and grow and in about two weeks die if allowed to have all they will eat.

\section{On the Range.}

After the hen takes them on the range, we feed them a little wheat or chick feed, or curd, when we bring them up in the evening. In a few days they will come up of their own accord, but still continue to give them a little feed to keep them tame and allow the turkey mother to do the rest. If she does not get all the food or water the poults need she will bring them to the buildings and by her call you may know that they need water or feed. Don't be afraid of the turkey mother tiring the poults to death by traveling too fast or too far nor that she will trail them through the wet grass and chill them, nor that she will allow them to get wet from a shower of rain. She will do nothing of the kind. A turkey mother knows much more than you do about the needs of her flock of poults. Treated in this way the flock is always tame and you will have no trouble to teach them to roost indoors when winter comes, but don't put them in a chicken house. A roomy shed for them I strongly recommend.

\section{Fresh Air Coops.}

Last year we sustained a great loss of poults from preciatory incursions of night animals, and we think now of trying a little different method-one practiced and recommended by a well known fancier. Instead of trusting wholly to our vigilant collie for night protection we will provide roosting coops with frame $6 \mathrm{ft}$. long, $4 \mathrm{ft}$. wide, $5 \mathrm{ft}$. high in front and $4 \mathrm{ft}$. in rear, roof and back boarded and ends and sides enclosed with poultry netting of small mesh. In this you may put low perches and keep the brood until they are ready to fly up out of langer, provided you move the coop onto fresh ground at least three times a week, and to move 
it daily is better. It is not best to have broods near one another. Sometimes two broods will go together from choice, and no evil will then result from this voluntary association.

\section{Fighting the Lice.}

I have left the most important item in the care of poults to the last-lice. We try to rid the hens from lice so that they are free from these pests when poults are hatched. We use different plans to effect this result. Fine cut tobacco in the nest is good. We use standard lice killers and Persian insect powder. A few days before hatching time take a can such as we get ground pepper in or an ordinary salt shaker, fill with powder and thoroughly shake dust into her feathers in all sections; turn the feathers forward and be sure the dust penetrates to the skin. When the poults are about three days old, take each poult and thoroughly fill its down with the powder and repeat this treatment twice a week until they are four weeks old-oftener if you can find a louse in the wing quills. After four weeks, frequently examine and treat when lice are in evidence until fully feathered.

\section{Prevention of Diseases.}

Did you ever lose turkeys from cholera? Cholera is a rare disease but bowel trouble from various causes is not rare. Overfeeding, lack of grit, lice, stagnant pools of water, feeding after swine, and exposure to cold and chilling rains are fruitful causes of many cases of so-called cholera and other turkey diseases. I don't know how to cure a very sick turkey except by applying the hatchet remedy, but the prevention of epidemics is not so difficult. Avoid the causes enumerated, and in addition do not throw out scraps of salt meat, or fish, or brine, or salt, and you will probably have but little occasion to doctor your flock. A disinfectant should always be at hand, and one of the best is Potassium Permanganate. A teaspoonful to two gallons of drinking water 
twice a week will go far toward neutralizing the evils of these causes. If you see a drooping turkey, remove it from the flock and allow it to have no water that has not been treated with Permanganate as directed, and give same to the flock daily and you may prevent the ravages of an epidemic.

A neglected cold may become roup. The fowl's nostrils moistened with a dilution of one teaspoonful of some good germ-killer to one pint of water will probably be all the treatment needed. A wound in the mouth from fighting may induce canker. Wash or rinse the sores with the same solution daily, also give it in the drinking water as above directed. Another remedy for canker is to paint canker sores daily with tincture of iodine.

If you have a drooping turkey, in addition to treatment above recommended, give one-tenth of a grain calomel or one common liver pill daily for three days, then give one grain of quinine daily for three days. If a turkey is sick its liver is always torpid and you should follow the same plan of treatment as you would for yourself.

This is, in general terms, the way we raise turkeys, but the attendant of a flock must use judgment in modifying rules to suit conditions. In conclusion I will add that confining poults in a coop many nights in succession on the same ground is fatal. A turkey hen always broods her flock in the open but can be taught to take the poults indoors. Lice and orerfeeding cause more fatalities than all other agencies combined. 


\title{
HATCHING AND REARING TURKEYS.
}

\author{
Strong, Well-Developed Breeding Stock Essential to Success- \\ Making the Nest-Setting the Turkey-Feed- \\ ing and Caring for the Poults.
}

\section{By L. H. Burpee.}

The first essential to profitable turkey raising is good stock; by that we mean not necessarily fancy stock, but stock that has been carefully mated and bred to produce hardy, vigorous poults, free from disease, that will attain good marketable size by Thanksgiving time. That is the time the market turkey raiser expects to reap the golden harvest for his season's work, and without the right kind of stock to start with all his efforts will be in vain.

We will take it for granted that the breeder has the right kind of stock and will try to help him to avoid the obstacles to success by giving a little experience of our own and knowledge that we have acquired by raising several thousand poults during the past years.

This is the season that one should carefully watch the breeding turkeys and keep them well supplied with grit and coarse charcoal. You will be surprised at the amount they will eat, especially of the latter, and nothing is so good to keep the digestive organs in order and the whole system in a healthy condition.

\section{Making a Turkey Nest.}

Owing to mild winters the hens will begin laying much earlier than usual some seasons and care should be taken to provide them with well sheltered nests where the eggs will be protected from the cold weather we are likely to have before the nesting season is over. We secrete old barrels in thick brush where we know the hens will look for a place to make their nests. These locations are easily determined 
after one season, for we have found that the turkey hen almost invariably selects a place to lay near her last season's nest; especially is this true if she was allowed to sit and

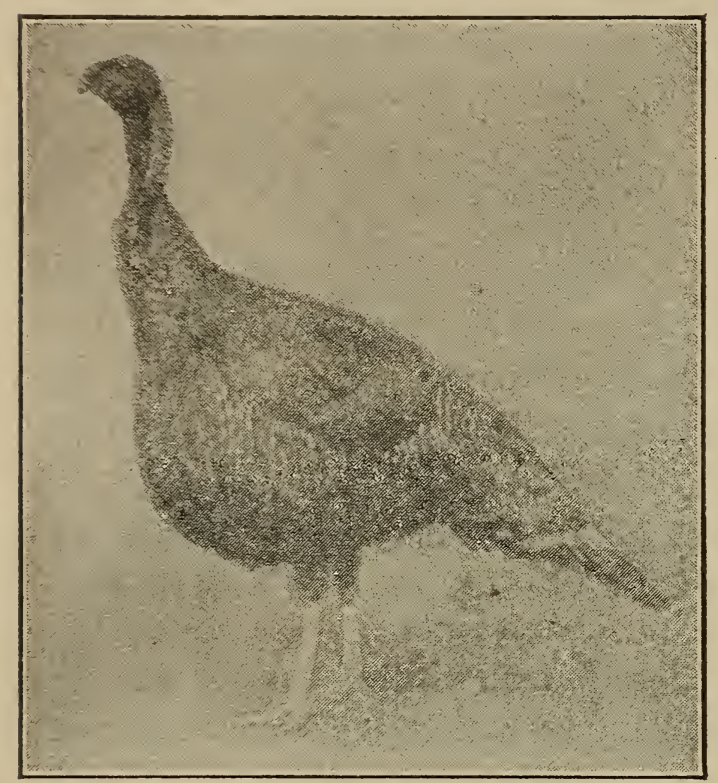

Bronze Turkey Male Showing Great Depth of Breast.

hatch a good brood there. Hence it is easy for the observing breeder to know just where to place a barrel to meet the views of the nest-seeking turkey. Many times the hen will choose one of these nests of her own accord. If she does not we can often induce her to use it by placing it near where she has her nest and putting the eggs in it, being careful not to disturb the general appearance of the place any more than is necessary.

It is nearly always advisable to keep the eggs picked up as fast as the hen lays them; a few stale eggs or china eggs may be substituted which will generally satisfy the turkey. I always substitute infertile duck eggs that have been tested out of the incubators as they are nearly the same size and easily deceive the broody turk. After she has laid from sixteen to twenty-three eggs the hen will want to sit and you can give her her own eggs or others as you desire, or she can be broken up by shutting her up for three or four days, after which she can be given her liberty and will soon begin laying again. Breeders who have only a few hens and wish to raise as many poults as possible should keep the turkey hens laying and hatch and rear the little poults with domestic 
hens: with a little more care the latter will do as well as the turkey hens.

When a hen begins to lay very early it is better to break her up when she becames broody and not let her sit until she has laid her second litter as the weather will be warmer by that time and there is not so much danger of the eggs becoming chilled when she leaves the nest to eat and dust herself. The poults of this second litter should easily dress twelve to fourteen pounds by the middle of November and we find this the size preferred for the Thanksgiving dinner. The eggs of the first litter may be hatched under domestic hens in protected quarters.

\section{Keep the Nests Separated.}

It frequently happens, where there is a large flock of turkeys, that two and sometimes more will nest within a few feet of each other. If they are allowed to sit, trouble is sure to follow unless all of them become broody at the same time, which rarely happens. When the eggs are hatched the others must be confined to their nests; otherwise they will immediately desert their eggs and go with the brood that has hatched.

Last season we had a nest where two hens laid. We did not find this nest until sixteen eggs had been laid and we noticed that there were two types of eggs in it. A little watching confirmed our suspicion that two hens were laying there. The nest was in a good location and well hidden so we decided to watch results. Thirty-seven eggs were laid when both hens became broody and twenty-nine eggs were left in the nest as that seemed to be as many as could be conveniently kept in place. The two hens set all right until the fourth week when trouble began. First one would have all but three or four of the eggs and then the other would get most of them. Many of the eggs were broken and the result was eleven poults; that experience decided me never to let two hens sit on the same nest again. 
When the hen becomes broody, if she is to be set, she should be given the number of eggs that she can cover well. Usually from fifteen to nineteen are enough, although we have given large hens more than that. Remember it is better to give them too few than too many. Have a box filled with grit and charcoal handy and throw a little whole corn where the sitter can get her fill without having to wander too far from her nest. It is an excellent plan to fix a place where she can dust herself, something easily done by spading up a little place a few rods from her nest, in a sunny location; if the dirt there is not fit it is very easy to carry a bushel of dry loam from some available source and you will be surprised to see how quickly Mrs. Turk will take aclvantage of her dusting place. A handful of lice-killing powder thrown into the dusting place will assist to rid the hen of lice and she should also be dusted thoroughly two or three times during the sitting period. These are all little things but should not be neglected on that account, for attending to them in time will help a great deal to swell the season's profit.

\section{Keep a Record of the Nest}

A record of every nest should be kept, showing when the hen began to lay, number of eggs laid, when she became broody, etc. This can be done with very little trouble and is useful for reference.

After the hen has set twenty-six days (four weeks is the time required for incubating turkeys' eggs) we always fasten her on the nest when it is possible to do so as she is apt to leave the nest before all the eggs are hatched and before the little poults that are out are strong enough. If. the hen cannot be fastened on throw a few handfuls of whole corn close to the nest where she can reach it; sometimes this will prevent her from leaving too soon and chilling the little ones that are not dried off and those that are not out of the shell. 
So much has been published about the feeding of little poults that the beginner is often at a loss to know just what advice to follow and I wish to say that what is successful in one place may not do at all in some other place, the natural conditions in the two places being so widely different. If they have a range, where there are plenty of insects and worms, two-thirds of the food problem is solved; if they do not have a range of this kind the breeder must use good judgment in providing those things that nature would provide if circumstances permitted. I have tried about all the different methods of feeding with varying success, both with broods that were confined to a limited area and with those that had a range where nature bountifully supplied them with insects, etc.

\section{Dry Food is Best.}

Where one is fortunate enough to have a good range all the food that is required is a little fine cracked corn and wheat mixed with about five per cent of cracked charcoal, such as is sold for small clicks, and a little whole corn for the hen. This should be given them early in the morning so as to keep the hen from leading the little ones around through the wet grass in search of food. Where it is practicable to do so, it is best to confine the hen until after the dew is off the grass in the morning as nothing is so fatal to the young poults as dampness.

Two years ago we tried feeding a well known chick food to the young poults, with such good results that last season we used nothing else. We mixed a little charcoal and whole corn with this food and fed once a day, early in the morning. This was to broods that had ample range where they could pick up plenty of insects, etc. There was plenty of coarse sand and gravel on the range and no grit was furnished except that in the chick food. This method of feeding was continued until the poults were about six weeks old when cracked corn and whole wheat was substituted for the chick feed. 
If the poults are confined to a limited area, where there is not much animal food, we feed a small quantity of beef scraps after the second week, and give them sour milk curds when we can get it without trouble. We do not consider this necessary as we have had as good results without its use as with it. We feed this in addition to the chick food, which is given them three or four times a day.

\section{How to Kill the Ticks.}

When the poults first hatch they should be caught and their heads greased with ointment made by mixing a little lice powder with clean lard. This will kill all head lice and also the ticks, which in some localities are fatal to young joults. These ticks resemble a sheep tick, and suck the blood from the poult by burying their heads in the poult's neck and top of its head, and will cause death in a very short time unless attended to.

We liave seen a dozen or more of these vermin on a single poult, some of them nearly as large as a small pea. If used in time the lard ointment will kill the pests.

The breeder should always remember that a close study of his flock and its surroundings will enable him the better to supply those things for their benefit which nature has not already supplied, and which are essential to success. 


\title{
HATCHING AND REARING TURKEYS.
}

\author{
The Various Methods of Setting the Turkey Hen and Feeding \\ and Rearing the Brood, Which are Used Suc- \\ cessfully by Leading Turkey Breeders \\ of the United States.
}

By H. A. Nourse.

The business of turkey. culture is and will always remain in the hands of the farmer. No one else is able to furnish the required range and without range the business is seldom satisfactory or profitable. Various methods of rearing them in confinement, subjecting them to the conditions enjoyed (or tolerated) by domestic fowls, have been tried but none of them have proved worthy of repetition.

The turkey is by nature a wild bird and wild or semiwild habits are as necessary for its successful propagation as is rain to the flowers of spring. The properly managed turkey hen (which usually means the hen that is permitted to manage her own affairs) commences to lay in March or April according to the season and to the latitude. As a rule she selects a secluded place, in a fence corner, perhaps, or under a clump of dry bush, and there deposits her eggs. If left to herself and the eggs do not become chilled and are not carried away by animals, she will hatch them into vigorous poults, which she will take to the fields and remain as far away from the daily paths of man as she can. In a majority of instances she will find sufficient food for herself and brood and in the following autumn will present her owner with a flock of large, vigorous young turkeys showing robust development, vigorous health and brilliant plumage. This is the ideal method of rearing and the one employed by some of the largest turkey raising establishments in this country. 
It happens, unfortunately, that some breeders are not so situated that they can allow the hen so much freedom with safety to the eggs and brood. They are obliged to confine the hen as much as may be necessary to protect her from hostile animals, and are obliged to protect the poults in like manner, until well grown, and otherwise deviate from the line drawn by nature.

\section{Hatching the Turkey Eggs.}

If the turkey hen is allowed to select her nest, it is well to find it in order that the eggs may be collected, if in danger from frost or from animals or birds, before the turkey begins to sit and also to make sure that the sides are sufficiently high so that the eggs will not roll out and be spoiled after the incubating business begins. Any work of this kind should be performed while the hen is away from the nest. China eggs may be put in place of the eggs removed and when the hen becomes broody, her eggs may be returned to the nest. If the flock is rather wild it is advisable to make any alterations in the nest, such as building up the sides, etc., with material that can be picked up near, such as dry twigs, dry grass, etc. The use of other material will sometimes cause the hen to give up the nest and seek a new location. Some turkey raisers place boxes and barrels in secluded places early in the season, furnishing each with the material for a nest and one or two china eggs. If the hens take advantage of these fixtures, it saves the trouble of seeking the nests and also makes it possible to fasten the hen on at hatching time so that she cannot leave until the hatch is complete, if she should be so disposed. If the owner desires to keep the hen confined until the poults obtain a fair start in life, it is a much simpler matter to remove a hen from the box or barrel and to secure the poults than it is to capture her on a nest in the blackberry patch and seek out the little ones from a dozen or fifteen hiding places among the dry leaves. 
Whichever method is followed, the rule is to leave the hen pretty much to herself until the eggs begin to produce poults.

\section{Care of the Turkey Hen and Brood.}

If the simple method of permitting the hen to take care of herself and handle the brood as nature intended is followed practically no care is necessary; in fact the only thing that can be done is to hunt up each hen and brood once a day, if they are not sufficiently hungry or if they are too much afraid of human beings to approach the farm buildings, and furnish some whole corn for the mother turkey and a little of some of the prepared dry grain chick foods for the little ones. Even this is not necessary if the season is so far advanced that the grass begins to get green and the bugs and worms appear, though it is to be recommended in any erent as an aid to better growth.

If the hen is to be confined, a coop not less than three feet square and three feet high should be provided and one four feet square is better. This should have a slat front and in warm weather should be turned away from the sun. One without any floor is preferred unless the floor is necessary to protect the inmates from animals, and such a one should be moved to a fresh location each morning.

The turkey hen should be thoroughly dusted once a week with sufficient lice-killing powder to fill her plumage to the skin. This should be done in the morning so that the powder will have a chance to get in its work and at the same time become less suffocating before the poults are brooded at night. The young ones should be caught once a week and their heads and necks thoroughly greased with lard or vaseline. This to kill the large head lice and ticks which otherwise cause the little ones much suffering and occasionally cause death. This work is seldom either possible or necessary when the hen and brood have free range; the hen is then able to dust herself thoroughly with earth and the free, wild life enables the youngsters to over- 
come the lice and ticks, which appear less frequently on poults that live in the open.

\section{Feeding the Poults.}

The brood of the confined turkey should be yarded close to the coop during the first week, but after that may be allowed to run as they will, returning to the coop at the call of the mother.

Various mixtures for food and schemes for feeding are recommended by those who have had experience in the business and whose opinions we respect, but we have always found a simple diet of one of the dry grain chick foods for the poults, with some whole corn added for the hen, the best food that can be furnished for the first two weeks. Water, or water and milk, may be given to drink and fine grit should be sprinkled where the youngsters can reach it. Plenty of fresh air and absolute cleanliness is more important than any particular kind of food or manner of feeding, though no more feed should be furnished than will be quickly consumed three times a day.

Occasionally the successful turkey raiser finds it advisable to employ the services of a domestic hen from his farm yard flock to incubate the turkey eggs and brood the little poults. When this is done the hen and brood must be confined in coop and yard. The manner of feeding does not differ from that pursued when the young are mothered by a broody turkey, neither does the manner of cooping and yarding require any change.

\section{A Wind-Proof Run.}

In the early spring (and in the Northern states that means until nearly the first of June, for cold days are likely to prevail up to that time) it is well to provicle a runway in front of the coop made of boards twelve to fifteen inches high, set on edge, to break the wind. Three of these boards, each twelve or fifteen feet long will make a very satisfactory enclosure of very nearly triangular shape. The sum shin- 
ing into this enclosure, which is free from wind, will make it warm and comfortable for the little poults, which will grow and thrive much metter than if attacked by heavy, chilling winds every time they venture out of the coop.

Such an enclosure should always be located on high ground, where the slope of the land will carry away all the surface water from heavy rains, or water may settle in the low places and the poults become wet or drowned by venturing into it.

When young, the poults are very susceptible to winds and dampness and on that account many are lost in a wet season, especially when allowed to run at large with the mother hen. It seems, too, that the mother of any other kind of farm fowls uses better judgment in the care of her young.

When bottomless coops are used it should be part of the caretaker's business to see that they also set on a well drained place, else the water will sometimes settle under the mother hen and drown the poults even while they are being brooded. Occasionally larger enclosures are made of boards and the hen and brood placed therein, without a coop. The hen is then allowed to leave the enclosure, if she desires to do so, though she will never venture far away from the poults, which for the first few days cannot get over the boards. If the hen is confined in a coop and the poults allowed to run at liberty, it is seldom wise to give the hen her freedom for she will almost invariably take her brood into the brush or into the fields and can seldom be enticed back into the coop.

When the poults become strong and sturdy, perhaps when six to eight weeks old, it is usually best to give the hen her freedom in order that she may teach them to forage for themselves, thereby cutting down the cost of feeding and obtaining for themselves food from nature's stores, which is better for them.

Occasionally it is preferred to keep hen and poults in 
their enclosure until the young "shoot the red" as the saying is, which means until they show a strong red color in their faces and heads.

\section{Care of the Growing Turkeys.}

The care of the poults after they are set at liberty on the range with their mother is practically nothing. If the range abounds in natural food, if grasshoppers are plenty and wild berries can be found, the brood will not only get along without much, if any, grain from the farmer's bins, but will develop better and faster and will be stronger, more vigorous turkeys in the fall.

When natural food is plenty the feeding of much grain will often prevent the young ones from developing their ability as foragers. If fed a heavy meal in the morning, they have little incentive to range widely and to search for the natural food. On some farms where turkeys are raised, the nature of the range is such that a turkey and brood would not secure sufficient nourishment to promote a reasonable growth and in such cases a supply must be furnished and in such quantity that the natural food will be supplemented to the amount required to make a full ration. Since the most should be made, however, of the nourishment which can be obtained on the range this supplied ration should be given at evening, though a light feed in the morning is sometimes advised. Whole grains should be used, principally wheat, corn and oats. No mash should be furnished.

\section{No Shelter Needed.}

Any attempt to house the growing stock is a waste of time and a useless expense. When the little ones are old enough to roost, the old turkey will take them into the trees or perhaps on some of the low buildings about the farm. If they roost too near the buildings, or anywhere that the owner does not find desirable, they may be induced to take 
up new roosting quarters by being driven from those first selected on two or three successive evenings.

It is well, however, to encourage turkeys to return to a place near the farm buildings at night to roost as they will be in less danger from human prowlers who sometimes feel inclined to take advantage of a good opportunity to gratify their taste for the bird of the nation's Thanksgiving. It is also well to count them every night and if any do not appear in the evening they may be looked up and the cause of their non-appearance ascertained. If the range does not supply sufficient food the lack of it may be noticed when the turkeys come in at night.

For the labor involved, no-farm product offers so great remuneration as a flock of turkeys.' In favorable seasons a flock of twenty breeders will produce two hundred young. After reserving a score of these for next year's breeders, the remainder may be sold in the market at Thanksgiving for from four to five hundred dollars. It sometimes happens that the farmer's turkeys, which receive but a small share of his attention and but a very. slight expenditure of money, produce a greater income in the fall than all the other products of the farm combined. 


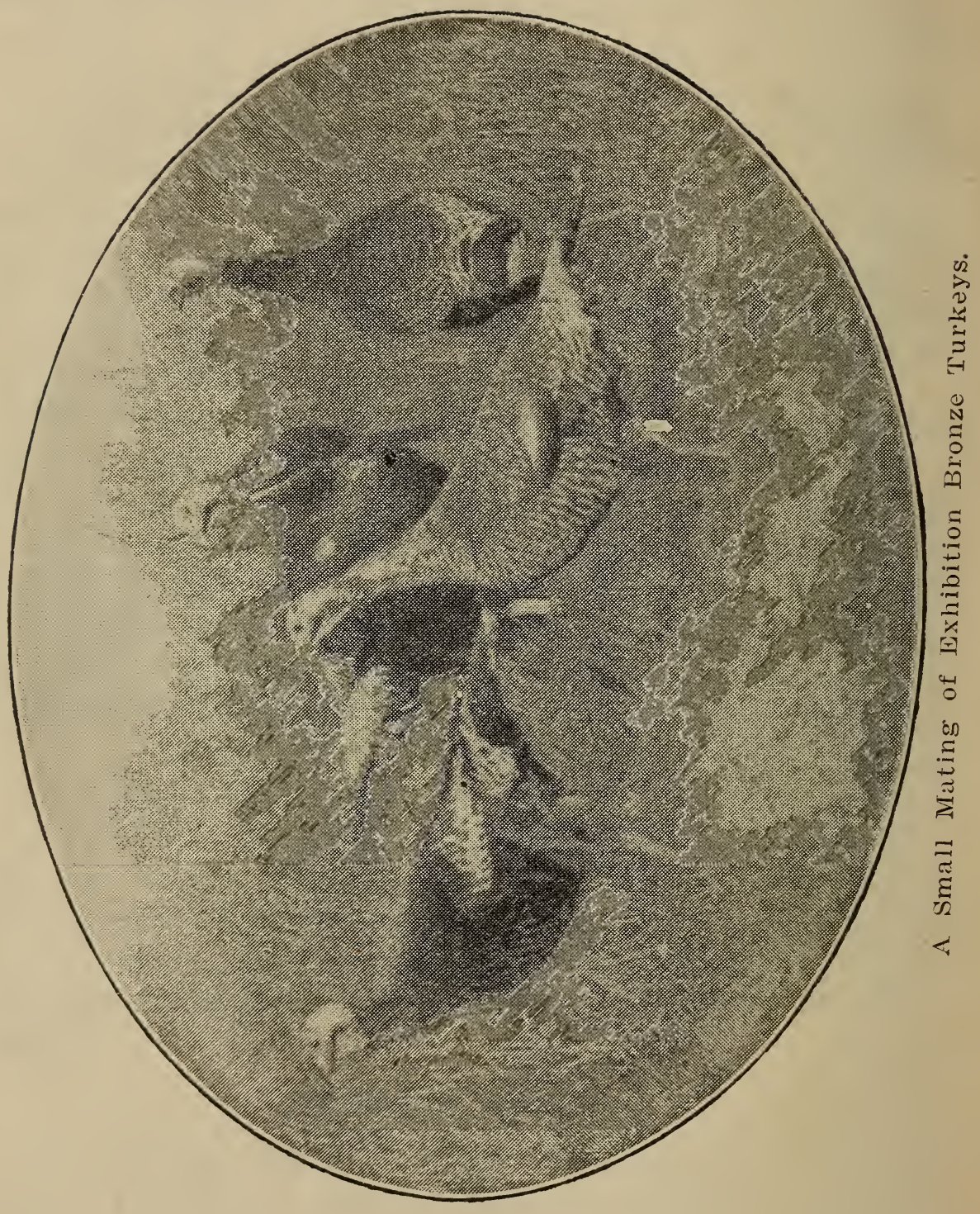




\section{REARING TURKEYS.}

\section{Young Turkeys From Hardy Stock Are Easy to Rear - Confine the Little Ones-Guard Against Lice and Dampness.}

\section{By Harry D. Dunbar.}

To be successful in raising turkeys requires no more care than with chicks, although many imagine it does. If turkeys are hatched from eggs from hardy stock there is little trouble, provided clean feed and clean quarters are given them.

The first feed usually consists of curd made by warming sour skim milk and then squeezing out as much of the moisture as possible. With this we feed chopped boiled eggs, usually those tested out of an incubator because infertile, and a bread made of fine corn meal mixed with skim milk and seasoned with salt. This is baked until quite brown and then soaked in skim milk or water, to soften it, but must be squeezed and fed as dry as possible. We sift the fine part out of oyster shells and mix it in the feed for grit.

\section{Coops for Young Poults.}

For the first week or two the hens are kept in coops, which are frequently moved to fresh grass, and a pen is built by fastening I2-inch boards together at their ends, which gives the little ones plenty of room and prevents their wandering so far to get lost. This also allows the little turkeys to get plenty of green food.

Last year, having some dried blood on hand, we used it to mix in their feed to take the place of bugs, until the turkeys were large enough to catch them, and were greatly pleased with the results. Care must be taken to not feed too much, however, as it will loosen the bowels. 
It is necessary to dust the hen and poults about once a week with insect powder, especially about the wings and body; use grease for the top of the heads of the young. Lice are perhaps the cause of death more often than all other things combined.

\section{Dampness is Often Fatal.}

After turkeys are about two weeks old we let the old ones out and let the hen and brood get their own feed, except a little which we give them in the morning and at night. Do not let them out in the morning until the dew is off the grass as little turkeys cannot stand the wet, and many little ones are killed by their mother leading them out too early in the day. After turkeys are about six weeks old we let them get their own living, which they easily do by catching grasshoppers and bugs, etc.

\section{A Profitable Farm Product.}

We consider them the most profitable property we have on the farm, for they kill each year perhaps millions of bugs, etc., which would injure the oats and other grains. With turkeys selling at eighteen cents to twenty-two cents a pound, dressed, as they have the last two or three years, it is queer that more are not raised.

The demand for stock has been so great during this time that we could nowhere near supply it. As a profitable business there is nothing better for farmers or farmer's wives than turkey raising. 


\section{REARING TURKEYS ARTIFICIALLY.}

\section{This Writer Is the First We Have Known to Recommend Rearing Poults in Brooders.}

\section{By D. W. Kolbe.}

For the last three years I have been brooding turkeys artificially. The turkey eggs are gathered daily and a few china eggs placed in the nest to keep the turkey hen from changing her laying place. When the hen is ready to sit we place from fifteen to eighteen eggs under her. Five days before they are due to hatch, the eggs are tested and the good ones placed in an incubator. Thirty-six to fortyeight hours after they hatch, the poults, being free from vermin, are placed in brooders, not over thirty to a brooder.

Those having success brooding chicks can brood turkeys. The feed for the first week should be hard boiled egg, lettuce chopped fine and rolled oats. Later gradually reduce the amount of egg and substitute small grains. Give plenty of green stuff and keep grit and charcoal before them. They also need bone-forming material. After three weeks they can go without heat and at five weeks old can be colonized. They learn to know their colony house and as they grow older will come back to roost in it. I always whistle to them when I feed them as they get to know my call and I can always call them home to feed them and to lock them in the colony house at night or in rainy weather.

My per cent of brooder poults raised, this season, after the heat was shut off, was 90 per cent. I ran one lot of thirty-five eggs in incubators, tested out one infertile and hatched thirty poults. I am a little doubtful about advising artificial incubation as I think the hen will hatch more weak germs than any incubator; but I had rather brood turkey poults artificially in large numbers than trust them to turkey hens. 


\section{TURKEYS ON THE FARM.}

\section{An Opportunity for the Farmer, Farmer's Wife or Daughter, to Increase the Family Income.}

\section{By D. G. Bromaghim.}

It is strange that there are so few turkeys raised on farms when farmers and farmers' wives have such unlimited range for them.

Riding over the country and seeing the large fields of waving grain, fields of corn that look like young forests and the patches of clover in bloom, with the busy bees at work on the beautiful red blossoms, I thought what a place for young turkeys. The grasshoppers were thick, and these with the bugs and worms that greatly interfere with a good seed crop of clover are just what the young turkeys need to make large frames and grow fast, and it would benefit the farmer to have them there. They will not touch the grain nor will they do any harm to the corn fields.

I wish I could say something that would induce girls living on a farm to take up this most fascinating work. A good flock of turkeys will bring the money to help any girl attend the school she has been so anxious to attenci. Nearly all the work of caring for the young turkeys can be done during vacation. In the fall it is very little trouble to care for them, and they are very profitable if you go at it in a sensible way.

The first thing to do is to choose a variety of turkers and be sure you get good breeding stock from a reliable breeder. Then you must have a place to keep then. They do not require a warm place; some let them shift for themselves and roost in the trees all winter, but they will do much better if protected from the cold storms. They will not do 
well roosting with the chickens; they are apt to get the lice from the chickens, which is sure death to young poults.

Corn and plenty of fresh water is all they need until the laying season; then give mixed grains. They will find all the insects they need. Gather the eggs every day and keep them in a cool place. I have spoken about the care of the young turkeys in my talks before, but it will do no harm to say, be sure and dust the old turkeys, and the young ones, with lice powder. Be careful about their feed for the first two weeks, giving them just what they will eat up each meal and plenty of fresh water. Keep them in out of the dew in the morning. When the red begins to show about their heads they are nearly out of danger and can be taken to the fields. Ours are not allowed to roost away from home a single night. After they are brought home a few nights and fed they will give you very little trouble.

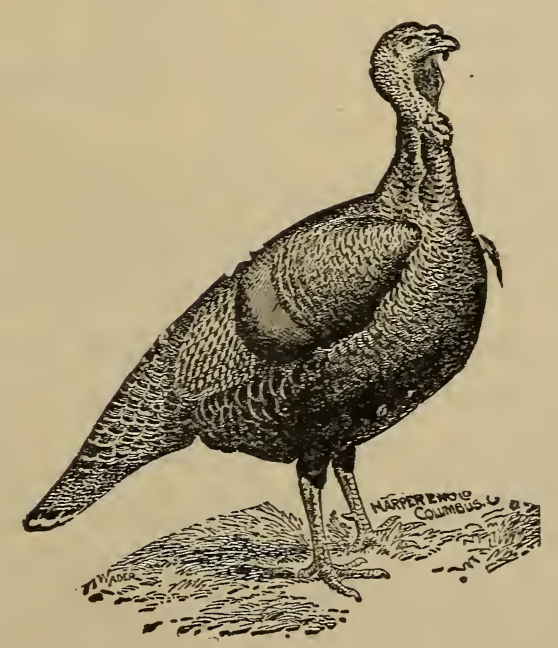




\section{MARKETING TURKEYS.}

\section{Fattening, Killing, Dressing, Cooling and Packing Turkeys Intended for the Open Market.}

\section{By H. A. Nourse.}

A very large per cent of the revenue in the turkey business is made from sales of market turkeys. A goodsized flock, raised on the farm at very slight expense, will often put more money into the farmer's pocket about Thanksgiving or Christmas time than will suffice to clothe the entire family until the next turkey crop is sold. These turkeys cannot usually be sold alive with advantage because when shipped they lose too much weight from fright and lack of nourishment enroute. Moreover, the markets demand dressed stock at the time when turkeys are usually' sold.

In view of these facts, the matter of killing, dressing and packing the turkeys is fully as important as the fattening.

\section{The Fattening Process.}

The usual method when fattening poultry is to confine them in coops or at least in buildings and small yards where they cannot exercise too freely and feed them foods, strong in fattening materials and flesh-makers. This method is not usually successful with turkeys and although occasionally a turkey raiser whose flock is very tame finds it advisable to confine the fattening birds in yards, by far the greater portion allow them to run about and provide plenty of good, yellow corn for them to eat twice or three times a day.

This is partly because the average turkey will become disconsolate and pine in confinement and will not lay on flesh, and partly because some turkey breeders believe that the turkeys make better use of the fattening food and turn a greater part of it into flesh and fat if allowed to combine 
with it the bugs, worms, tender roots and blades of grass which they pick up about the farm. The writer's experience, which has been principally with turkeys grown on

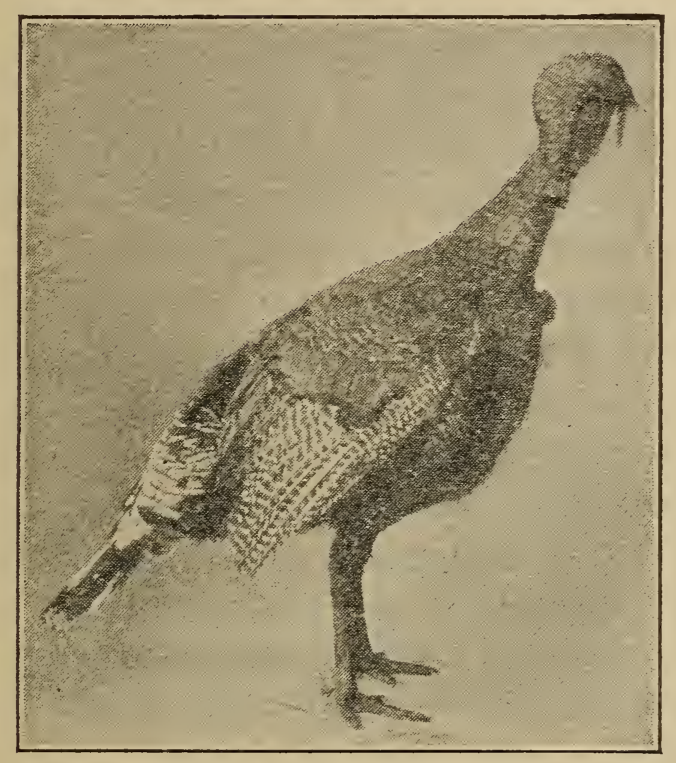

A Young Bronze Tom. free range, has indicated that under the circumstances $\mathrm{t} \mathrm{h}$ e only practical method of fattening the flock is to proceed in the manner last described. The flesh of those at liberty while fattening is almost always brighter and more attractive looking than that of those which have been confined in yards and stuffed with food while taking but little exercise.

The turkeys should not have any food for twenty-four hours before killing and may be kept in a yard where they will not be frightened. Water may be given up to within twelve hours of killing and if they drink liberally of it they usually dress out cleaner and brighter.

\section{Humane Methods of Killing.}

It is bad enough to be obliged to take the life of these birds at best but since it has to be done the methods which inflict the least pain should by all means be advised. With this idea in view, the writer has adopted and always followed the method which is here described. A noose of stout cord should be suspended from a support overhead at a height so that the noose is about even with the shoulder of the operator. The turkey is placed with his feet in this 
noose and stunned by rapping on the back of the head with a short, stout club. This puts the bird beyond the reach of pain and it may then be bled by reaching the knife through the mouth and cutting crosswise to sever the arteries in the throat. To keep the head straight downward, a weight with a short cord and a hook to insert in the nostrils, or in the beak, may be attached. If the blow was rightly delivered the muscles of the bird will relax and the feathers may be easily removed.

The Process of Picking.

The main feathers of the tail and the wing feathers should be pulled first and should be yanked straight out. In some markets, however, the main tail feathers and the primaries of the wings are demanded on the carcass and in that case they should not be removed. Next, the breast feathers should be removed as the skin of the breast is tenderest and most likely to tear. They should be pulled straight outward from the bird as it hangs and should be removed with a quick jerk, a very few at a time. From the breast the expert picker moves up over the body and then on to the back, finishing on the neck. A few of the neck feathers next to the head are usually left on. Do not draw, or remove the head or feet.

\section{Air Cooled Carcasses Keep Best.}

In some cases it is customary to put the birds in cold water immediately after picking and to take them out later and dry them. The writer's experience, however, is all in favor of keeping them out of the water, washing the carcass with a sponge to remove all dirt and washing out the mouth to remove the blood, then hanging up to dry and cool in the open air. This, of course, refers to cooling in reasonably cool weather and not during warm days when the cold water method must be resorted to.

\section{Packing the Turkey。}

After the turkeys are thoroughly cooled they may be packed for shipment. As a rule a lot of fine turkeys will 
bring better prices if forwarded in boxes containing one dozen, but they must be selected and sorted so that each box will contain turkeys of the same grade. When mixed grades are placed in the same box the price is almost always determined by the poorer quality.

The box should be of clean, bright lumber just large enough to hold the turkeys, six in a row, two rows deep. It should be lined with paper and any vacant spaces should be stuffed with paper tightly enough so that the turkeys cannot shift about during the journey, but not so tight as to crush them out of shape so that they will appear as if roughly handled when opened in the market. No ice should be used in the packages and for short distance shipments no ice will be needed. For longer shipments the stock should be forwarded in refrigerator cars.

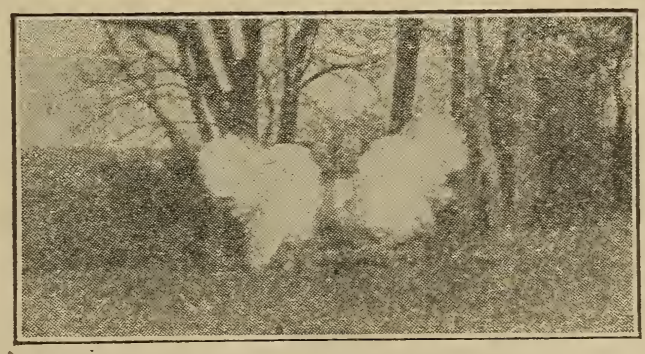

A Disagreement. 


\section{EXHIBITING TURKEYS.}

\section{The Simple Method of Preparing Turkeys to Win in the Show Room.}

By H. A. Nourse.

Preparing turkeys for exhibition is a comparatively simple matter. The various complicated methods which are employed by some in getting their fowls in the best condition for the show rooms cannot be used with turkeys, for if an attempt is made to confine the turkey, or change its regular course of living, it usually spends most of its time trying to get out and worries so much that it loses flesh and attractiveness.

The turkey is in the best possible condition when it is running with the rest of the flock and enjoying the good health that outdoor life and good feeding usually give. If it could be placed in the show coop directly from the range and not be frightened by the array of visitors that pass before the coop, or by the judge when he undertakes to examine him, no additional attention would need to be given it. Most turkeys, however, do not take kindly to the exhibition coop and first make a fast and furious effort to get out. That action frequently damages the plumage, sometimes breaking the wings and tail so badly as to put the bird out of competition, so far as a chance to win is concerned. After it finds its efforts to escape useless it usually stands well, but retreats to the rear of the coop, where it stands cowering on the approach of the judge.

To avoid these things, so far as is possible, the turkey should be tamed while running with the flock to the extent that it can be easily caught and placed in a show coop without frightening it. The bird may then be accustomed to the show pen at home and also accustomed to the man- 
ner of handling which the judge uses in investigating its shape and color. By this method it is possible to put the turkey on exhibition in his best possible physical condition and in the best color and gloss of plumage, and at the same time with that fearlessness which will permit it to make a proud appearance before the judge.

\section{PROFITABLE THANKSGIVING TURKEYS.}

How Turkeys for the Nation's Feast-Day are Reared, Fattened, Dressed and Shipped to Obtain Thirty-Five Cents per Pound-A Profitable Retail Trade wlth the First Families of the East.

\section{By H. A. Nourse.}

It is generally acknowledged that the best turkeys are raised on farms, where they have free range. Flocks so environed obtain the greater part of their food in the fields and around the buildings from the time when they are first set at liberty in the spring until cold weather sets in. This takes them to the fattening time at very little cost to their owners.

If the cost of growing a flock of young turkeys is small it is plain that the cost of fattening is not great. If, then, a considerable number is sold at thirty-five cents a pound it is evident that the profit made is large. For instance, a young tom weighing fifteen pounds when dressed would sell for $\$ 5.25$; and as the cost of food required to grow and fatten such a specimen would not exceed $\$ 1.00$ under almost any conditions, the owner would receive $\$ 4.25$ for the labor connected with dressing and marketing. It is not difficult to figure on this basis that a small flock of turkeys would pay the farmer's grocery bill.

To those who are in the habit of marketing a dozen or more turkeys each season at ten to fifteen cents a pound, 
this may sound like a fairy tale; but if they make a profit (as most of them do) on those they sell at an average of twelve and a half cents, a plan to double the price received, without increasing the cost of production in proportion, will appeal to them, if it is practicable.

At a certain large Eastern turkey farm, this price is obtained every year from families in large eastern cities, including New York, Philadelphia and Washington. There is no secret in the manner of producing and marketing the product to obtain the high price mentioned; it is simply that the manager knows how to produce the quality required and where to find purchasers who will pay the price.

\section{Growing the Turkeys.}

Hatching and growing the poults on this farm is a very simple matter, for practically all of the work is done by the turkeys. They live as free a life as do wild turkeys, ranging over 5,000 acres of rough land and living without shelter throughout the year. Their food during the warm months is almost entirely what they pick up in the fieldsgrass, roots, berries, bugs, insects and worms. No manner of feeding from the grain bins will produce turkey meat with a flavor equal to that grown by those that obtain their nourishment in the manner nature intended. Thus the turkeys of this farm reduce the cost of their "keep" and improve the flavor of their flesh by the same means.

The turkey hens lay their eggs in a nest of their own selecting, hatch out the poults and care for them until grown, almost without assistance from man. Some of those that can be reached are fed occasionally when the poults are young, but most of the food of turkey and brood is found by them upon the range. This method, or lack of method, may not raise so large a per cent of the poults hatched but the survivors are healthy, vigorous and probably capable of taking on more flesh and fat, of a better quality, than those which are protected from the weather when they are young. 
The vigorous poult is easily fattened and these youngsters possess plenty of strength and a vigorous appetite when the fattening process begins and take on flesh rapidly and uniformly.

\section{How the Fattening is Done.}

When the up-to-date poultryman desires to fatten a number of fowls he at once thinks of confining them so that

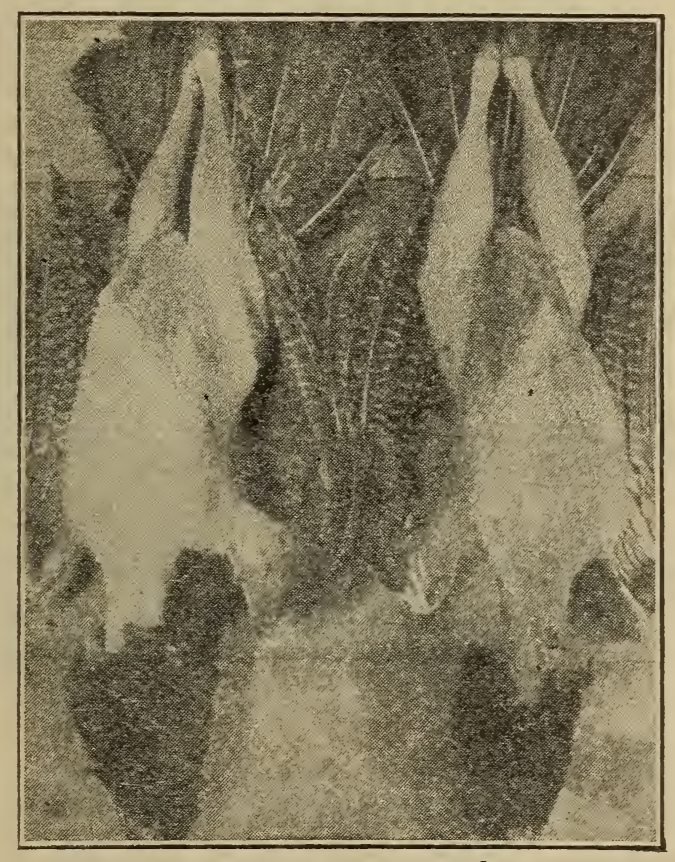

A Pair of Dressed Turkers.

they cannot exercise too freely. Not so at this establishment; the turkeys there are fattened under conditions identical with those of their growth a $\mathrm{n} d$ development. The process is simplicity itself. One heavy meal of yellow corn per day, fed just before dark, produces satisfactory results.

Feeding begins in the early days of October. About that time the supply of natural food in the fields begins to shorten and the flocks are more easily approached. During the first week of the fattening period but very little corn is given. After, the allowance is gradually increased until, at the beginning of November, every turkey destined to grace a Thanksgiving table goes to its roosting place on tree or fence with its crop crowded full with fattening, yellow corn.

The green stuff needed to promote digestion is secured by the flock and the beef scraps used by the professional 
fattener of smaller fowls is displaced by toothsome bugs and worms found by the turkeys in the fields.

That the turkeys exercise vigorously during the day is not considered a detriment, but rather an assistance; it keeps them in good health so that the extra food supplied builds flesh as well as fat and the fat is more evenly distributed.

This method of feeding is continued until killing time and produces full-fleshed bodies with a healthy appearance and bright yellow color.

\section{Killing and Dressing.}

Careful preparation for marketing often determines the price received for the product. Carelessly dressed stock never commands "top" quotations, however well fattened it may be. Scalded stock, or carcasses with torn or bruisec? skin are not wanted, except at the prices for lower grades than the same stock would be classed in if properly prepared.

The turkeys are killed by stunning by a sharp blow on the skull and bleeding through the mouth, from a cut made with a sharp knife across arteries back of the roof of the mouth. The feathers are removed, dry, by expert pickers, without injuring the skin.

Each turkey is carefully washed and hung in the open air to cool and dry. When thoroughly cool each specimen is taken down, weighed and the weight then taken is charged to the purchaser at thirty-five cents a pound.

The turkeys are then prepared for packing. The heads are removed and the skin of the neck drawn over the bone and tied with a clean string. All are drawn and the shanks are taken off at the hock joints. The lower thighs are pressed upon the upper ones until the former are even with, and horizontal to, the keel-bone. This gives the breast and body a full, round appearance. The turkey is then ready to be packed for shipping. 
Each specimen is packed in a new, wooden box. A well padded nest of fine excelsior is made in each box and lined with two thick-

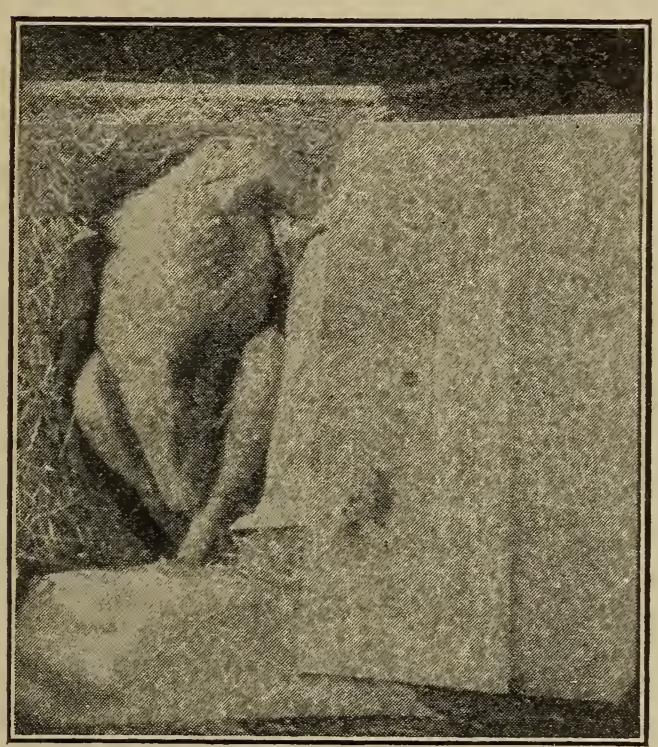

Packed Ready for Shipment. nesses of heavy wrapping paper that has a smooth surface, with the paper projecting over the sides of the box. The turkey is placed on its back in the nest and the projecting parts of the paper are wrapped about it. Sufficient excelsior is placed over it to prevent shifting, the cover is nailed on and the box is despatched to the purchaser.

Fine excelsior is used and it is not packed too firmly in the box, or the carcass might show the impressions of it through the paper, when it is unpacked.

Not every turkey breeder can sell his turkeys at thirtyfive cents a pound; but it will pay every breeder to properly fatten and dress his stock and then seek the market which will pay most for it. In almost any city there are families that will be glad to pay a few cents per pound more than market price for Thanksgiving turkeys that are worth it. The finest quality will not want for buyers if properly advertised. 


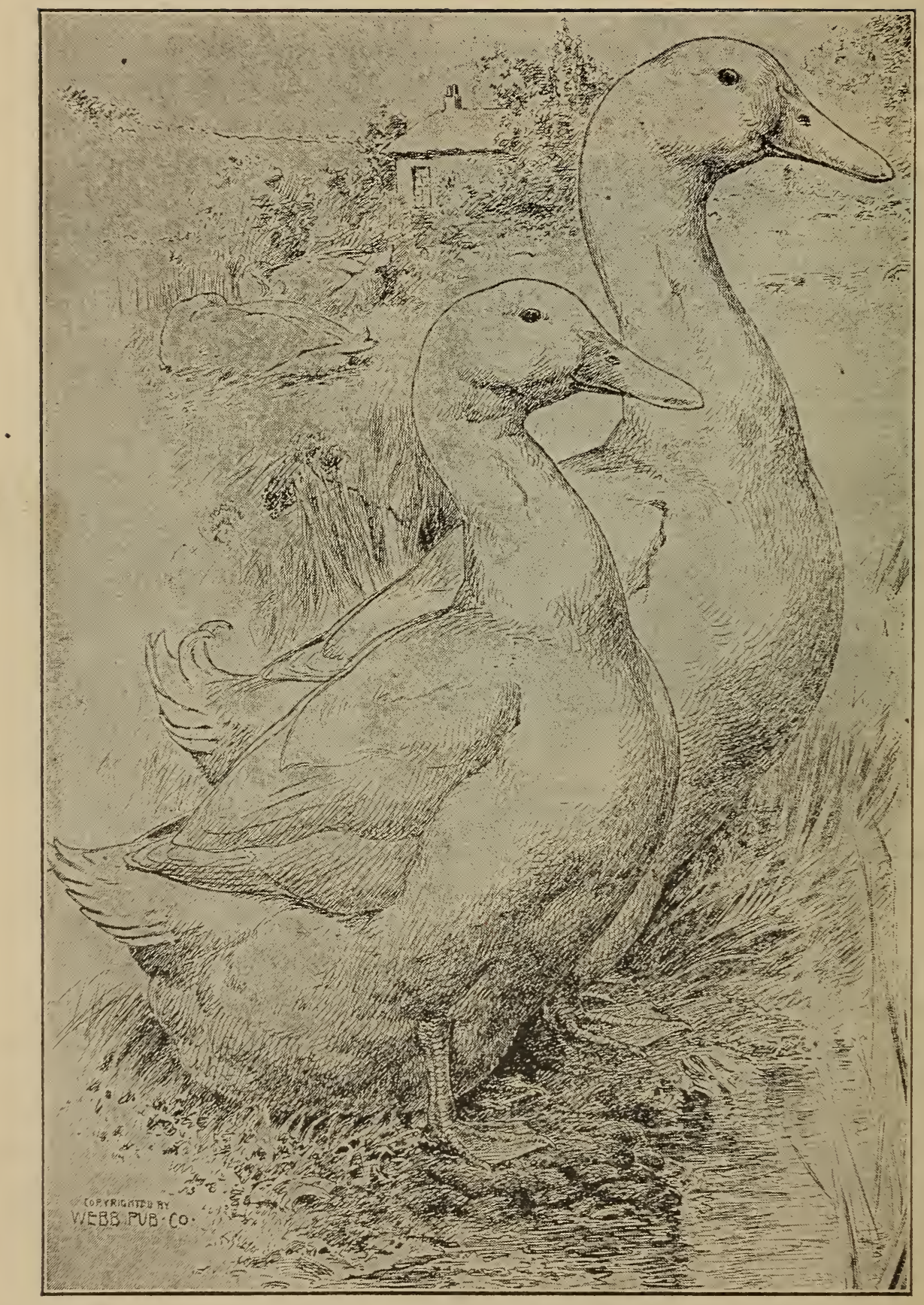

Standard-Bred Pekin Ducks. 


\section{LEADING VARIETIES OF DUCKS.}

\section{A Brief Description of the Popular Breeds and a Comparison of Their Characteristics.}

\section{By H. A. Nourse.}

Among the varieties of ducks, recognized by the American Standard of Perfection, a few are more prominent than the rest, namely: Pekins, Aylesburys, Rouens, Muscovys and Indian Runners. Of these varieties the Pelins are by considerable the most popular. A large per cent of all the market duck business done in America is in this variety.

They occupy practically the same position with respect to other varieties of ducks as do fowls of the American class with respect to other varieties of fowls. They are not as large as the Aylesburys, the Rouens or the Muscovys, but they have long, deep bodies, capable of carrying a fine amount of meat in proportion to their size and are goor breeders, rapid growers and easy fatteners. They are very good layers in the breeding season and when the young are past the first ten days of their age, they will thrive under any reasonable conditions. It is these characteristics which have made them America's most popular ducks.

The Aylesbury, a breed a little larger than the Pekin, according to standard weights, is and has been very popular in England, but it is not bred in America to any such extent as the Pekin. In general characteristics it is rery much like the Pekin except that its plumage is pure white while the plumage of the Pekin is required to be creamy white. The same difference extends to the beaks and legs and feet.

The handsomest of the larger ducks are the Rouens, which are of the same standard weights as the Aylesburys and much like them in shape characteristics except that the 
Rouens have rather shorter wings. In color they are decidedly beautiful and this characteristic is responsible for much of their popularity, despite the fact that they are reasonably good for practical purposes.

Muscovy ducks are the largest of the class and are generally considered first class for market purposes. They are more active than the ducks we have so far mentioned, standing higher from the ground. Their most noteworthy characteristics which distinguish their appearance, are the crest-like formation of feathers on the head of the drake, which lays close to the head when the bird is at rest but which,is elevated when the specimen is alarmed, and the large red face of both the duck and drake. In this respect they are somewhat like the White Faced Black Spanish except that the face of the Muscovy is red rather than white. They are the only ducks which fly and which can roost in trees. Later in this book we present an article by Mr. McClave, America's best practical authority on water fowls, treating of this variety.

The Indian Runner duck came into this country shortly before I900 and was hailed as the coming market duck. Several of the extensive duck growers of the east gave them a thorough -trial and found them decidedly inferior to the Pekins. The main point against them was their small size, which did not permit them to carry sufficient meat to meet the demands for weight. It is generally conceded, however, that they are excellent layers and that they prove satisfactory for the use of those who desire to keep a small flock, principally for home use. 


\section{MUSCOVY DUCKS.}

\section{A Useful Variety for Practical Purposes-Some of Their Peculiar Characteristics.}

\section{By Chas. McClave.}

"The duck that never quacks." Native home South America, and found largely in Guiana, Brazil, and adjoining equatorial countries. In their native state they are a wild variety, and are decidedly different from any other domesticated or wild variety of ducks known. A peculiar feature of the Muscorys is that they do not quack like all other ducks.

The drakes are at some seasons of the year very pugnacious, especially at laying time, and will battle viciously among themselves. Other domestic varieties stand no show whatever with a Muscovy in a test of strength and endurance.

The Standard of Perfection recognizes two varieties of the Muscovy-the Colored and the White. There is practically no difference except in color.

The drakes are large, nearly double the size of the ducks, and often weigh nine to eleven pounds each. They are large in frame, long in body, and broad across the back, short in shank, with broad web feet armed with long, hawklike claws, and are the most powerful of any variety of the duck family. Their wings are of good length, very compact and are their chief means of battle and defense, striking sledge hammer blows with surprising rapidity. During the autumn and spring we find it necessary to "wing" both males and females, as they delight to fly all over the farm, and also adjoining farms, simply for exercise. This is easily accomplished by cutting off seven flights of one primary. They are not a migratory bird and fly simply as a 
means of transit about their home surroundings. They are largely bred at the present time nearly all over the civilized world, especially in the United States along the Atlantic. coast. One drake will mate with ten or a dozen ducks, however, if the flock contains enough males they will mate in pairs.

Being less of a puddler and swimmer than other ducks they do not require as much water and food; not over onehalf as much food as other domestic varieties.

\section{Muscovys are Good Layers.}

Some writers have described them as "poor, or ordinary," layers. This we have found incorrect. Having bred them for many years and in large numbers, we believe them to produce more eggs than any other standard variety. They usually commence to lay in April and if not allowed to sit will continue until November.

Unlike all other varieties of ducks, unless it be the little ornamentals-Calls, Carolinas, and Mandarins, the Muscovys invariaby prepare their nests and deposit their eggs, while other domestic varieties must be penned at night, otherwise they scatter them broadcast. The Muscovy duck prefers a hollow log or stump for her nest, and will usually lay fifteen to nineteen eggs for a sitting and all will invariably prove fertile. The young are active and strong from the shell and barring accidents all will grow to maturity.

Another peculiar feature of the Muscovy is that it requires five weeks to hatch their eggs, instead of four, the time required by all other varieties of the duck and goose iamilies. If not allowed to sit, the Muscovy will continue to lay until late autumn.

Unlike other varieties they molt but once a year and being natives of countries near the equator they cannot stand zero weather as well as some other varieties.

It is no uncommon sight to see one or more Mus- 
corys sitting on the fence or some building just as contented as if on the ground. The original color of the Muscovy was black and white, the latter predominating. By careful selection for many generations the Whites have been produced: however, the young will nearly all have a black patch of feathers on top of the head and occasionally a few colored feathers on hollow of back, which usually disappear after the first month.

\section{RARE VARIETIES OF DUCKS.}

\section{A Description of Some of the Varieties That are Compara- tively New, or Prized for Their Beauty.}

\section{By F. L. Sewell.}

It is not surprising that lovers of water fowls should be pleased to see a greater variety of ducks exhibited at the exhibitions of late years. Our breeders of land fowlschicken fanciers, I mean-are pretty sure to show an early interest in anything novel in their line. So we were pleasantly surprised at the quality of a pair of Buff ducks shown at Boston some time ago. We were told at the Boston Show that Mr. Buffington imported these ducks from England. They were the first we have ever seen that were truly buff all over.

These ducks are of a tawny buff throughout, slightly lighter in front and back of the wing bar, where the Mallard shows narrow bars of white. Just above the eyes the brow is lined with a lighter shade. The color grows somewhat richer on top of the head. At first glance there is, however, little variance in the degrees of buff. They are true buff-a rarity in the duck line.

In form these new ducks are quite unlike any of our standard varieties. They are of medium size, heavier than 
the Indian Runner, but not approaching the weights of the largest kinds, such as the Pekins or Rouens. Their bodies are plump and well rounded-broad for their height. The neck and legs are shorter than most other breeds of domestic ducks.

\section{Indian Runner Ducks.}

It is not an easy undertaking to get our American people to see the value of the little Indian Runner after being so long educated to think that everything that is good in the way of ducks was to be found in the large breed of Pekins that have proven such money makers. It is the productiveness with the sweetness and game flavor of the Runner's flesh that placed it in the front rank as an egg producer and proves its true value as a table duck.

The Indian Runners have proven themselves wonderfully generous as egg producers. Besides this, they lay in the autumn, and at seasons when other less vigorous races are not productive. Their eggs also prove remarkably fertile. Some have reported them as unusually early in reaching full growth; this experience may have been obtained by others under a more forcing diet than we give ours, but as to rapid growth our Pekins have done equally well and naturally. were larger at the same age, but in point of quality of flesh the Pekins would have to be set aside and preference given to the Runner. The Pekins could not come in the same class as a table delicacy. None of the English writers seem able to find just how or when the Indian Runner came first into their country and only since I893 has it had a prominent place with breeders there.

We have observed that Indian Runners are exceptionally active foragers, not being content with the ordinary waddle of most ducks, but so ambitious to find the tidbits that hop and crawl, or fly the fields over, that they are impelled to actually run in chase of their food, obtaining by their busy habit a great deal of insect food that would only 
cause aggravation to the sight of less active ducks. They are appropriately named "runners."

The Runners stand in relation to our domestic ducks as the Leghorns do with fowls as egg producers, and in the

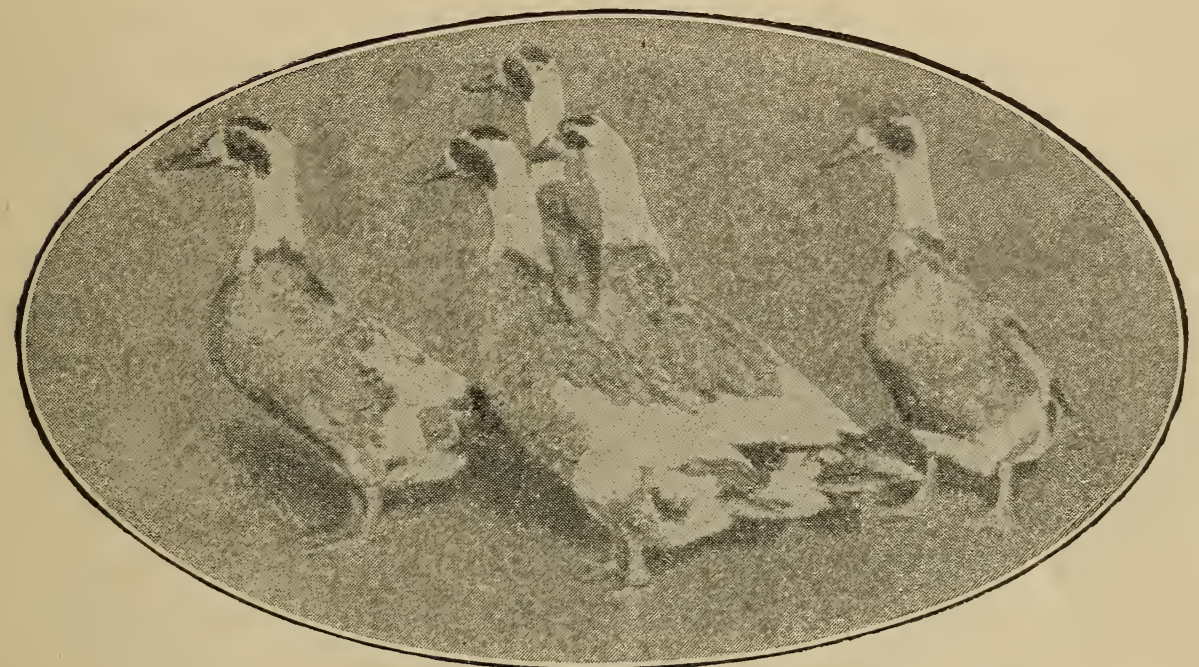

Indian Runner Ducks.

place among ducks that the Game and Dorking hold among chickens as table poultry.

\section{Black East Indians.}

A small, black breed of ducks of a bettle green gloss throughout, the Black East Indian, of highly metallic luster is shown in the English shows and a rare little duck it appears, too-when at its best. We have never seen it shown at its best here in our country. We could not help admiring them very much at the English shows, where we saw them bronght to the extreme of condition and luster.

In England much stress is laid on the smallness of size of these little waterfowls. The large Black Cayugas being kept, where black ducks are preferred, with weightiness a consideration; the little East Indian being valued for its charm of luster and neat form. English writers say that they should be almost "dazzling" in brilliancy of gloss and 
should weigh as little as two pounds if possible-and that some there, at mature age, do not attain that weight.

\section{Mandarins and Wood Ducks.}

Two of the most superb little gems in the way of waterfowls that have occasionally been shown, and have attracterl a great deal of attention from fanciers and the visiting public, are the little Mandarin ducks of Eastern Asia and the Carolina or Wood ducks of our own country. Scarcely a brighter plumage can be found than that displayed by the drakes of these two species. If fanciers only knew how well these little fellows can adapt themselves to a small covered aviary, spanning a clear brooklet, more of those who possess brooklets on their estates would make places where these charming pets could be kept and admired. They would be living pictures that would cultivate an interest for such charming fowls in most every one who saw them; indeed, I cannot imagine a being who would not be fascinated by them. Both of these species pair off and become inseparably mated, showing wonderful devotion to their one choice.

The Japanese call the Mandarin duck "Oshidori," or "pair birds." It is commonly related by many who have kept them that a bereaved mate has died after apparently pining away with grief. 


\section{DUCK RAISING FOR PROFIT.}

\section{A Well Bred Duckling Properly Hatched and Reared is \\ Ready for Market and Weighs Five Pounds When \\ Eight Weeks Old-How the Work is Done on Successful Duck Farms.}

\section{By H. A. Nourse.}

We can name off-hand a dozen duck farms east of the Mississippi river where more than 25,000 ducklings are hatched, reared and marketed every season, between the first of February and the first of October. These young ducks are hatched in February, March, April, May and the fore part of June and marketed when eight or nine weeks old, when they will dress from four and a half to six pounds each and sell for from fourteen to thirty cents a pound. Most of them are marketed in New York, Philadelphia and Boston, though some of them find their way to other cities. The cost of producing a nine weeks' old duckling is variously estimated and, of course, depends upon the cost of grain, labor, etc., in its particular section of the country. It is apparent, however, that with grain as high as it is at present, nothing but bad management could prevent a considerable profit being made when the ducks are sold for the prices mentioned.

The land and buildings required for a large duck business are by no means as expensive as are required to produce an equal number of chicks. A flock of one hundred ducks will thrive in an inclosure that would not be sufficient for a quarter of that nimber of chickens and after the youngsters are ten days old they will stand considerable cold and rough weather provided they have a diry and warm brooder to retreat to occasionally. A single boarded shed, made wind and water proof by a covering of prepared roofing, contain- 
ing a heater and pipe system sufficient to heat the hovers to the right temperature, will be as satisfactory for the rearing of ducks as a much more expensive building will be for the rearing of chickens.

\section{Incubators Do the Hatching.}

All the hatching on these duck farms is done by incubators, which are operated in buildings constructed for the purpose, most of which are partly under ground and partly above. The brooding is done almost entirely by hot water pipe systems, very much like those used for brooding chicks. The box hovers sometimes used for chicks are not at all adapted to the needs of young ducks, which require more ventilation than is possible in these hovers. The style of hover used on most duck ranches is a sort of cover or platform of boards, which rests flat upon the pipes, extending three or four inches beyond them on each side and is furnished with a hanging curtain or skirt of felt or flannel which reaches nearly to the sand upon the floor. For bedding these brooders, sand is preferred to chaff or any other substance.

\section{The Best Breeding Stock.}

Almost all the market duck business of this country is done with Pekin ducks. Although it is desirable to have all breeding stock of good size, extra large specimens seldom prove as satisfactory as breeders as do those of medium size, or a little larger. The former almost always produce a smaller number of less fertile eggs than the latter under the same conditions.

Not more than four ducks should be allowed to each drake in the early part of the season and not more than six during the warm weather. Breeding ducks change condition very rapidly and on that account the eggs from each pen should be marked when collected so that a lack of fertility discovered when testing the eggs may be traced to the pen in which the eggs were laid. 
Care must be taken not to allow the breeders to get too fat or very thin and even when they are apparently in goorl breeding condition, it is frequently necessary to change the males in order to get the best results. The pens should be bedded well so that all eggs laid may be kept clean without washing; as washing injures the egg somewhat by remor. ing from the shell some of the oily substance which na-

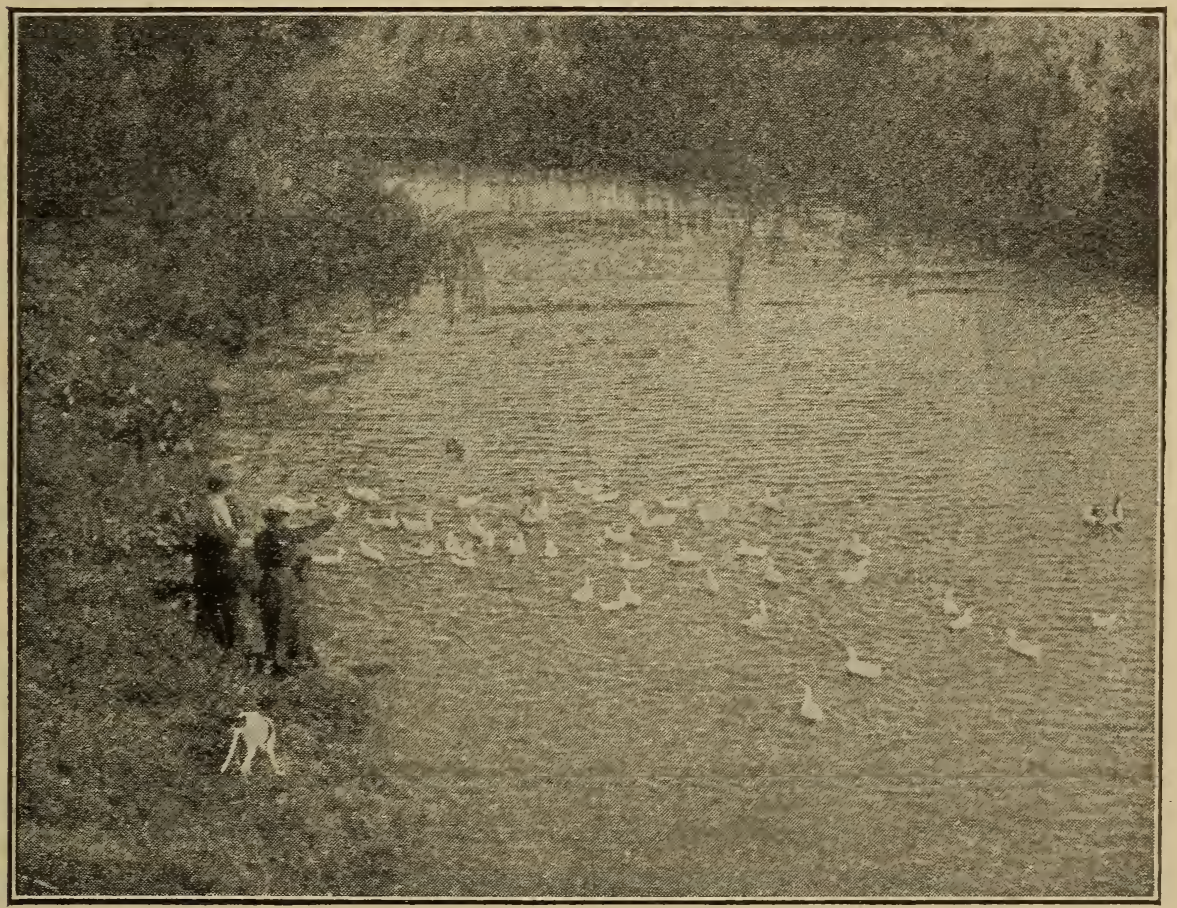

Pekin Ducks Enjoying a Swim.

ture intended should remain there. Duck eggs cannot be kept as long as hen eggs and hatch well. Ten days is as long as they can be kept with safety.

\section{Care of the Young Ducks.}

The care of the duck eggs during incubation is not much difierent from the care of hen's eggs; but after the ducks hatch, if a good per cent come out, it is necessary to remove the early ones as soon as the hatch is completed, or they are 
likely to crowd the later hatched ones and injure or kill them. Young ducks are far easier to handle in brooders than young chicks. Drive a flock of young ducks out of a brooder and in again twice and they will thereafter find the way t!ımselves uiless they suddenly become chilled or are frighteneil.

Ducklings are very timid. A sudden or unusual movement $\mathrm{on}$ the part of the care-taker, or the presence of a strange person or an animal will frighten the youngsters out of a day's growth.

Fully seventy-five per cent of the ducks reared and marketed are brooded under pipe systems heated by hot water. This method of brooding is particularly well adapted to ducks which are not good climbers and will not readily accustom themselves to going up a steep incline, such as is frequently necessary to gain access to a lamp broorler. Yet, if ducks are to be raised on a small scale, it will scarcely pay to install a hot water system and lamp brooders may be lised; but the incline should be as moderate as possible and more attention paid to teaching the ducks to ascend and descend during the first three days in the brooder. If this is done faithfully, the ducklings may be depended upon to find their way in and out, thereafter.

Like chicks, the little ducks should be confined pretty closely to the hover during the first twenty-four hours, though to cover the hover too closely, thereby preventing sufficient ventilation, is to invite disaster, for the little ducks must have air to breathe and plenty of it.

\section{Mash Food for Little Ducks.}

Dry food will not do for. ducklings which must have mash, fed fairly damp, though not wet, until they are at least four weeks old and market ducks need have no hard or dry grain at any time. The water should be given the brood as soon as it is placed in the brooder, but food should be withheld until they have become somewhat accustomed to their new home, perhaps twelve hours. 
The first meal should consist of stale (not mouldy) bread, moistened with milk, in which is mixed fine grit to make about five per cent of the mixture. This ration will be very satisfactory for two days when cornmeal and bran, in proportion of two parts of bran to one of meal, may be added, a little at first and the amount gradually increased until but little bread is used at the end of ten days. After the fourth day a little good quality beef scraps can be added with advantage and the amount may be increased until it is seven or eight per cent at the end of two weeks.

\section{Grit Must Be Furnished.}

No matter how well they are cared for, or how carefully they are fed, young ducks will not thrive unless they are supplied with plenty of coarse sand or fine grit. This they need to assist them to digest their food and without it they will literally starve to death in the midst of plenty.

Unlike chicks, they will not obtain a sufficient supply from hoppers or grit boxes nor will they pick it up from the floor of their pen; it must, therefore, be furnished in their food.

\section{Plenty of Water Required.}

A duckling cannot eat a square meal without taking almost as many swallows of water as he does mouthfuls of food. He fills his beak full of mash and then rushes to the water fountain, where he obtains water to wash it down. If he cannot obtain water he is quite likely to choke, and frequent losses are sustained from that cause. When the ducklings are old enough to be fed out of doors, water may be given in troughs or any sort of utensil in which the youngsters will not soil the drink by getting into it. When they are fed indoors, or in the brooder, the problem becomes more difficult, for fifty young ducks will distribute the contents of a two gallon drink fountain over a space four feet square in five minutes. It is advisable on that account to set the fountain in a shallow pan so that the water will 
not cover so large a surface when spilled by the drinking ducklings.

If the water fountain or dish can be placed upon a floor of slats through which the water will drain and beneath which it will be carried away in some manner, it is a distinct advantage.

The duck raiser who has plenty of water, piped to his buildings, can and should construct a trough, in front of the yards, through which a stream of fresh water may run while the ducks are eating. If this trough is placed against the fence (which should be of vertical slats) the youngsters will be able to obtain plenty of water and cannot get into it to soil it or tip it over.

Although young ducks will stand more neglect and live than will chicks, they will not thrive and be profitable if they are not well and intelligently cared for. It seems to be the impression in some quarters (among those not acquainted with the duck industry as at present conducted) that mud and other forms of dampness are substantial aids to a duck's prosperity. That, however, is far from the fact. Though a young duck will revel in a pond of water and will prefer a mud puddle to no water at all, neither damp quarters nor a swimming pool is necessary or even an advantage. The best market ducks are.raised where they have no water except to drink and where the drinking water is so supplied that they cannot get into it or distribute it over the surrcunding ground.

The brooding houses and coops should be thoroughly dry and frequently cleaned.

\section{Food for Growing Ducks.}

The requirements of the growing ducks are very simple. A mash made of one part cornmeal and two parts bran, with ten per cent of high quality beef scraps added and five per cent of coarse sand or fine grit makes a mash on which the ducklings will thrive. Although they are not particular 
about the make-up of their ration they require plenty of it and should be fed at least four times a day until they are four weeks old, after which three times is sufficient. The mash should be mixed (preferably with whole or skim milk), a little damp, but not sloppy, and fed in troughs. A small shovel should be used to distribute this mash, which must be placed in the troughs quickly or the young ducks will consume it as fast as the feeder places it within their reach.

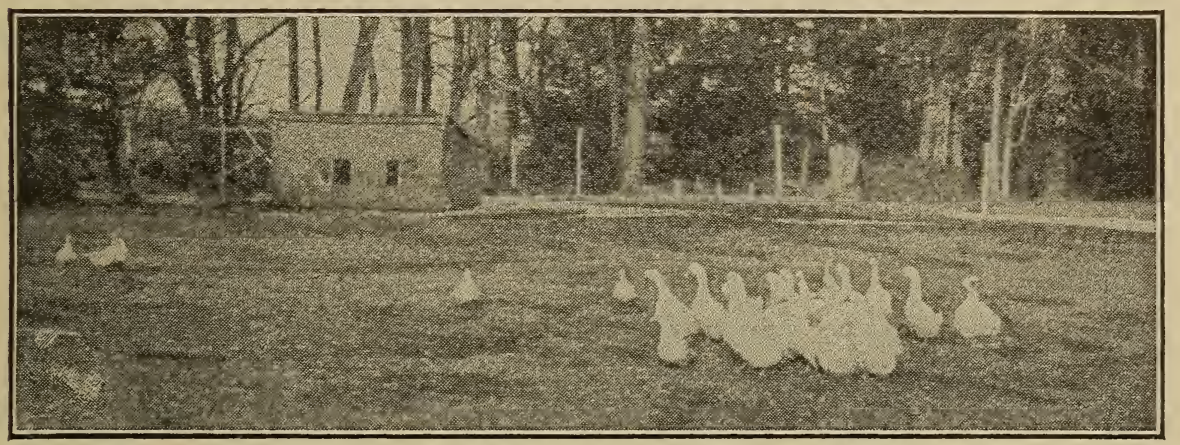

Breeding Ducks on Summer Range.

This means that the stronger members of the flock will get most of the food and the weaker ones go hungry. When the flock has finished eating, the troughs should be cleaned of any focd that remains and turned over or placed upright against the fence; if it is convenient to remove them from tiic yardis entirely, so much the better.

\section{Green Food Must Be Provided.}

Providing green food for a large flock of ducks is now an easy matter if these ducks are confined in yards where there is no grass to be had, which is always the case in the yards where ducks are kept for any considerable length of time. A plot of fresh grass kept green by frequent water. ing and tender by keeping it mowed fairly short is of much value to the duck raiser. A feeder can mow on such a plot a half bushel, bushel, or more, fresh grass in the morning when the dew is on and furnish the young ducks all they 
will eat. If green clover can be obtained it is especially good for this purpose and even prepared dry clover is useful if no green material can be found.

\section{Suitable Shade Necessary.}

Young ducks are often injured by the direct rays of the sun and growing ducks will not make so good use of the food consumed if exposed to the noon day heat as when they are protected from it. The yards can frequently be located where the ducks can find shade under trees or bushes; where that is impossible, artificial shade must be provided by building sheds or tents. Stakes three feet long, driven one foot into the ground, may have burlap, cotton cloth or canvas stretched between them to form an inexpensive but satisfactory protection from the sun's rays. If the ducks are well feathered, they require shelter from storms much less than shelter from the sun, in warm weather, and may be placed anywhere on the place where it is convenient to build the yards and where the grass is green. If the yards can be moved on to fresh locations as soon as the grass is consumed, it will not be necessary to feed any sort of green food.

\section{Ducks are Easily Frightened.}

Although anyone who is not acquainted with ducks would not imagine, if observing a flock from some little distance, that they are easily. frightened, it is a fact that the slightest unusual noise, the presence of a person to whom they are not accustomed, or the approach of a strange animal will so frighten the ducks that they will lose in an hour more flesh and strength than can be built up by two days of good feeding. It is necessary, for best results, to guard against the intrusion of both persons and animals. Duck yards should not be located close to a traveled path or roadway, but away from possibility of interference as much as possible. 
To fatten a well-grown, healthy duckling is an easy matter. Mix a mash of three parts cornmeal, one part bran and one part beef scraps with skim milk, add a little grit and a little charcoal and give the ducks as much of the mixture as they will eat three times a day, removing any that is left after each meal. Provide plenty of water and your ducks will be fat in from seven to ten days.

If yellow skin and flesh are required by your market, feed plenty of green food; if white skin and flesh are preferred, omit the green food entirely.

Ducks are killed by bleeding through the mouth from a cut made by a sharp knife in the arteries at each side of the throat, back of the base of the brain. The writer prefers to stun the specimen by a sharp blow on the head, made with a light club, before sticking. Dry picking is seldom practiced on the largest duck farms although a few employ it to satisfy a certain demand in their markets.

The duck to be scalded is dipped in water, which is almost at the boiling point, as soon as life is extinct and after thoroughly sousing three times, it is removed and wrapped closely in a piece of canvas. There it is allowed to stand two or three minutes to thoroughly loosen the feathers, when the canvas is removed and picking begins. It requires but little experience to pick a scalded duck well and rapidly. When the picking is finished the carcass should be placed in cold water and allowed to remain there until the bodily heat is entirely destroyed, when it may be removed and hung in the air to dry. Ducks are shipped to the wholesale market undrawn, but when sold at retail at a nearby market they are usually drawn and the heads removed.

Wherever a market can be found which will pay an average price of twelve cents or over per pound during the season duck growing is profitable if the methods used are up-to-date. 


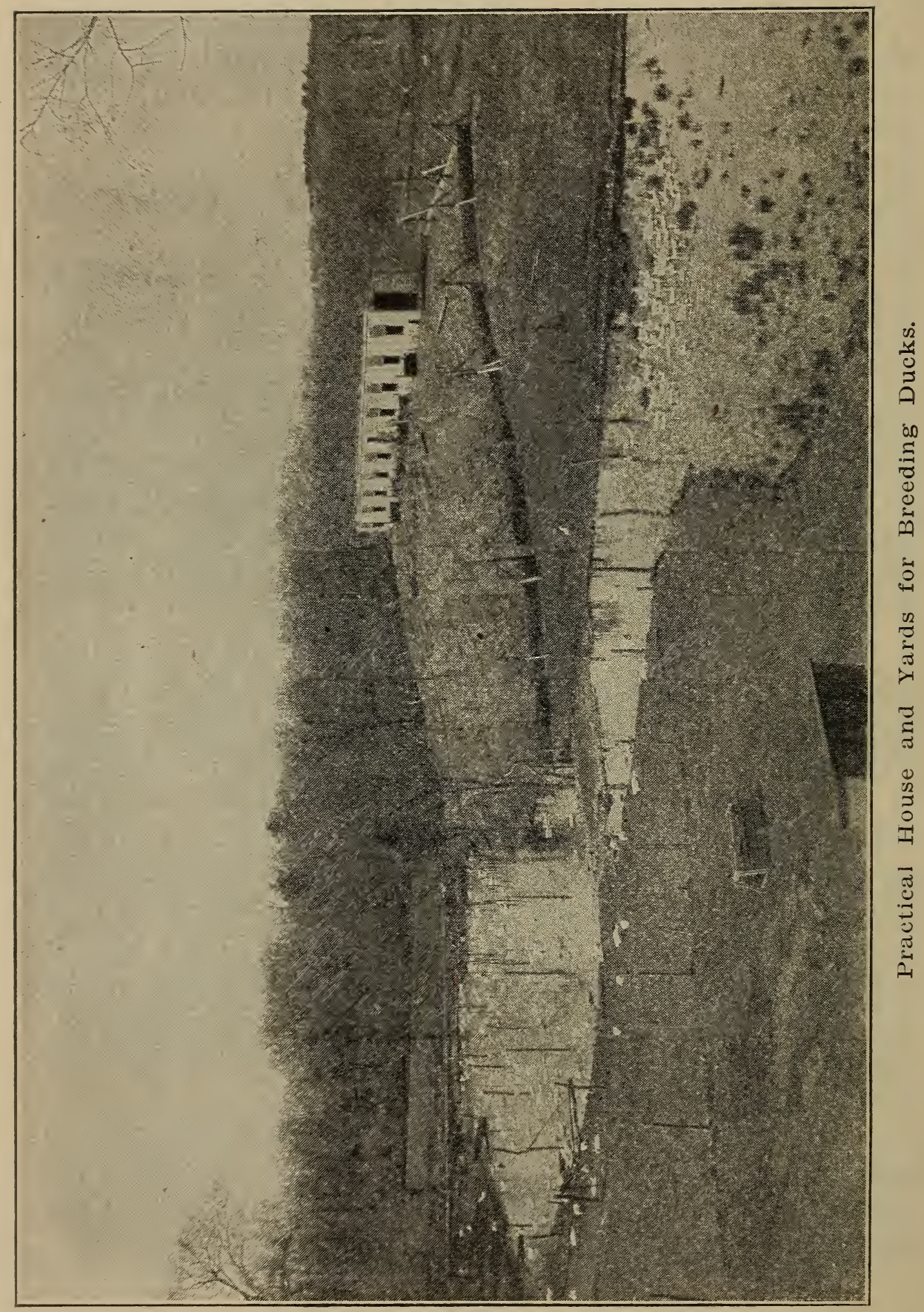




\title{
PRODUCING MARKET DUCKS.
}

\author{
The Pekin Has Assured the Success of Commercial Duck \\ Raising-How the Business is Conducted at a \\ Profit-Care of the Breeders-Hatching, \\ Rearing and Marketing.
}

\section{By Geo. H. Pollard.}

The production of ducks is an important branch of the poultry business. While less commonly used than fowl and turkeys they are usually in good demand and may, if intelligently handled, be counted upon to pay good profits on the cost of production.

Of the many varieties of ducks only two, or three at most, claim any special attention as utility birds. From time to time interested breeders dress up a boom for some new aspirant, but so far in this country there has been only one breed, the Pekin, which could properly be called popular, or which has proven profitable in the open market-the criterion by which all ducks, and eventually all other poultry, must be judged. Owing to several reasons ducks have not been so much the favorite of the fancier as have land fowl, and the sales of breeding stock and eggs for hatching are, therefore, less frequent and less profitable. In the middle nineties there was quite a boom on in duck raising and more or less in exhibiting. This boom gradually petered out, and since then the business has, with the usual ups and downs of all industries, had a substantial and a steady growth in production and the resultant profits have been of a very reasonable average.

The P.ekin duck grew to its great popularity solely on its own merit as a market bird. Before its coming in the seventies "puddle" ducks, a nondescript bird made up of 
Rouen, white and scrub bred ducks were all the market had to depend upon for a supply. The great bulk of the birds were grass-fed, and allowed to run at large until around the holiday season, when they were caught up, scalded and sent to market. The result was a carcass as tough as a rubber heel and a frame painfully devoid of meat. Naturally, such goods did not appeal to the fastidious trade, and the buying was mostly by such new, or recent, arrivals as "used to eat them at home." Manifestly, a "boom" was scarcely probable under the conditions. With the introduction of the Pekin a new day dawned, and it took only a very short time for duck producers to appreciate the fact that at last they had something in the duck line which would appeal to the appetite of practically all who had the price; that they had and could offer a carcass not made up of sinews and hope but covered with juicy, dark meat, which was both pleasing to the taste and tender to the teeth.

\section{How the Demand Was Created.}

The vicinity of New York City has always been the principal seat of duck culture in this country. No doubt this condition is due to the fact that New York and its great market for food stuffs has always been the home of a large foreign born population, and it is to the demand of these classes that duck raising on a large scale is primarily due. The next avenue to the family table was through the hotel and the restaurant. High class resorts are always on the lookout for new and novel dishes. Cost does not count so the food is satisfactory and a good many, with appetites excited by the novelty, appreciate food more when eaten in public places, or at least away from the familiar surroundings of home, carry away with them pleasant memories of its merits, and plan to repeat the sensation by its reproduction at the family table. So sure is this avenue of introduction that makers of meritorious food stuffs and dirinks often make great discounts to popular public eating places 
in order to get the product before the public in the most convincing manner.

A serious drawback to the more rapid spread of "duck. on the table" is that-sorry as we are to admit it-duck is not so economically adapted to the family table as are most other kinds of fowl. What there is of meat is most delicious, but the waste is more in proportion than in turkeys and chickens, and though there are large numbers who buy "regardless," the great body of the possible consumers consider this point, and for this, if for no other reason, the duck will always follow the others in popularity and in sales.

\section{Duck Eggs and Production.}

There is a good sale for duck eggs for table and culinary uses in the spring and early summer months, especially about Easter season. The duck begins to lay the last of February or the first of March under usual conditions. If fed a grain and scrap ration young birds may be got to laying in the fall, but they rarely continue steadily through the season, though they may be induced to lay quite freely through December. Then they gradually increase until they are at flood-tide in April. They begin to slacken in June and are practically through in July. The period of laying differs some according to the location and climate, being earlier in the warmer sections of the country. Rouen ducks are good lavers and good table birds, but their dark plumage and lesser size count them out as market birds. The Indian Runner has had a good deal of advertising, but, while holding a place of its own in the estimation of its breeders, it cannot be called in any sense a rival of the Pekin.

The first eggs the duck lays, if kept in confinement and fed rather stimulating foods, rarely hatch well. They are usually quite infertile and many of the germs do not live through the hatching period, which is twenty-eight days for Pekin ducks, and about thirty or thirty-two for the 
Muscovy-a duck which, but for the fact that the sexes vary greatly in size, would be quite the strongest competitor the Pekin has. It carries a lot of breast meat, which is of a very good flavor.

\section{Care of Breeding Ducks.}

Ducks are not seriously troubled by any degree of cold, but if early laying is desired, they should have a reasonable protection from storms and drafts. If allowed the run of a large yard or green plot and given an open front house they will do well, but if a stream or waterway can be included the eggs will hatch better. In the early part of the season five ducks may be mated to one drake; later, in April and May, it will probably be found best to increase the number of ducks. The house should be kept littered with some soft material. Many use straw and chaff, which should be kept reasonably dry. This is a hard job as a duck seems to spread dampness without half trying. Planer shavings make the best litter as they keep dry better and the top can be easily removed and a dry surface is again exposed. No nest boxes are necessary as the ducks will hollow out nests and will cover the eggs when they leave the nest. In cold weather the eggs must be gathered early to avoid chilling. This is more necessary with ducks than hens as they usually lay early in the morning. The eggs can be hatched under hens. or in incubators; ducks do not make satisfactory sitters.

\section{Incubating Duck Eggs.}

All the big ranches use incubators and brood artificially. Nine eggs in cold weather and eleven in warm are enough to put under a hen. In incubators they should be turned and tested the same as hens' eggs. They may be tested successfully on the fifth day and all the infertile ones will be good for cooking purposes. Make a second test about the twelfth day but don't cook what are then taken out-at least not for the table. Duck eggs are heavy, 
and they must be carefully handled to avoid cracking; they must be turned gently as once cracked they are spoiled. The temperature of the incubator should be the same as for hens' eggs. Do not turn the eggs after they begin to pip. Ducklings often, indeed, usually, begin to pip about 36 to 48 hours before they break the shell, and during this period they should be left entirely undisturbed.

Feeding has a good deal to do with hatchable eggs as well as the number laid. By a system of feeding which supplies a highly nitrogenous ration throughout the winter the ducks can be induced to lay very early and to keep laying pretty steadily after beginning. December and January eggs do not hatch so well as the later ones, and it is an open question whether, in the long run, the forcing does not hurt the hatching quality of the subsequent eggs to a greater degree than the profits from the comparatively few early birds will overbalance. The special market conditions, with which each producer has to reckon, will probably point to the proper conclusion.

Ducks are rapacious feeders and will stow away a lot of food. If too concentrated, too rich, they will overdo the job and will go off their feed, or their feet. Where they have a water way or free range they will stand heavier feeding than when confined. The ration may be made up in various ways, but should generally be fed soft, in the form of a mash. The duck naturally feeds on soft roots, grasses and water plants and though long divorced from - primitive ways we must still consider some of his instincts. Many have tried complicated mixtures of corn meal, wheat bran, red dog flour, gluten feed, and other forms of cereal "sawdust." . It is doubtful if anything is better than a plain ration of two parts wheat bran, two parts corn meal, one part best beef scrap, one part cut clover or alfalfa and one part of red dog flour mixed to a crumbly mash with water and fed night and morning. During the winter months reduce the beef scrap one-half and add meal in its place. From 
Jannary first give a noon feed of cracked corn and oats. Feed what soft feed they will clean up within fifteen or twenty minutes and enough grain at noon to give them a substantial bite. Ducks lay big eggs and they can't manufacture them unless they have the raw material to work on.

Always have water nearby at feed time, and in warm weather it should always be accessible in considerable quantities and reasonably clean. A store of ,crushed oyster shell should be within reach and grit or gravel supplied. As a rule duck eggs hatch well where the breeding stock has proper care and range. As with hens, there are good seasons and bad seasons and no one seems to know the reason, though all have an opinion.

\section{Shipping Duck Eggs.}

Ducks' eggs are heavier and do not stand shipping as well as hens' eggs. While they may be and are shipped long distances and hatch well, there is less certainty of arrival in good condition and a successful hatch than with the hens' eggs. Only very fresh eggs should be shipped, as with age the yolk and white become less firm and the jar of shipping churns them up and leaves a good many in bad shape for incubation. Before setting eggs shipped from a distance they should be allowed to rest for twentyfour to thirty-six hours. To get an idea of this condition, test a few with a good egg tester and the condition of the yolk may be readily determined.

\section{Brooding the Ducklings.}

Ducklings are stronger and hardier than chickens and will ordinarily live through more hardships, but it is just as well to make their way as plain and easy as possible. The brooder should have a hover heat of ninety to ninetyfive degrees when the newly hatched birds are put in. Regulate after that time by the evident needs of the ducklings. Watch closely and don't let them get to crowding as they certainly will if too cold. On the other hand too 
great heat means weak legs, and weak legs in ducks means disaster and no less. Ducklings grow surprisingly fast and need less heat than chickens of the same age. By the time they are three weeks old they will probably require not over eighty degrees of hover heat, but, as always, let the ducklings decide just how much. Where only a few are raised of course hens will be used and the hen and the ducklings will readily adjust themselves to the right conditions.

\section{Simple Methods of Feeding.}

Feed the little fellows according to any of the accepted methods and they will do well. Perhaps as economical a way is to mix equal parts of wheat bran and corn meal to which should be added, at first, two per cent of the best beef scraps. At one week old feed five per cent scrap, working gradually up on the proportion until at four weeks they are getting fifeen per cent, and more if they can assimilate it without bowel trouble or diarrhoea. Animal food in the form of beef scrap, milk, fish or other protein carrying food is absolutely essential to the rapid growth of ducks-or for that matter any other kind of poultry. Some feeders make a practice of using a larger proportion of corn meal the last few weeks before killing, but we have never found any gain in this method. Ducks are gross feeders, but are notional about changes and when contemplated the change must be made. with care and very gradually, otherwise the birds will go off their regular feed and every meal lost means a shrinkage in profits. While perhaps no fowl makes more rapid growth where conditions are favorable, none shrink more rapidly when either food or management is faulty.

If the brooder floors are sanded or graveled there will be no real need for other grit the first week, though to salve the feelings of those who wish to help them along a little sand or prepared chick grit may be mixed in the feed. Water should be always within reach. Always means night 


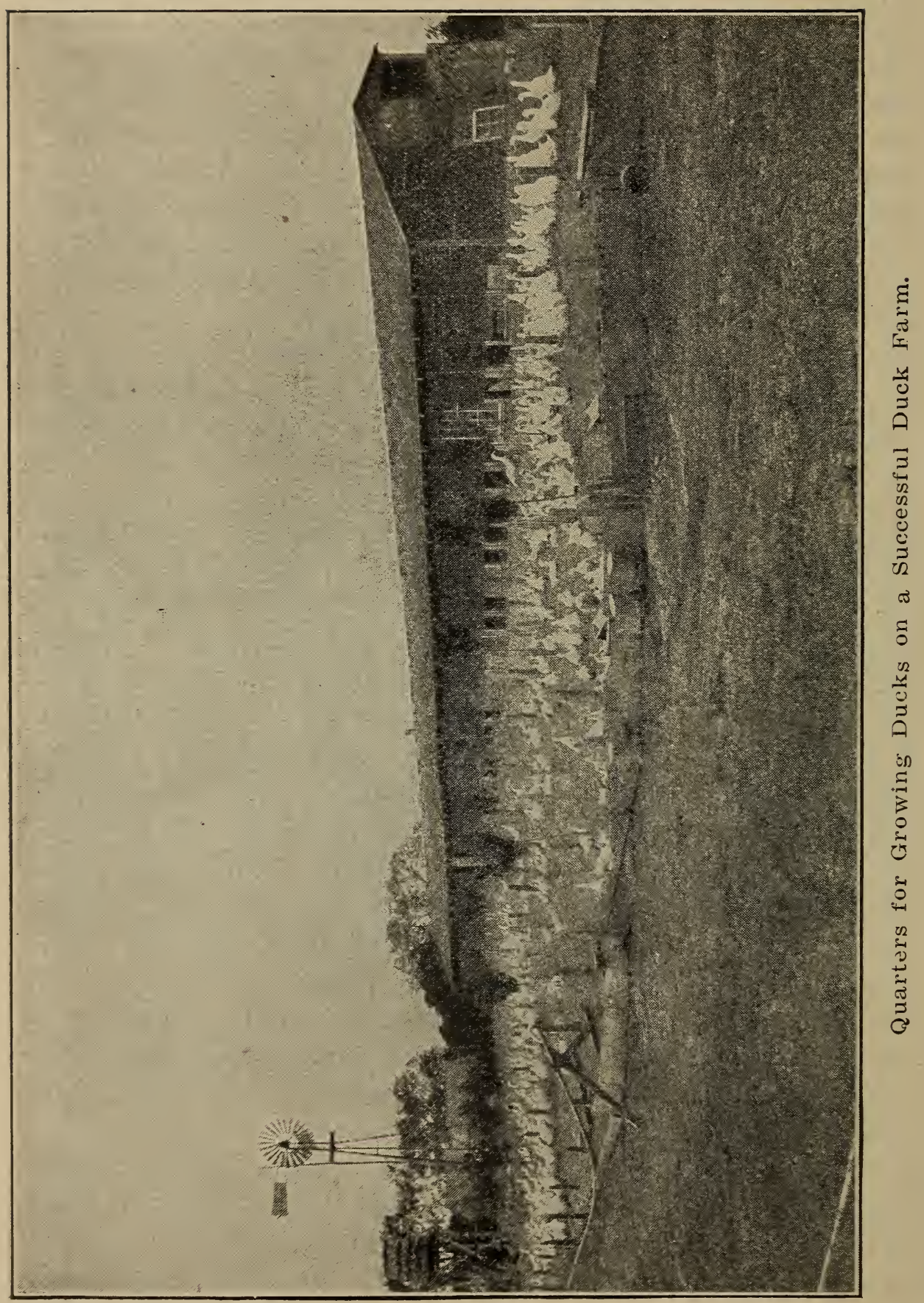


and day. Use any type of fountain which can be easily cleaned and filled and into which they can get only their bills. They should be able to get the full length of the bill into the water else there is always danger of the nostrils clogging and making trouble. Have the water near the food which may be fed in long, narrow, shallow troughs so the feed will be well distributed and accessible without too much crowding. The water should be near, as ducks wash down the food and run constantly from trough to fountain and return. Any avoidable waste of effort counts on birds that are supposed to be in prime condition for market at ten weeks old and we want to raise table poultry and not sprinters. Grit and oyster shell should be handy for their use. The shell may be something of an extra, but they will eat more or less and, as they are marketed undrawn, it may be the last feed eaten and it weighs well.

\section{Small Flocks Grow Best.}

A hundred or more ducklings may be brooded together, but it pays better to divide them into smaller flocks. Fifty to sixty is about right. Let them run out on the ground about as soon as they can find their way back to the hovers and watch lest they take a notion to huddle in the run outside the hover or out of doors. They sometimes do this and get chilled before they find their way back. As soon as the nights get warm enough, get the ducklings out of the brooder house into cold (unheated) buildings.

If kept in a cool house they will feed better and hences grow faster. After settled warm weather arrives not much more than a roof or sun shelter is necessary. In fact, more is detrimental. The young birds need protection from rain and shade from the sun. The yards should be kept as clean and dry as possible; this at best is a hard thing to do, but wallowing in filth is not conducive to the best results with ducklings.

Separate the flocks by wire netting of the ordinary two-inch mesh, thirty inches high. This can be walked orer 
by the masculine attendant, and climbed over by others. Twenty-four inches will do, but the added height makes a sure thing, and all cheap fences sag more or less.

Place only as many ducklings in one pen and yard as can be killed and dressed at one job. This is important as the birds have to be handled over and being naturally timid the fright causes considerable shrinkage. Where the flock is larger than can be killed in the day's work, those which are left are generally thrown off their feed for a day or two. Sometimes they get weak legs and occasionally one drops dead from the fright. In catching do not unnecessarily rush them about. Manage to have a corner where they can be slowly driven and confined with a light board panel. If the whole corner is boarded they will struggle less than when against the wire fence.

Pen only a few at a time, and such as are unfit for killing should be released and put into another yard. Handle by the necks and do not grasp them any harder than is necessary to hold them. Never handle by the legs. They are easily lamed or broken. Keep them in a quiet place while awaiting killing. It frightens them less, and it is just as well to be as merciful as possible in doing what is, at best, a disagreeable job.

\section{Killing, Picking and Pinning.}

For the best eastern markets ducks need to be dry picked. - For some other markets they may be scalded. In either case the age and condition must be right if the carcass is to make a satisfactory showing. A few pinfeathers may be overlooked, but where there are many, the carcass has a coarse, honey-combed appearance which grows more unsightly the longer it is kept. This growth of pin-feathers starts at from ten to twelve weeks old, according to the forcing which has been done. In dry picking the duckling is held firmly under one arm, or between the picker's knees, while the roof of the mouth is cut deeply across by a sharp, rather long bladed knife. This cut should sever the arteries 
and induce free bleeding from the mouth. Many stun the duck with a hard blow on the head before sticking, and some strike the head after. We prefer the first method as being more painless while the "bleeding out" is quite as effectual. If the operation is properly performed it seems to paralyze the nerves, or so affect them as to loosen the feathers and cause them to pull more easily and with less danger of tearing the skin. Inexperienced pickers will do better to pull the feathers in the same direction they grow by grasping a few at a time near the roots and pulling gently, but steadily, until they loosen. If there are pinfeathers which are difficult to pull, take a sharp knife, a good shoe knife is commonly used, and get it as sharp as a razor. Draw this carefully over the skin against the pinfeathers, which may be wet, and shave them off close to the skin. Pick the body clean. Leave the feathers on the wing from the second joint, all but the flight feathers, and on the head and about half the neck. Leave the head, wings and feet on and do not draw the entrails if to be shipped to market.

Where the birds are scalded before picking they are dipped into hot water and held just long enough to loosen the feathers. Some little practice is necessary to enable one to tell just how long to immerse them. They are then taken out, the feathers are quickly removed and the carcass is plumped in cold water. The feet and head may be held out. Some who have only a few wrap the bird in a cloth or blanket dipped in boiling water and steam the carcass enough to loosen the feathers. In either case the skin must not be cooked. Scalded birds do not keep so well as dry picked and they are less pleasing to the fastidious eye. If kept long they discolor more and have a mottled appearance which is not attractive. If the legs and feet are much scalded the skin peels. off and they dry up.

\section{The Profit in Feathers.}

Whether scalded or dry picked, the feathers should be carefully saved. In picking, the quill feathers should be 
thrown aside and only the soft body feathers kept. If dry picked these need no treatment other than exposure, in some dry, airy place, to a slight draft of air. Keep them out of the direct rays of the sun. Stir occasionally so all may dry thoroughly, and bag and ship when sufficient have accumulated. Wet feathers must be dried and the big establishments have piped drying rooms for curing them. White duck feathers make the bulk of the "live geese" feathers sold and are constantly increasing in value. They may be worth anywhere from twenty-five to fifty cents per pound at wholesale, according to the place and care which has been exercised in keeping them clean and dry. They are hardly satisfactory for bedding purposes until they have been steam cured. This operation removes the oily, "duck" smell which otherwise is in evidence as long as they are used.

\section{Cooling and Packing.}

As fast as the ducks are picked drop each carcass into a barrel or tub of cold water to remove the animal heat. It is important that all heat should be removed as quickly as possible in order that the carcass may harden and keep well. After a reasonable time take the body from the water, rinse out the bill and mouth, clean the feet and legs and repack in ice water until ready to ship to market. If the wings are tied close to the sides of the carcass with a clean white cord they will hold in better shape ańd look more attractive. Let the string go clear around the body about midway of its length and tie as tight as possible. Pull the breast meat full in front and let it harden in that shape. In shipping pack either in barrels or boxes. If shipping to a distance, barrels are the handiest. In the bottom of the barrel make a small hole or two and put in a layer of ice. On this put two or three layers of ducks closely packed and follow with more ice. Continue in this way until the barrel is full and top off with a good lump of ice and cover with burlap, or head. Sugar barrels are first rate carriers where there are sufficient ducks to fill them. 
Ducks properly cooled and packed in this manner may be shipped long distances in pretty hot weather and keep well. A good deal depends on proper cooling as soon as killed. If this part is neglected it is pretty sure to result in trouble and loss. The duckling is grown. so quickly and the fiesh is so soft that it heats quickly and once heated loss is certain. In shipping to commission merchants it is well to mark the number of birds and the weights on the package.

It is always more satisfactory to have the stuff sold before shipping or at least partially placed. There are lots of honest commission men perhaps, but it is asking a good deal of any man to expect him to hold the balance exactly true where he both buys the goods and makes the price. There is no doubt that a host of the dealers make a good part of their profits out of their pickings from the small and occasional shippers.

The things worth remembering in duck raising are that a few ducks will pay for family uses, but seldom for market; where there is a limited demand which can be directly supplied by the producer there is money in ducks; where only a few are raised and they have to be shipped to a distant market it will not pay; the producer must limit production to what can be personally marketed or produce enough thousands to make a business which shall warrant the outlay of considerable capital and time; between these opposite points there is only trouble and most often loss instead of gain. 


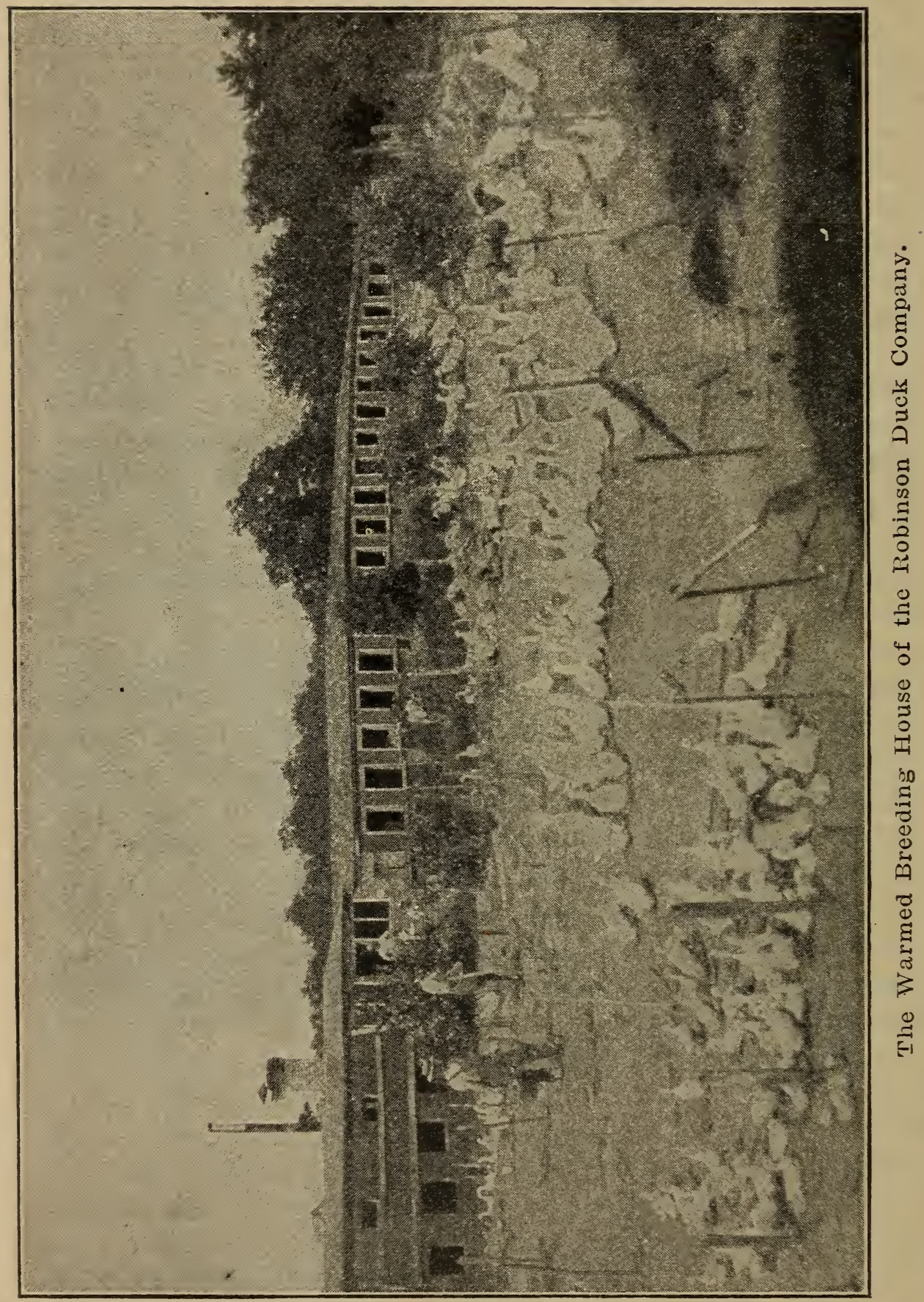




\section{A PROFITABLE DUCK BUSINESS.}

\section{A Detailed Description of an Up-to-date Successful Duck}

Farm-The Manner of Hatching, Rearing and

Fattening the Stock-Matters That

\section{Affect the Profits.}

\section{By Arthur C. Smith.}

The Robinson Company of Massachusetts raises ducks for the market. At present that is its sole business. Some years IO,OOO ducks are raised. These ducks are sold in both the New York and Boston markets and have brought on the average one dollar per head. Authorities tell us that it costs about 50 cents a head to rear a duck till it is. Io to I I weeks old, or to the marketable age. This would leave the company something like $\$ 5,000.00$ for its season's work. You are astonished and ask if it is possible to make \$5,ooo.00 raising I0,000 ducks. Frankly, the writer does not know, he has never raised ducks. But were you to allow him to judge, he would say that should the business show a profit of 25 to 30 cents per duck, there would still be left a good business proposition which would include a fair dividend to the stockholders and a good and well-deserved salary to the manager.

\section{Hatching and Rearing the Ducks.}

The ducklings are hatched in the incubator house. This building is built partly underground and is $32 \times 37$ feet on the floor, one and one-half stories high. The loft is used for storage. Seventeen special duck machines do all the hatching.

Hatching begins in January and ends in May. Once hatched, the ducklings are put into the nursery brooder. This building is I70 feet long and I5 feet wide. It has 
an aisle on the north side with hovers next to the aisle. Each pen is 4 feet wide and I I feet long. The hot water heater is in the west end of the building. This house is built with the ground and slopes toward the west. The hovers are heated by two 2-inch pipes, being natural flow and return. When first hatched, the ducklings are put at the east end of the house as that is the warmer, being the highest. This is contrary to the general procedure as the end next to the heater is, other things being equal, the warmer. As they grow older the young ducks are moved down toward the heater.

At the age of two weeks they are transferred to the double brooder house, so called on account of its construction. This is built with an aisle on both sides of which are pens. Those on the south side have hovers while those on the north side are for older ducks and are open. The house is 28 feet. wide and 223 feet long. The south side pens, into which the 2-weeks-old ducks are put, are 4 XI 5 feet. These hovers are heated by two 2-inch flow

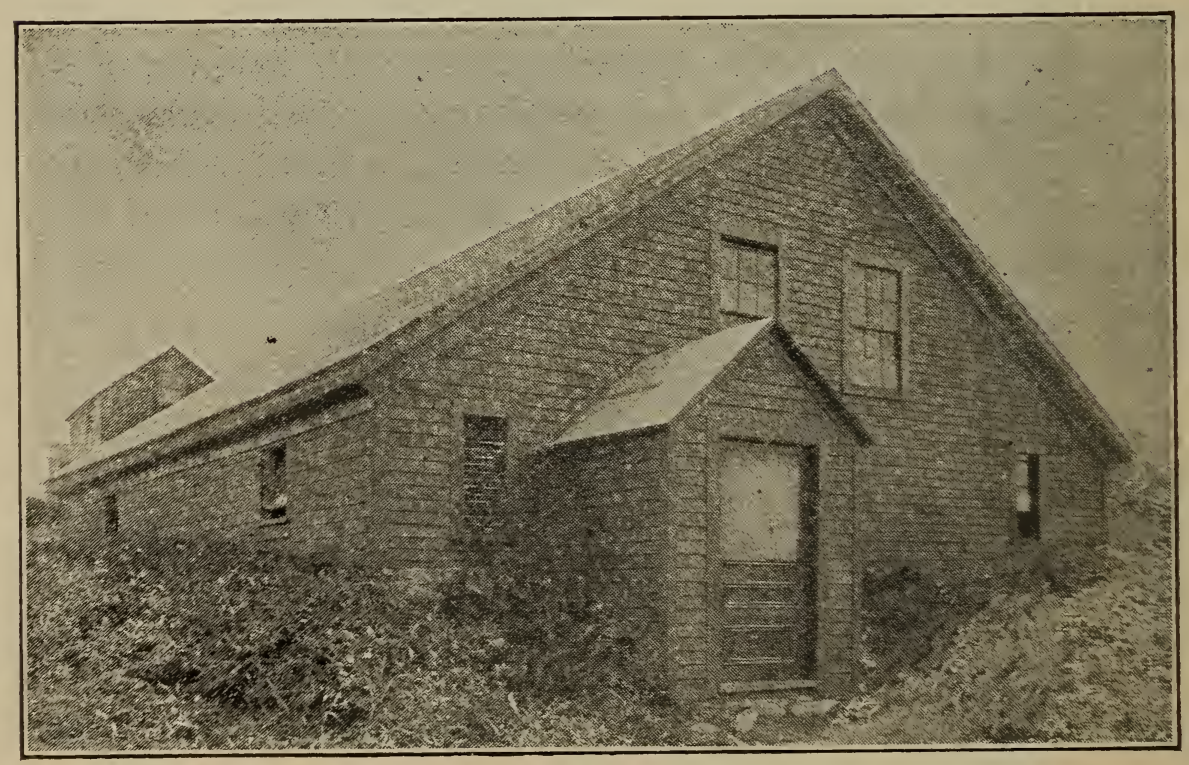

The Incubator House of the Robinson Duck Company. 


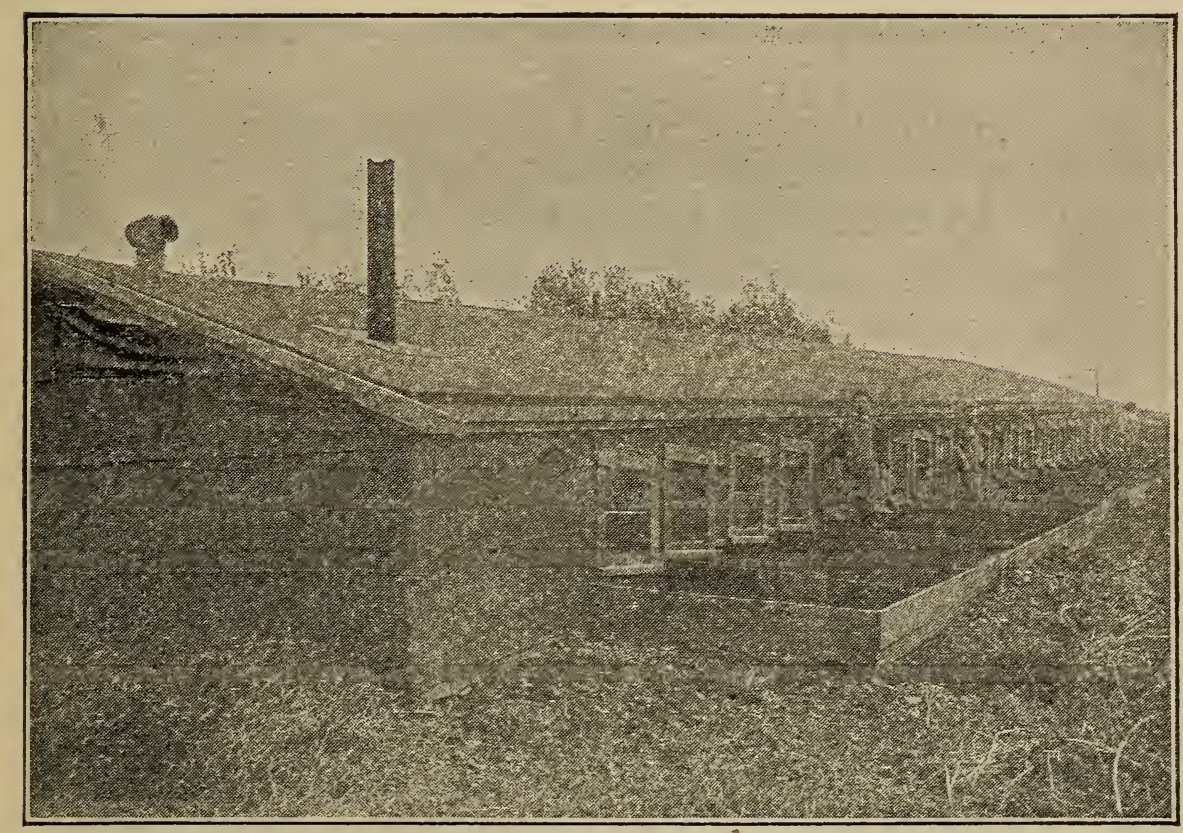

The Nursery Brooder House of the Robinson Duck Company.

pipes while the return pipe is outside of the hovers. This return is a 3 -inch pipe and is placed in the aisle against the hover. This arrangement gives considerable heat to the building.

To guard against extremely cold weather, a steam heater was installed. The pipes from this run overhead and when in use, heat the whole building. This heat is very essential early in the season as the older ducks on the north side of the aisle have no hovers and no other heat than that provided for the building in general. These ducks are moved into the north pens at the age of four weeks. These pens are about Io feet square. The ducks are kept here till they are seven weeks old and then they are moved to the fattening shed.

\section{The Fattening Shed.}

This is a large shed 200 feet long and about 20 feet wicle. It has an aisle running through the center. The 
ducks are here prepared for market and have large outside runs but not free range; nor do they ever have, but the older they grow the more room is allowed them. Thus, in the nursery building the outside yards are no more than six feet long and in the double brooder house those on the south side are but little longer. Those on the north side are very good size and give the ducks a good chance to exercise but not to range.

In the fattening shed, a cross-section would resemble the letter A: The sills rest on posts about three feet from the ground and the ridge is about 18 feet from the ground. This makes a very peculiar looking building and it was, at first, very hard to see the use of so much waste air space. The manager explained that it was built so to keep the ducks cool in very hot weather.

The house is also provided with a large ventilator at the top of the building. This allows the hot air which has accumulated in the top of the building to escape. From here the ducks, as they become fit, are taken to the killing house, which adjoins this shed. This room is equipped with three large cooling tanks and a large cool box. The tanks were full at the time of my visit and Mr. Robinson showed me several ducks with evident pride, and no wonder, for they were round, plump fellows with white flesh and no suggestion of the over-fat, greasy duck. It is not surprising that the duck market is reported to be broadening when we consider the quality that is being produced on this farm.

\section{A Convenient Feed Room.}

The feed room is also directly connected with the fattening shed. This room furnishes no novelties but is a good, handy room such as is seen on many poultry and duck farms. Bins are arranged along the sides and a large mixing trough pretty nearly takes all the room at one end. The writer had the pleasure of seeing a double portion of mash mixed and it was certainly done on the 
wholesale plan. Everything was measured by the double bucket full. The food fed these ducks is practically the same at all ages and all meals. It is invariably mash. It consists of seven different ingredients-corn meal, shredded wheat, red dog flour, gluten meal, bran, oil meal and grit. The afternoon that I was there, the $I, 600$ in the fattening sheds were to have I8 buckets of this mash.

\section{A Warmed Breeding House.}

The accompanying illustration shows the main duck house. In this house the breeding ducks are kept in

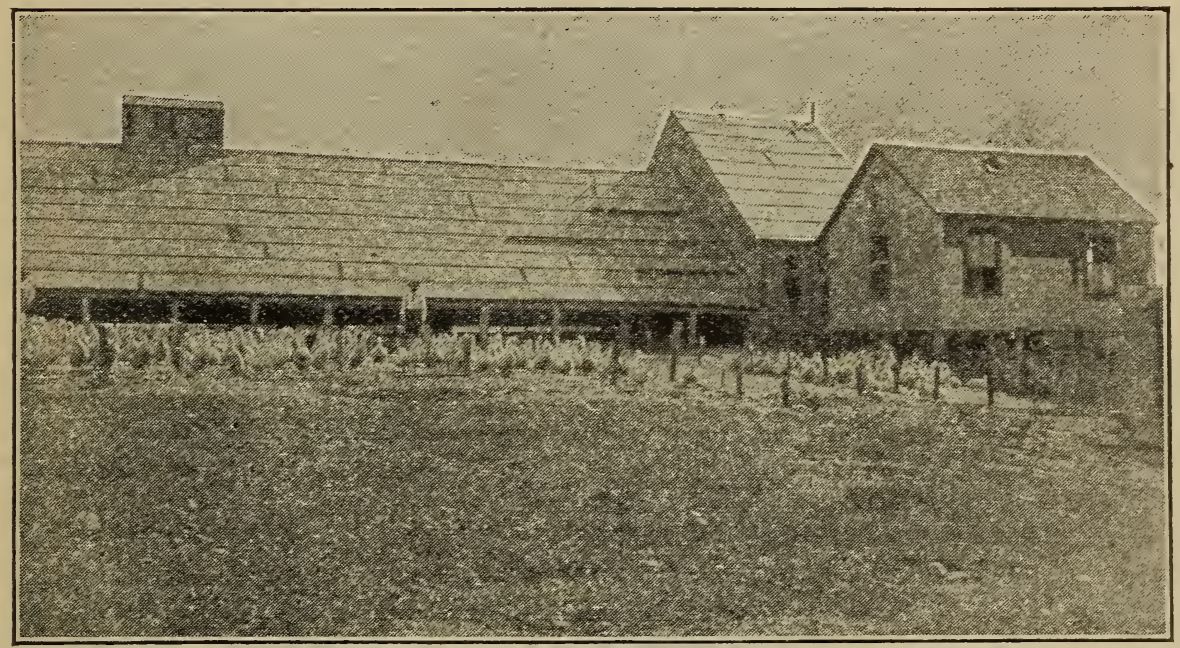

Part of the Fattening Shed of the Robinson Duck Company.

breeding season. This house is heated in the winter so that the eggs will not chill. It is during the early morning hours that the ducks lay and before an attendant could collect the eggs they would be chilled and therefore spoiled for hatching purposes. As the early ducks pay best, it is highly important that the eggs be kept at a temperature that will preserve the fertility. Forty degrees F. is found to be safe. This house has been heated by steam but Mr. Robinson finds that hot water suits him better and is changing the system. 


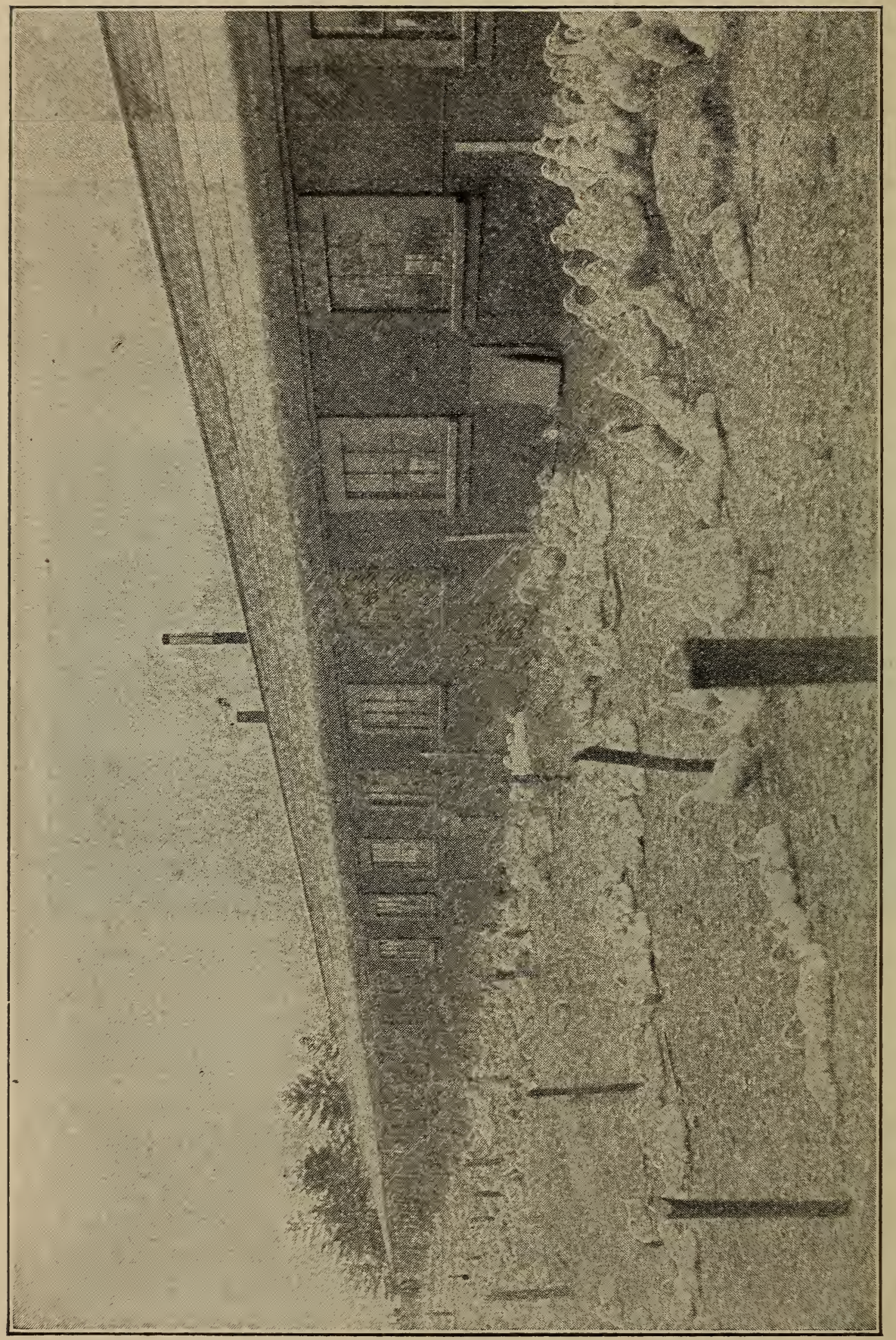

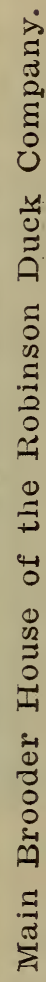


All the houses are lighted with electric lights. Light during the night is absolutely necessary with ducks, to keep them quiet. They are timid in the dark; every shadow or the slightest shifting or change in the light will set them running and squawking. With a light they are rerfectly quiet.

\section{The Keynote to Success.}

Much might be said about this plant and one could dwell upon many of the noticeable features that insure the success of this venture. A few cannot in justice to the reader be overlooked. The keynote to the whole management is the maximum results for the minimum labor. Not one useless chore is performed or an ounce of power wasted or misdirected. That is what has made a margin of income over expenses. In the first place, the buildings are as near as possible to one another and allow yard room for the stock. This saves steps and steps count in this business. Another unique feature is found in the way the cook room, killing house and fattening shed have been arranged, all connecting, so that by traveling 200 feet and back a man can feed the $1,600,2$, 000 or whatever number of ducks happen to be in that shed. To feed that number of chickens the man would have to travel from half a mile to a mile and a half if they were properly arranged to do well. The third feature was running water. In the brooder house the water was run into a cistern made of an oil barrel where a man can dip his buckets to the brim and is not obliged to wait for them to fill from the faucet. This is a simple device, but one of the best labor savers that I noticed.

The close proximity to the Boston market has proved very advantageous. The catalogue states that they ship to Boston at one cent per duck. The plant has telephone connections and this enables this company to be in close touch with the market. While this is a market business, breeding stock is sold if engaged ahead. None are held 
unless engaged. It is not good business to keep any stock for which you have no use beyond the time when it can be sold and they do not do it here.

The results that are obtained here may be obtained anywhere that a market for dressed ducks can be found, or reached without shipping to a great distance. Home or nearby markets are best and most profitable. To raise the ducks is not difficult; to sell them at good prices is the main point.

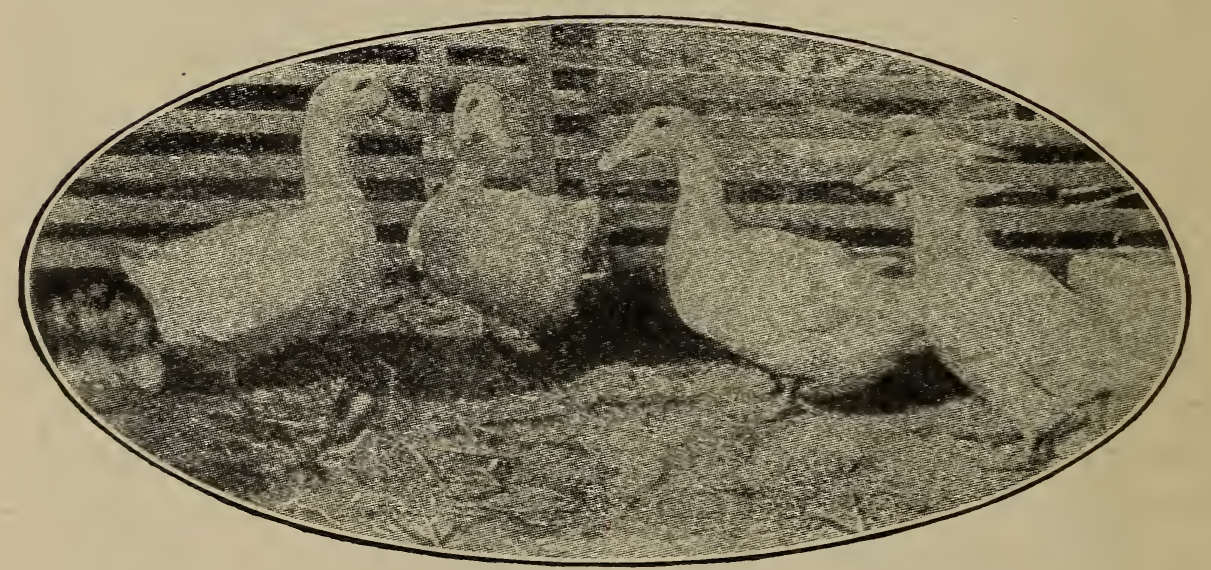

Aylesbury Ducks. 


\title{
EXTENSIVE DUGK RAISING.
}

\author{
Duck Growing as a Business-One Hundred Acres Devoted to \\ the Production of Thousands of Market Ducks- \\ Descriptions of the Incubator House, the \\ Brooder Houses and their Equipment \\ -Feeding the Ducklings- \\ Killing and Marketing.
}

\section{By Frank G. Thayer.}

To the observer the sight of thousands of Pekin ducks is one not to be forgotten. At the same time there is no poultry establishment where visitors are less desired than on a large duck farm. The Pekin duck is probably the most timid of all domesticated ducks, and strangers as a rule are prohibited from visiting on this account, as all stampeding, scaring or otherwise disturbing the duck causes loss in flesh, vitality and profit.

The duck business of today is probably one of the most firmly established profit paying branches of poultry husbandry. But there is no branch of poultry farming where failure is so certain when proper methods are not followed. It requires a large outlay of money and an extensive and varied experience. It takes time to develop a market and to know when and where to ship the product to advantage. The person who has the chance to visit a large duck plant should consider himself fortunate in the chance to see how ducks are raised on a large scale, and on a profit-paying basis.

\section{The East Controls the Business.}

Long Island has the reputation for ducks and here and there over the eastern states are to be found a few duck tarms of considerable size. In other parts of the country very few large duck plants are in evidence. Hundreds of 
thousands of ducks could be reared in this country in excess of those already produced and still not over-supply the market. There are numerous places where they could be raised and disposed of at a profit.

While one of the most profitable branches of the poultry business, there is plenty of good hard work connected with it, as I know by practical experience. It means early to rise and late to bed if you expect to realize a fair profit. The ducks will be up and ready for their morning feed as soon as it is light, and it is not good policy to keep them waiting long, as it will cause them to fret off good flesh, or affect the egg production. From the beginning of the hatching season until the last stock hatched for the season is ten weeks old, the caretaker must work early and late.

When Pekin ducks were first introduced, numerous persons went into the business with little or no experience, expecting to get rich in a hurry. Prices then were high and, naturally, the price declined, because it takes time to create a demand for a new market product and in consequence "green ducks" could scarcely find purchasers at any price.

\section{Good Prices are Obtained.}

In the spring of the year, in the New York and Boston markets, "green ducks" now bring from twenty to thirtyfive cents per pound at wholesale. The season of greatest demand and production is in June, July and August, when they will average fifteen to twenty cents per pound at wholesale.

The lowest price which these ducks have brought in five years in New York and Boston markets is ten cents per pound, while the highest on record is thirty-five cents. Remember, these are all wholesale prices paid by commission men. The retailer gets from ten to fifteen cents more per pound than the grower. Recently the Long Island Duck Raisers' Association met in New York City to decide on the spring selling campaign. There is consider- 
able talk of the growers installing their own stores and cutting the middlemen off.

The census of Igoo shows that the total number of ducks (all kinds) raised annually in the United States was $4,807,358$, and during the next six years this was greatly increased, especially in the eastern states, where more ducks are being raised each year for the New York and Boston dealers whose demands they cannot satisfy.

\section{A Mammoth Duck Farm.}

It was in the spring of 1905 that I was so fortunate as to obtain a position on one of the largest duck farms in America: Weber Bros., of Massachusetts. The Messrs. Weber Bros. are considered among the most successful of all duck growers. They have been in the business nearly twenty years, and are certainly making money, as shown by the new dwelling house built by David Weber, costing $\$$ Io,ooo. Therefore the knowledge of their methods is worth having. They are located twenty-three miles southeast of Boston, Massachusetts, on good state roads running between Providence and Boston. They are within easy access to their shipping place, Pondville. The farm consists of Ioo acres, situated in a valley where it is extremely cold in the winter, and very warm in the summer. In July for five days the thermometer stood at Io 3 in the shade with no breeze blowing. If it were not for good management during these days it would have been very disastrous to the ducks.

The water that is used on the place is pumped by means of a gasoline engine when the windmill is not in operation. This water is pumped through a series of pipes to the various yards and houses, where it is distributed to the ducks by manual labor: no automatic watering devices being used. The ducks have water for drinking only, being reared without any water for swimming for either green or breeding ducks. The three feed houses are centrally lo- 
cated, thus economizing labor and time. They are large enough so they will hold immense quantities of feed at one time. In the busy season 4,000 pounds of feed are fed claily. The feed is all bought in carload lots at wholesale prices. The good roads make it easy to haul it to the farm. The equipment consists of one nursery, three feed houses, one feed store house, two double brooder houses, heated by hot water; three cold brooder houses; two large fattening sheds; one breeding house; one incubator house and one ice house. All of these buildings are of large size, requiring a large capital to build.

\section{Much Depends on the Breeders.}

The management makes it a practice to carry 400 head of breeding stock each season. When selecting breeding stock only well-matured, sound, vigorous stock is desired. With Pekins, as with fowls, the success in hatching and raising ducklings depends largely on the selection and care of breeding stock. These ducks are selected just before the stock is put into the fattening sheds for market. They are driven into a corner and a board is put up to keep them in so they can be sorted. They are always caught by the neck and never by the legs or wings. They must be broad backed, good lunged, strong on their feet, and without lopped wings. These breeders are given a green run in a large orchard where they receive the best of care, and are not forced in any way. They are gradually broken into eating whole corn. Weber Bros. get their breeding stock to laying by December I5th. They are fed a mash morning; and night, and at noon one quart of whole corn to twentyfive ducks. The mash consists of the following: fifteen per cent (by weight) meat scraps, twenty-five per cent (by weight) bran, one bushel cut clover or alfalfa, three pails of boiled carrots, one-half pint of salt to a thirty-pail mixture, enough flour to make it sticky, and the balance of corn meal to make a thirty-pail mixture. 
The breeding ducks are all shut in at night, both in warm and cold weather, so that their eggs will be laid inside of the house. They are let out of doors at eight o'clock in the morning in good weather. The house is heated in cold weather to take out the chill and to keep the eggs from freezing. Lanterns are hung in all of the pens

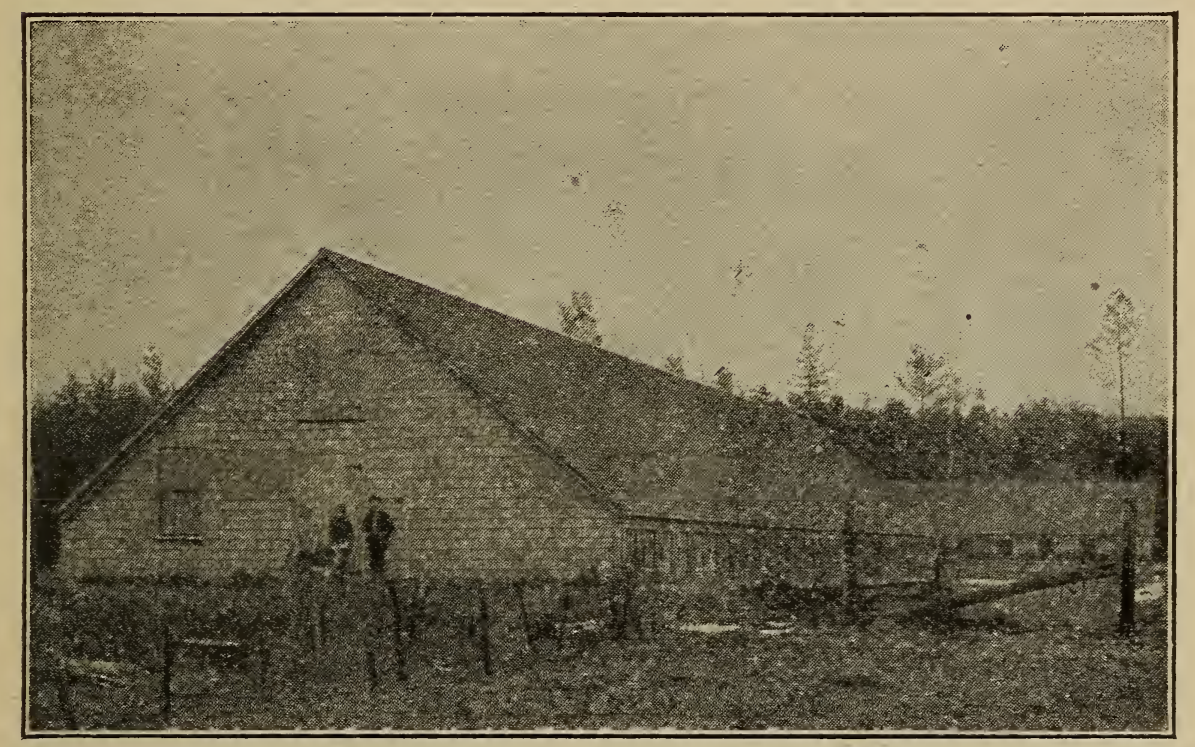

Double Brooding House on Weber Bros. Duck Farm.

to prevent the ducks from stampeding and to keep them quiet at night. Five drakes are allowed to a pen of twenty ducks.

\section{Incubators Do the Hatching.}

Incubators are used exclusively for hatching. They are operated in a separate building, built underground with overhead and end ventilation by means of muslin curtains. All windows were whitewashed so as to shut out the direct rays of the sun and to assist to keep the air within at as even a temperat'ire as possible. To further help, and also to afford more entilation, shutters are used on the windows. The ground floor is cement, and it is the practice 
to keep the floor wet down constantly as it keeps the air moist and does away with some adding of moisture in the machines.

Hatching is commenced in January and is continued until the latter part of July when the fertility runs low. The average of fertile eggs hatched runs very high. The mortality is very low. The eggs are put in the machine as soon as possible after being laid. Duck eggs spoil quickly and should not be kept over a week. Great care must be used in handling duck eggs intended for incubation. The sack containing the yolk is easily ruptured, causing the growing germ to die between the second and seventh days. The eggs are turned twice daily, and tested on the sixth day. They are never cooled, as it dries the egg too much. Those tested out are disposed of. The clear or infertile ones are shipped to Boston where they sell for eighteen cents per dozen. These clear eggs make stiff custards and bakers in large cities pay a good price for them.

From the incubator house the ducklings are removed to the nursery. This building is heated by hot water and is 273 feet long and twelve feet wide. It is divided into seventy-three pens. Each pen accommodates fifty ducklings. There is a narrow walk next to the hover. The floors are covered with new sawdust daily. The young ducklings are kept near the hover at first and then they are gradually allowed a larger run. During the first week they are not allowed outdoors at all. After that they are allowed a small run outside. As soon as there is any indication of a storm, they are all driven in the house and shut up, to avoid being wet and chilled. They are kept in the nursery until they are two weeks old when they are remored to the double brooder houses, also heated by hot water. Here they are given larger pens, and runs. Seventy-five are put into each pen. This house is built with an aisle, on both sides of which are pens. Those on one side have hovers, 
while those on the other side are for older ducks and have no hovers. The older they grow the more room is given them.

\section{Feeding the Ducklings.}

The newly hatched ducks are fed the first day a mixture, by measure, of four parts crackers, one part hard boiled eggs, and five parts of rolled oats. Extremely fine grit is also mixed with it. This is moistened and fed at 5:30 a. m., g:00 a. m., I I :00 a. m., I :00 p. m., 5:00 p. m.

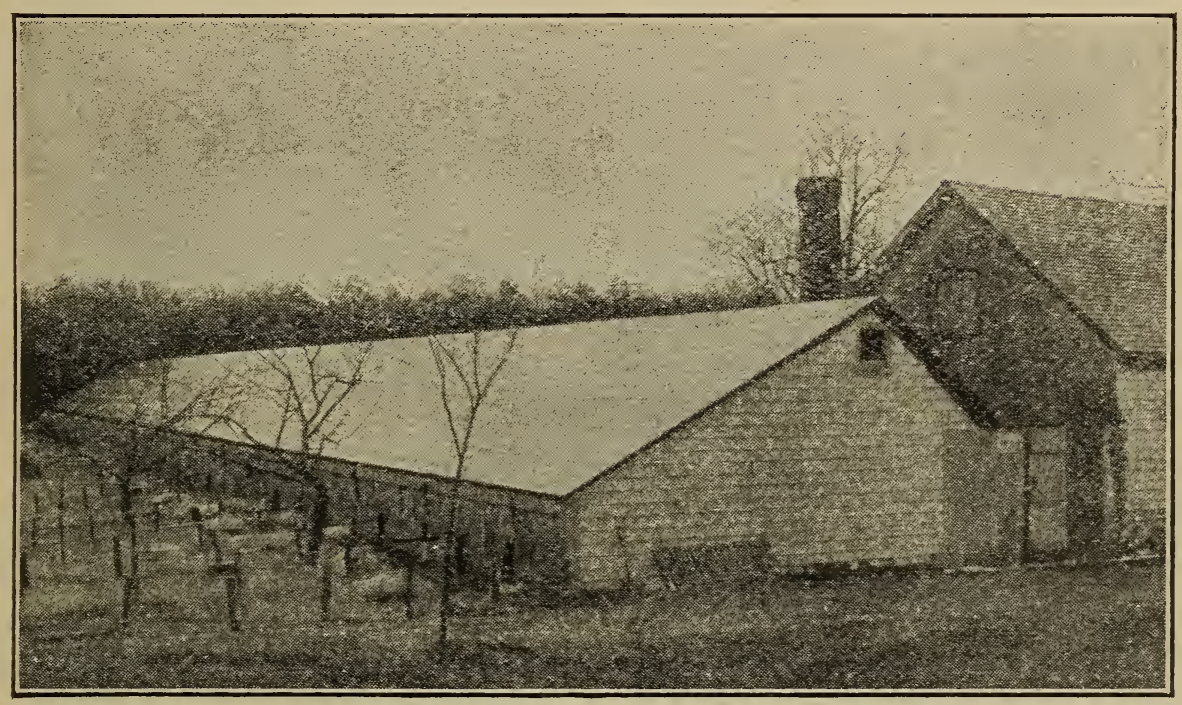

Single Brooding House on Weber Bros. Duck Farm.

As ducks have no crop to store away food like chickens, they cannot eat much at any one time, but must eat often. They are always watered before being fed so they will not choke when eating. No food is left on the boards because it will sour and cause sickness among the ducklings. They are fed on small boards with cleats nailed on the sides just high enough to keep the food from getting into the dirt. A man goes along with a pail, walking on top of hovers, and feeding all in the pens in a short time. He then comes back, and where they are still hungry he gives them some more. The second day they are given a mixture, by meas- 
ure, of rolled oats four parts, bread crumbs two parts, scalded corn meal two parts, with fine grit mixed in. It is mixed with water to a crumbly state. This is fed for three days five times a day. They are never allowed to be without water to drink. The third feed is equal parts of second feed and rolled oats. This is fed for two days five times a day. The fourth feed consists of rolled oats one pail and regular feed (described later) four pails, with plenty of finely cut green food, such as rape, young corn, clover and rye. This is fed until they are two weeks old, five times a day. This is called the "oat meal feed." The green food is all raised on the farm and cut when needed, so it will be fresh and green when fed. It is all cut from a hand ensilage cutter.

\section{Care of the Growing Ducks.}

In the double brooder house they are fed on what is called the regular feed, consisting of I5O pounds of corn meal, three bushels of bran, ninety-five pounds of low grade flour, and thirty-three pounds of meat scraps, with occasionally linseed oil meal, pin head oat meal and screenings from breakfast foods added. To all of this is added finely cut green food. Gradually, as the ducks increase in size from two to five weeks, the number of meals is reduced. At five weeks old they are moved into the cold brooder houses. These houses, as the name implies, have no heat. Here the ducks are fed more sparingly morning and noon. At night they are given as much as they will eat and a little is left on the boards which they will clean up before it is dark. No matter what the age of the duck, no food is ever left on the boards at any time except at night. Shelters should be built for them in the yards to shield them from the heat of the sun so they can keep cool when the houses are too warm for comfort. They cannot stand the hot rays of the sun which will cause them to have paralysis. From four weeks old until marketed they are watered in large troughs. They are now fed three times a day until they are marketed. 
They are kept in these cold brooder houses until they are eight weeks old, when they are moved to the fattening sheds. These sheds have open sides built close to the ground, with yards on both sides. The ducks are fattened here and then driven to the killing sheds when wanted for market. They are about ten weeks old when marketed. Here they are especially fattened from one to two weeks

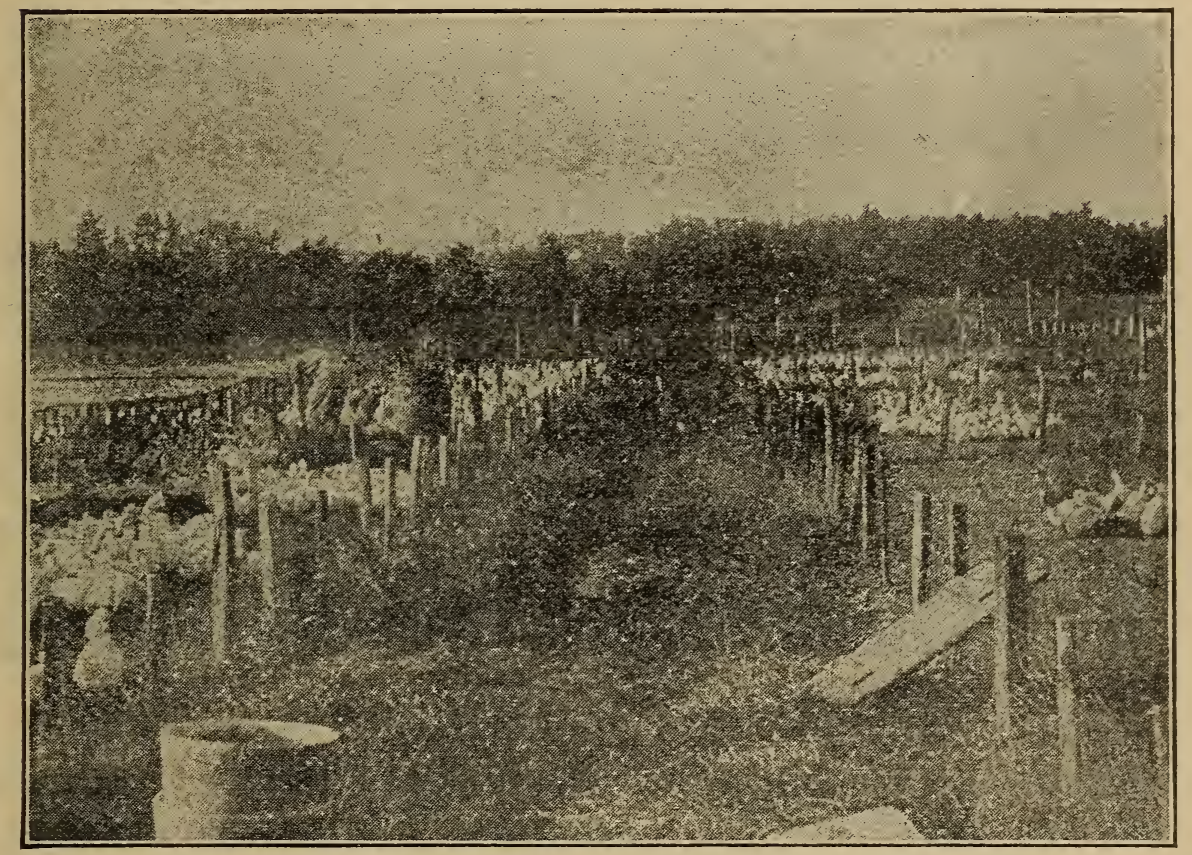

Feeding Thousands of Growing Ducks on Weber Bros. Duck Farm.

before killing. They are fed the regular feed morning and noon and at night a fatter's food, consisting of Ioo pounds corn meal, sixty-six pounds low grade flour' and sixty pounds of meat scraps with plenty of green food mixed in. In very warm weather the corn meal feed is dispensed with on account of its heating power, as it is likely to throw them off their feed. The night before being killed they are driven up to the sorting pens where they are all fed and watered for the night. The next morning they are given water 
only. In driving the ducks they are moved slowly and quietly, as they are weak on their legs and cannot stand undue excitement. The morning they are to be killed they are sorted; the ducks with full breasts, well filled out, are

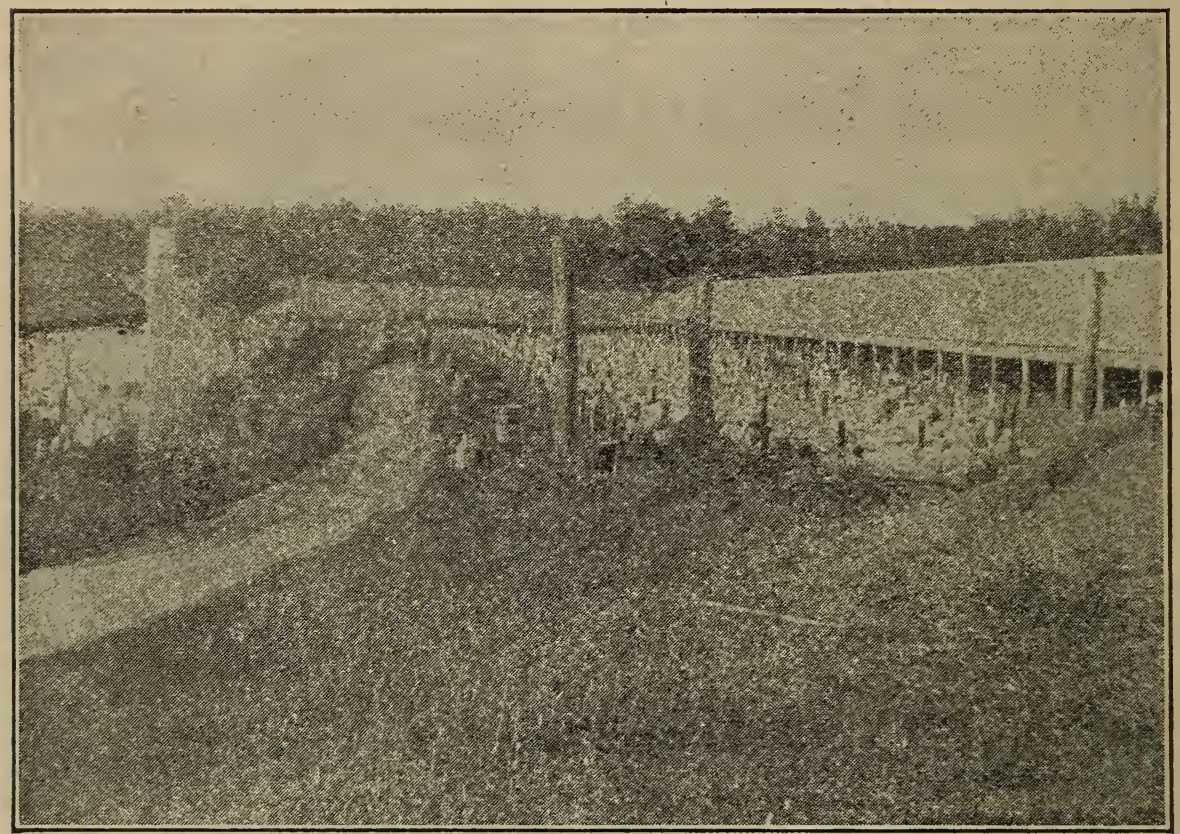

Fattening Sheds in Use on Weber Bros. Duck Farm.

taken up to the killing house and put into pens connected with it. The poor ones are taken back to the fattening sheds.

\section{The Ducks Are Dry Picked.}

The ducks are all dry picked. This method gives the dressed duck a fine appearance; the skin is not torn or bruised in any way, it keeps longer and sells for a higher price. The feathers can be saved and sold as uncured duck feathers. They are collected each evening and spread upon a floor in the second story of one of the large feed houses where they are dried and then are ready for shipment whenever desired. They are packed in large white bags and shipped to the various markets where the highest prices 
are obtained, Chicago being the main shipping market. The purchaser pays the freight or express charges. In I905 they were bringing forty-eight cents per pound at wholesale. The pickers receive seven cents per duck and as it takes eight ducks to make one pound of feathers, you see the picking of one duck costs only one cent after you deduct your price of feathers from price paid the pickers. The pickers will average fifty ducks per day, and some of the pickers have picked as many as seventy-eight in one day of ten hours.

'The picker takes the duck by the neck and stuns it by hitting it just back of the head. He then runs a knife down the throat and severs the main arteries. On the way to the picking bench he pulls out the tail feathers and throws them on the floor. He then places the head of the duck between his leg and the picking box and commences to pick the feathers from the breast first, because it is the tenderest part of the duck. He then picks the feathers from the back and to the first joint on the wing. When the feathers are all off the duck is shaved with a sharp, concave knife to remove all pin feathers and down that could not be removed otherwise. The duck is then cooled in ice water to remove bodily heat. They are never drawn for market. When the ducks are thoroughly cooled they are taken from the ice water and packed for market. In the early part of the season they are shipped to the New York markets and later to the Boston markets. They are packed in barrels for New York and in boxes for Boston. The method of packing is as follows: First a layer of ice and then a layer of ducks, then another layer of ice; and so on until the box or barrel is filled. In June, I905, ducks were selling for nineteen cents per pound at wholesale.

The cost of rearing a duck to five pounds is considered thirty-six cents, including the dressing of the duck. This will vary on account of the different methods employed and prices of the feeds used. The cost of the food is 
twenty cents, cost of labor and brooding ten cents, cost of picking six cents. This, when the duck is marketed at from fifteen to twenty-five cents per pound, leaves the grower a good profit.

The main part of the employees are through with their work by November first. The pickers have left and all of the surplus stock has been disposed of.

All houses, as soon as vacated by the stock, are thoroughly cleaned and six inches of sand taken out and new sand put in, all ready for the next season's work. The fences are all taken down and the yards plowed up and sown to rye.

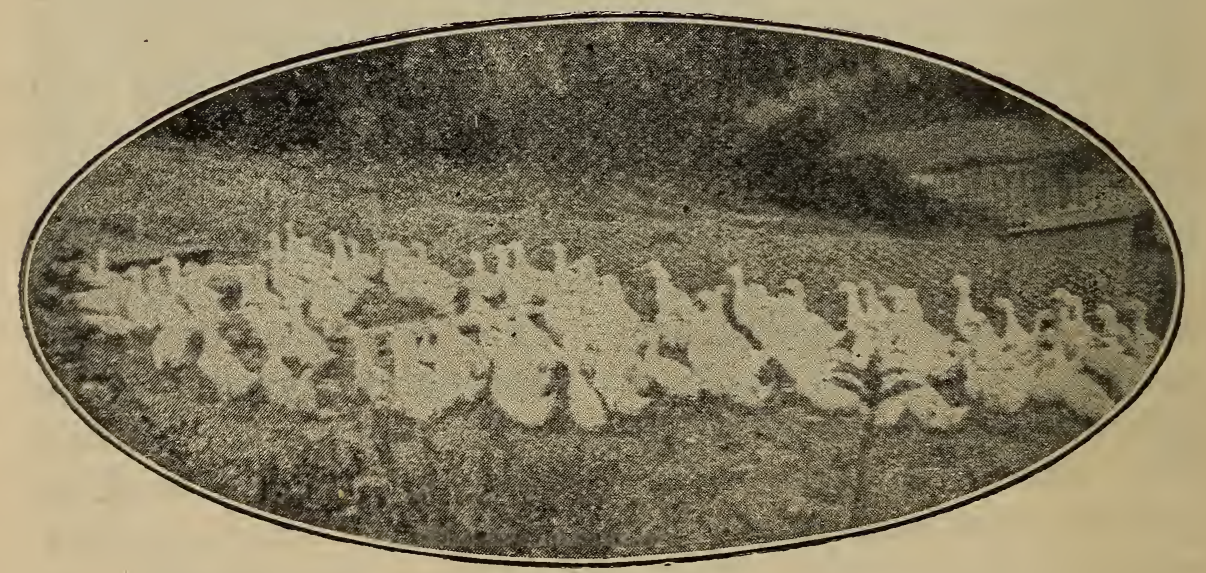

Ready for the Next Meal. 


\section{DUCKS ON A SMALL SCALE.}

The farmer or village poultry keeper who does not wish to raise ducks on a large scale but who desires to produce a small flock each year for his own table, does not need the expensive equipment usually found on the farms of extensive duck raisers. If he does not want to trouble with incubators he can hatch the duck eggs under hens, or under the ducks themselves, and rear them without the aid of brooders.

When reared by hens, which are usually more successful mothers, all things considered, than the ducks, the process is not different from that of rearing chicks except that the food for the ducklings is of mash while the up-to-date methods of feeding chicks call for an entire dry grain ration.

The hen must sit four weeks before the ducklings will appear instead of three, the time required to hatch hen's leggs. When the ducklings come out the hen and brood may be placed in a coop and occasionally the hen may be let out for an hour after the ducklings are a week old.

The little ducks do not need water to swim in any more than do little chicks, but they must have plenty to drink and always have it when they are eating. It is necessary for them to take first a mouthful of food and then a drink of water in order to be able to swallow the mash. As they grow older, say after ten days old, they should always have their water in a dish deep enough so they can plunge their heads into it up to or over their eyes. This is to keep their nostrils and eyes clean and is very necessary. If a very deep vessel is used, however, the top should be covered with slats through which the ducklings can reach the water but near enough together so that the youngsters can not fall through and be held head down in the vessel until they drown. 


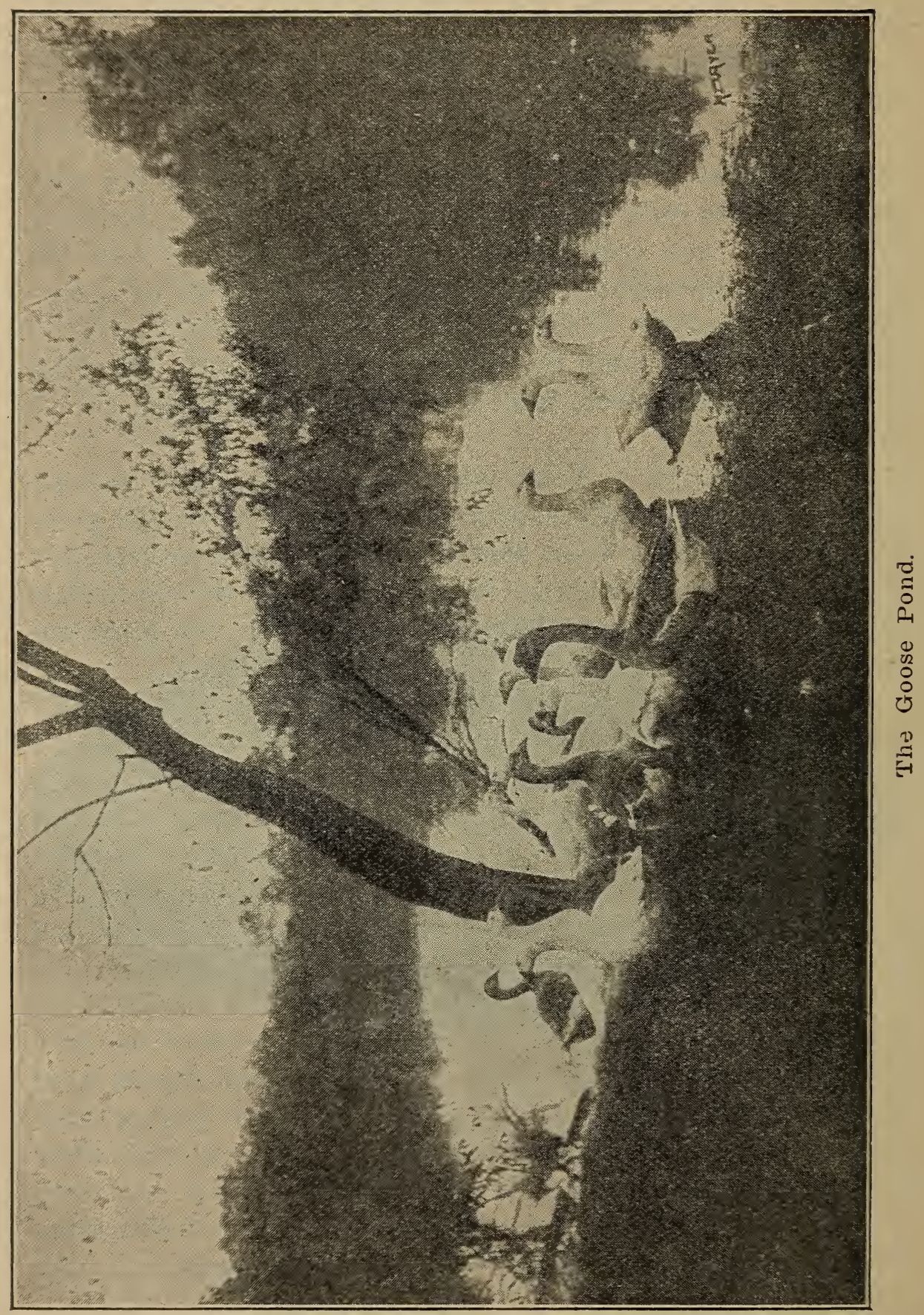




\section{BREEDS OF GEESE.}

\section{The Principal Characteristics Which Indicate Their Usefulness for Practical and Ornamental Purpeses- \\ A Comparison of Size.}

\section{By H. A. Nourse.}

The American Standard of Perfection recognizes six distinct breeds of geese, namely: Toulouse, Embden, African, Chinese, Canadian or Wild, and Egyptian. Only one of these breeds, the Chinese, has more than one variety and it has two, the Brown and White.

The largest of these breeds are the Toulouse, African and Embden, all having the same weight requirements in the Standard, though the first two are larger as a general rule than the Embdens. Specimens of Toulouse and African varieties, which weigh a good many pounds over Standard weight, are very common and now and then an Emb-den exceeds the weight required by the Standard, but as a rule that breed does not attain the size of the other two.

The general color of the Toulouse and African breeds is gray, but that of the Embden is pure white. In practical qualities there is probably very little difference in the three breeds, though some breeders claim that the Africans are rather better lavers and that they mature at an earlier age. Of the three the Toulouse is undoubtedly the most popular in America, with the Embden second.

In the second class, as regards size, are the White and Brown Chinese and the Canadian geese, all of which have the same Standard weights. These are rather more ornamental than the larger breeds and have longer necks, rather more gracefully formed and carried. The Chinese varieties are said to be excellent lavers for geese and the 
White variety especially is quite extensively bred and highly recommended as a practical, general-purpose goose.

The Canadian or wild breed is comparatively domesticated, but is more inclined to roam than the other breeds we have mentioned. It will fly high enough to get orit of almost any enclosure unless the wings are clipped or tinless the last joint of the wing is removed when they are very young. They are not bred to any considerable extent, except for ornamental purposes, and are found most often in the yards of fanciers and in public parks and gardens.

The Egyptian geese are the bantams of the goose tribe and weigh scarcely more than a full-grown Plymouth Rock fowl of Standard size. They are bred principally on account of their odd appearance and small size, which is to say, they are almost purely a fancier's breed. They are born fighters and quarrelsome at a most all times.

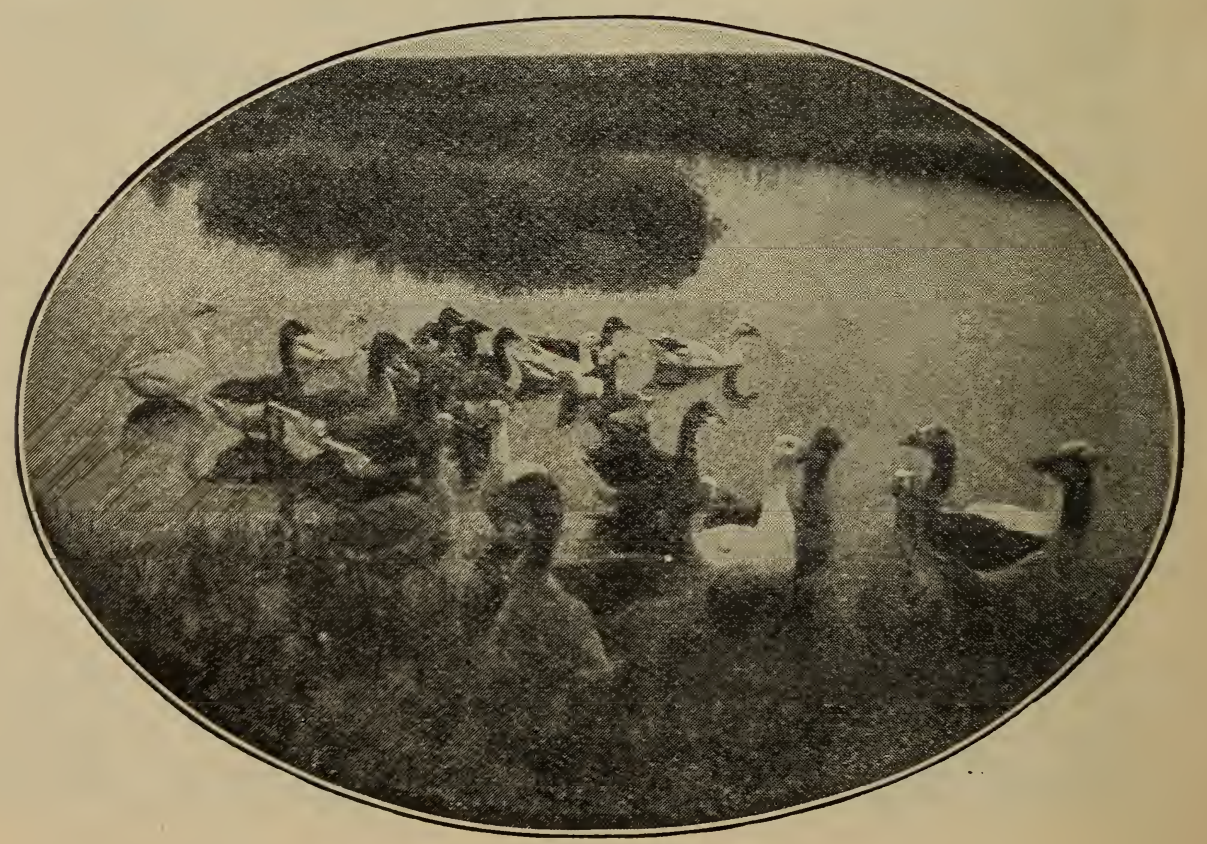

A Profitable Farm Flock. 


\section{TOULOUSE GEESE.}

\section{A Breed That Combines Large Size, Rapid Growth and Heavy Egg Production-The Market and Fancy Demands.}

\section{By Joseph C. Dethloff.}

Several years ago I decided that the raising of geese would furnish me a good incone in connection with my other poultry. The first thing for me was to decide which variety would be the most profitable for me to breed. I tried to learn what the common market demanded, knowing that this demand would go hand in hand with the fancy trade. I easily learned that the market wanted the heaviest and fattest geese, and I decided that the Toulouse were nearer this type than any other variety.

\section{Toulouse Are Good Layers.}

The Toulouse geese are very good layers, averaging forty eggs in a season, and if properly mated and in good condition the eggs will prove to be very fertile. I find I get the best results from having them mated in pairs. Although two or three geese may be mated to one gander, usually such matings are unsuccessful. The Toulouse geese are called by many the dry land geese; if they are supplied with sufficient water to drink they will do well without a swimming pool, although a swimming pool will do them no harm.

\section{Rapid Growers.}

The goslings grow rapidly from shell to maturity. They are very vigorous and with good care seldom die, barring accidents, as the lice and the common ailments of other poultry do not affect them. My goslings reach from Standard weights up; from twenty to twenty-two pounds 
for females and twenty-three to twenty-five pounds for inales in December. Average birds weigh sixteen pounds for females and nineteen pounds for males. The highest weight birds are exceptionally fine.

The market for fancy geese is good. It is true one does not receive as high a price for single specimens as for chickens, but will receive a good average price for all, as

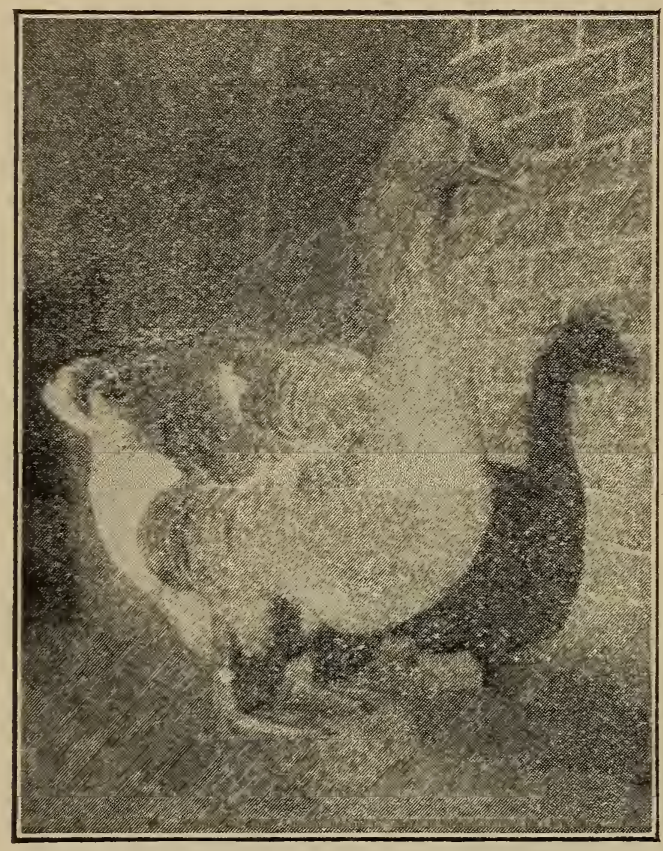

A Winning Toulouse Gander. most geese are good specimens in a wellbred flock. Goose raising is fast becoming a leading industry. The goose is now the Christmas fowl, the same as the turkey is the Thanksgiving bird, and there is a bright future for all breeders of geese who will pay careful attention to the requirements of the breeds they keep and the markets they supply. In the common western markets geese bring from nine to twelve cents a pound, while good breeders range from two to fifteen dollars apiece according: to quality.

\section{The Farmers' Geese.}

The Toulouse geese are more compact in shape than other varieties and are preferred by many for this reason. They have broad backs of moderate length, their breasts are broad and deep, and they are not as noisy and pugnacious as some other breeds. Being large birds and not 
laying as many eggs as ducks, they cannot be satisfactor.ly handled by artificial methods. Anyone cannot coniluct the goose business on as large a scale as the duck business. But every farmer sliould have at least a couple of pairs of breeders to raise a nice flock of young geese each year.

The goose occupies the same place among poultry that the sheep do among live stock and if rightly cared for are just as profitable in proportion. On farms where they have unlimited range they will gather the largest portion of their food, consisting of grasses and insects, and therefore require very little grain except in the winter months, when they need a small quantity each day to keep them in good condition.

\section{Simple Shelters Suffice.}

Geese do not need elaborate houses or shelters. Breeding geese prefer to stay in the open both summer and winter except in the coldest and stormiest weather, when any rough shelter will do.

The young birds keep changing in color until they are in full feather, then they remain the same, both male and female. The male is the coarser and larger bird, with more of a masculine look about the head. But one not familiar with them cannot distinguish between the sexes until they about reach maturity, when their voices become different, that of the female being hoarse and the male squeaky. 



\section{AFRICAN GEESE.}

The Writer Claims That They Are Especially Valuable on Account of Their Rapid Growth, Early Maturity and Excellent Laying-The English African Compared with the American TypeDistinctive Features.

By F. L. Sewell.

It was Mr. Samuel Cushman's experiments as man- ager of the poultry department of the Rhode Island State Agricultural College at Kingston, some years ago, that convinced him of the superior value of the African geese, and afterwards led him to establish a farm where the majority of the geese kept were Africans, numbering several hundred. A number of other Eastern farmers have found it very profitable to keep the Africans pure and breed them extensively. One of them gives as his reasons for thinking the pure-bred African "the most perfect goose": "They lay more eggs, mature earlier and make more pounds of flesh in the same time, while they are very vigorous and hardy, and you will almost always raise all you hatch."

Their proud carriage, with their immense size and peculiar markings, have caused much comment and their early laying is remarkable. A well-known breeder writes: "My African average has always been the largest. Thirty years ago I rarely had a bird that would lay over thirty eggs; now they often lay sixty and occasionally more. When I was a boy my father used to say: 'If you raise ten goslings from a goose you are all right.' Now we feel that we ought to raise from twenty-five to thirty."

Geese eggs have never been a matter of merchandise, as they are too valuable in the rearing season to raise 
goslings from. However, these Africans sometimes lay in the autumn, and the value of eggs laid at this time for table purposes helps considerably towards paying for their keep. Geese of such grand size, with such vigor and hardihood, laying so early in the season and producing such large goslings at so early an age, and gaining much of their living directly by grazing like cattle and sheep, are worthy of more attention from farmers who study to make the most from their land.

\section{The African in England.}

English writers do not make separate classes for African and Chinese geese as is done here in America; in fact, they class both under the head of Chinese, but credit this class with coming from China, India and even Africa.

The several importations of "Hong Kong," "Knotted Geese," "Guinea Geese," etc., brought among the earliest importations the large breed now known to the American fancier as the "African Geese." These have shown quite a distinct type from those later acquisitions called the Chinese geese, which are considerably smaller and lay much smaller eggs.

Lewis Wright, a noted English authority, says of the Chinese: "In size it is midway between the common goose and the swan, whence it might probably be bred with care to very great weight, and in one point it has a most decided advantage over all other breeds of geese, viz., in prolificacy; while other geese lay as a rule once a year, though some will lay twice, the Chinese goose usually lays about thirty eggs before desiring to sit and will raise three or even four litters in one season," and goes on to say, "the eggs are not so large as those of the common goose, not exceeding about two-thirds of their size." This would lead us to believe that the Chinese geese of England are of the same breed as those of the later importations which came to America, as these lay small eggs as com- 
pared with those of other geese, (though many of them); while the African geese of the type first brought to America., lay the largest eggs of all breeds of geese.

It is very probable that both types, the African and the Chinese, must have sprung from the same source at a very early date, but that the African has been improved along some very different and distinct lines is very evident in its immense size, its eggs being the largest of all geese, and its goslings attaining such unusual size at so early an age. It has certainly been improved in very sensible and profitable ways.

The English breeders do not claim to have the African seese, nor do they claim to possess stock of the type with such weight as the earliest importations of "Africans" still bred and kept up here in America. However, some of the Ispecimens which they call Chinese show characteristics which are held by some breeders of Africans to be distinctly African and not to belong to the Chinese, as for instance, the well developed dewlap.

\section{The American Type.}

We can describe the African type by the sketch of a promising young gander, hatched the Ioth of April, five months old when sketched and in show condition. It is remarkable how closely and firmly put together and yet what immense bodies these Africans develop. This sketch presents one of good, moderate, all-round proportions, broad, deep and heavy in body, with neck long enough to look graceful and showy, yet not of such extreme length as to appear ridiculous or uselessly long in that section, if dressed for market. We do not favor extremly long necks or legs on any type of fowls bred for market. The market favors the more compact kind.

We once heard an old veteran breeder say: "Show me the head of a fowl and I can easily tell what's behind it." The broad, deep, massive head of the African goose is very 
indicative of the body that it belongs to ; it is easy to foretell, the body that will be developed in a young African by the type of its skull and bill. The young goose whose head is portrayed in the sketch, a massive head for a young goose, at an early age showed this massive type of skull and bill. She not only made the heaviest young goose, but she gained her full growth at a remarkably early age, and was at a

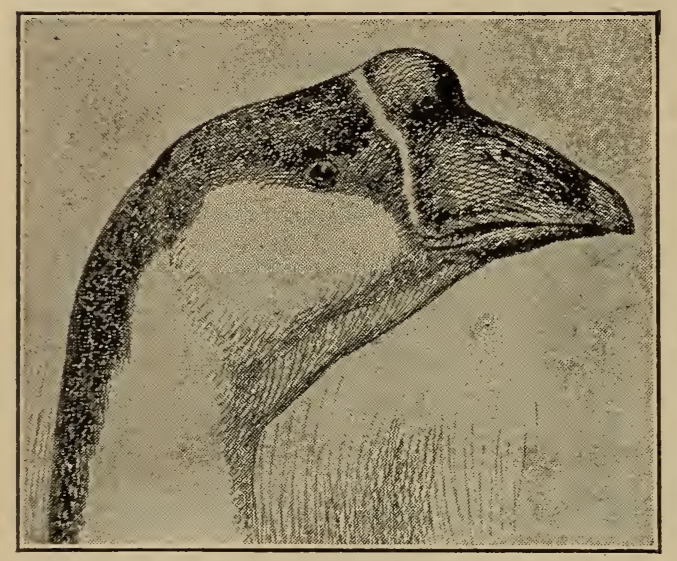

Head of Toulouse Goose. marketable stage two or three weeks ahead of the rest; naturally her value as a breeder was much enhanced by this early maturity, as this is one of the first qualities sought by progressive goose raisers.

The sire of this young goose just mentioned and the young gander sketched, possessed an extraordinarily massive head. The accompanying sketch shows him as he was at eighteen months. The head, bill, knob and throat is very correct for the African. Particular value as a fancy point would be credited by fanciers of Africans to the square front of the knob; a knob which grows loose and flabby and has not good foundation, but lops forward or sideways, is especially disliked by breeders of this variety, for the show rooms. The shape or position of the knob on the head is a point which exacting fanciers are giving attention to just as chicken fanciers look to the combs of their fowls, realizing that it can be an ornament or a great blemish to an otherwise showy bird. The dewlap of the African is only siightly developed the first year. However, it should make its appearance when the bird is a yearling, and grow grad- 
ually until fully developed, which is about its third autumn. Then it should be a well-hung dewlap, from an inch to two below the throat, to as low as the depth of the head, as it is seen in some aged specimens.

A very pretty mark on the nicely bred African is the white line that divides the dark forehead from the knob and the base of the bill. We trust nevertheless $\mathrm{t} \mathrm{h}$ a $\mathrm{t}$ fanciers of the Africans will never be so carried away by their many beautiful characteristics as to lose sight of those qualities which have been

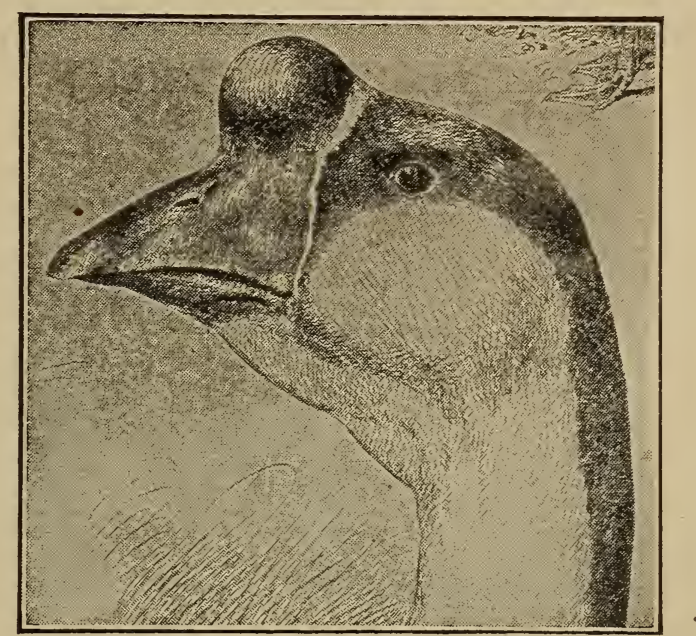

Head of Toulouse Gander.

so clearly brought out by practical comparisons, showing the great value of the pure bred African geese.

One of the factors in goose culture which simplify it considerably, is the long term of years through which the breeding geese are useful. This makes it possible for the farmer to secure the number he needs, to raise the required flock from each year, and keep that parent stock without change for several years. This does away with all the troulble of making new matings every year and of producing and worrying about the new blood which poultrymen frequently feel that they must add to their flocks. 


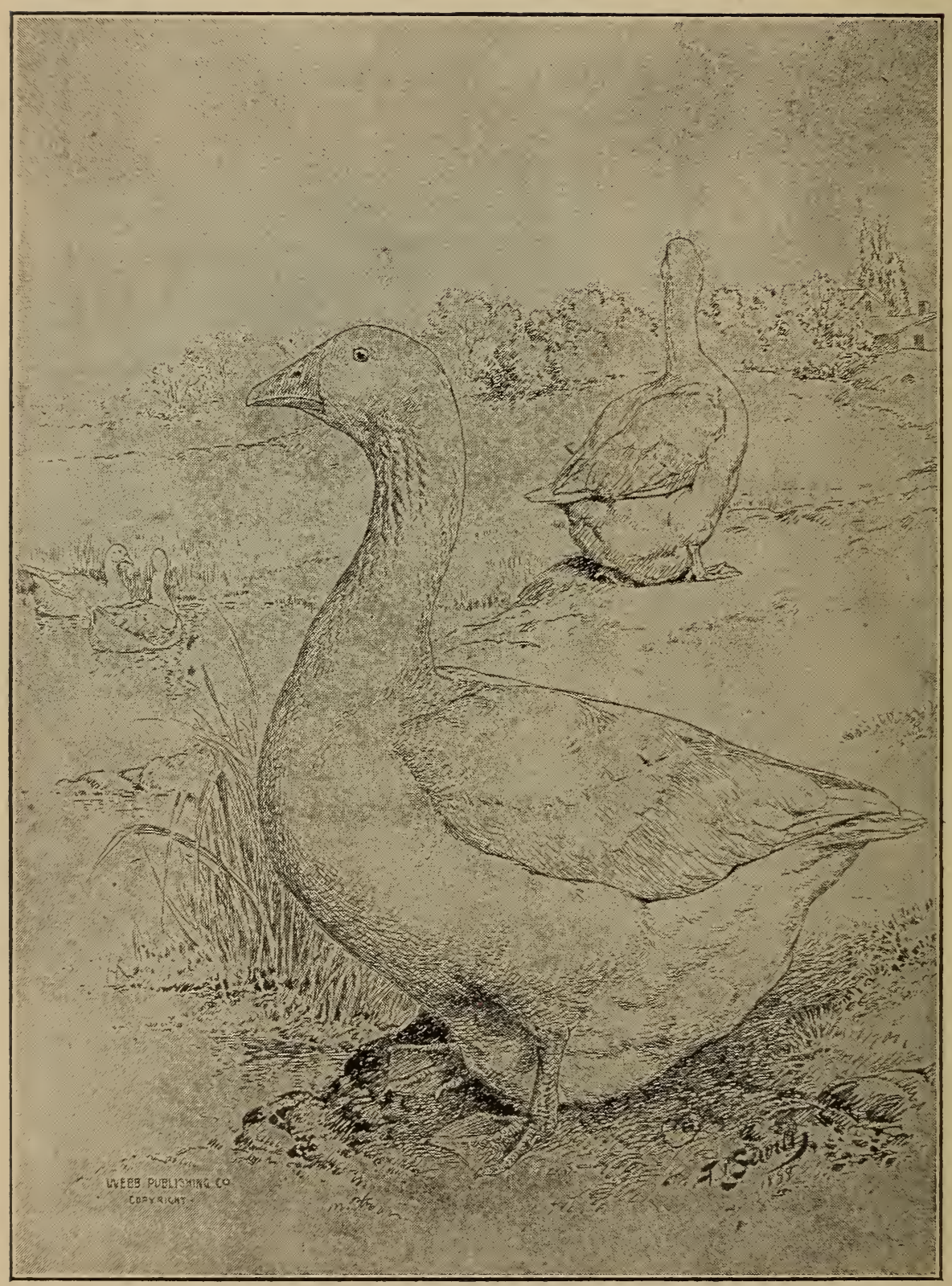

Standard-Bred Embden Geese. 


\title{
EMBDEN GEESE.
}

\section{Facts Concerning Their Introduction in America-Their Size, Longevity and Usefulness.}

\author{
By F. L. Sewell.
}

This breed was first introduced into this country in 1821, by Col. James Jacques, of Boston, who had them for many years on his estate at Medford, Mass., under the name of Bremen Geese, as it was from the seaport city of that name, in Germany, that he obtained them. The name Embden is derived from a seaport city in Prussia, in the province of Hanover, East Friesland, and it is interesting to note that the letter of instruction to the captain of the ship relative to the care of this importation of six geese (two ganders and four geese) is dated "Embden, I 7 th August, I82I." Under the date of December I2th, I850, Samuel Jacques, Jr., writes, "The original stock has never been out of my father's possession, nor has he ever crossed it with any other kind. In 1826 one of the imported females was marked by cutting a hole through the web of the left foot with a gun-wad punch, and in 1850 she was in as fine health and vigor as any of her progeny. She has never failed to lay from I2 to I6 eggs every year for the last 27 years, and has always been an excellent breeder and nurse. In I 849 one of her brood, at exactly nine months old, weighed 22 pounds. The progeny of this importation was sold in almost every state in the Union, as also Canada and Nova Scotia."

In I826, James Sisson, of Warren, R. I., imported a trio from Bremen, and others were imported about the same time by John Giles, of Providence, R. I. In 1852 a pair imported from Bremen by Burnham weighed on ship- 
board, alive, $55^{3} / 4$ pounds, and was sold with four others to a gentleman in New Orleans, La., for $\$ 50$ per pair. This is interesting as showing the age to which many geese attain and continue productive, and to note the high figures obtained for the Embders in their earlier days in this country.

Some aged geese in England are credited with having been "in full breeding to at least forty years old." This

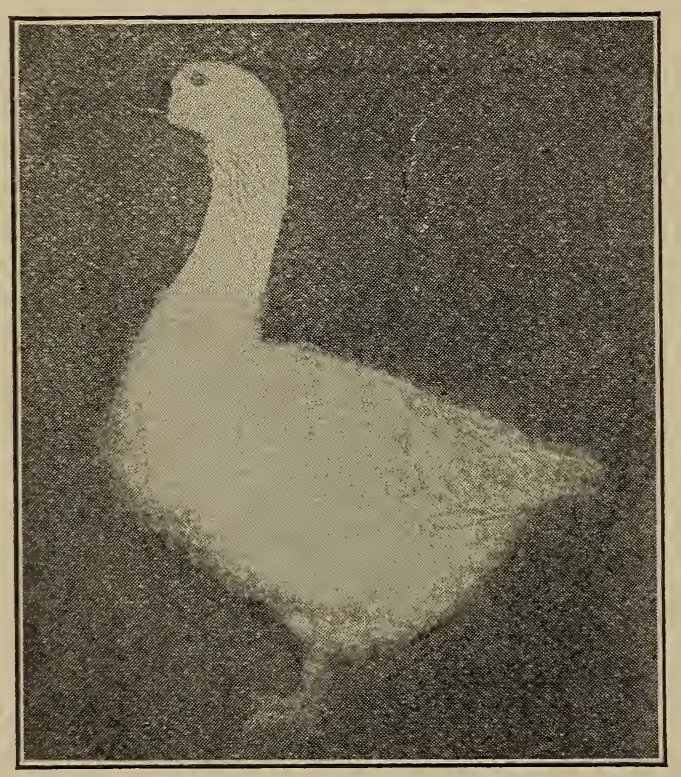

A First Prize Embden Gander. longevity of the goose makes it unnecessary to add new blood to the stock nearly every year, after the sufficient number are obtained, as is the case with chickens and ducks.

The white feathers from the breast and under parts of the Embdens bring the highest price; and their light colored flesh and bills seem with the majority to prove the most attractive in the markets, especially so with the Jews, who purchase a great many geese for their feast days. It is said that it is almost impossible to sell a Jew a dark billed goose if he can find one with a light colored bill in the market. The pickers also say that it takes less time to get a white goose into a marketable appearance than one of dark plumage. These conditions and popular prejudices help to make the Embden geese very profitable for the farmer to keep and rear for the best paying markets. 


\section{WHITE CHINESE GEESE.}

\section{Two Prominent Breeders of Geese Tell Why They Believe This Breed is the Best.}

\section{By Glen Oak Farm.}

Being comparatively a new breed in this country, a few words about White China geese would not be objectionable. We have had experience with Toulouse, Embden and African geese, so can judge by comparison. This article is not written to condemn other breeds, for they are all profitable, but we prefer the White Chinas for the following reasons.

As they are not so common as other breeds, they draw the attention of strangers at once on account of their beauty. They very much resemble swans, especially when swimming with their breasts low in the water and their long, graceful necks towering above them. Their pure white plumage, of fineness next to swans' down, makes their feathers of high market value. Being medium sized geese, they bring high prices when sold in the market.

Where we think they are vastly superior is in their great laying qualities. Our geese average nearly fifty eggs during the spring seascn. What surprised us was our young geese, hardly six months old, starting laying November first and we have been getting a number of eggs every day. We do not say this is the rule with all White Chinas, but we know that twenty-five per cent of our young geese are laying now-November tenth. They have had plenty of feed and good care, which accounts for it. The solution of the great problem in goose culture, to have a profitable flock, is to be able to have a large flock of young goslings from a few breeders, so as to keep the first cost of goslings as low as possible.

The wintering of old breeders is quite an item as the winter feed is much higher in price than their summer feed. 
In disposition White Chinas are kind and clocile and not so vicious to other poultry. Being a coming breed with good demand, and not plentiful at present, they bring high prices for breeding purposes. Any one who likes to raise geese and has a good, short pasture for summer feed can make no mistake in starting in this beautiful and profitable breed.

\section{By E. E. Smith.}

The White Chinese geese are the oldest of all breeds of geese-as old as the Chinese Empire. These beautiful geese are a most deserving variety. They combine beauty and utility. They are called the "White Swan Geese," having a very long, slender neck, orange bill and large orange knob on their heads. As now bred they weigh two to six pounds over standard weight. They will weigh, when fat for market, from twelve to eighteen pounds. The feathers are very abundant, fine and soft like swan's down, with flexible quills. White feathers sell for thirty per cent more than colored ones, which is quite an item in their favor. They are early maturing and will lay the first fall, are as good breeders when one year as other breeds at two, and will prove sure and profitable breeders up to twenty-five years old. The Chinese have put hundreds of years of work to breed them to lay until they have developed the laying power so strong that we get reports of 100 to $\mathrm{I} 20$ eggs. But one can be sure of fifty and better, under farm conditions. Their eggs are very fertile and will hatch goslings that live. From the fact that one gets more eggs that hatch well, it is easy to see how one can grow large numbers from a few breeders.

We have grown 150 this season by artificial means; they hatch as well in an incubator as ducks do and are as easy to handle in brooders. It is to one's advantage to buy early, for located breeders prove the most profitable the first season. 


\section{BUILDINGS FOR GEESE.}

About all that geese require in the way of buildings is protection from the wind and storms. Mere cold does not even inconvenience them, provided they have a well-ventilated, dry place on which to sit down and rest. A shed-like structure, six feet high in front and three feet high in the rear, may be built of any length and width that is sufficient to accommodate the geese, allowing each member of the flock at least ten square feet of space. It is not advisable, however, to have it more than twelve feet wide as a wider shed will not dry out quickly when warmed by the sun's rays.

Such a shed may be built of very cheap lumber and covered with tar paper, or may be made more lasting by covering it with some brand of prepared roofing. The front of this shed may be closed with curtains of heavy cotton cloth. These curtains may be tacked on frames which can be made to swing open like doors on hinges, or swing up inside the shed when they mav be hooked to the underside of the roof. The writer is inclined to favor making them to swing open like doors, when they may be held open by hocks attached to posts diriven in the ground.

The main objection to those which swing up inside the shed is that dust accumulates on them and makes them less able to admit light and arr. These dloors may be swung open in fair weather and need be closed only at night, in severe weather and during storms which would otherwise beat in and malie the interior damp and uncomfortable. 


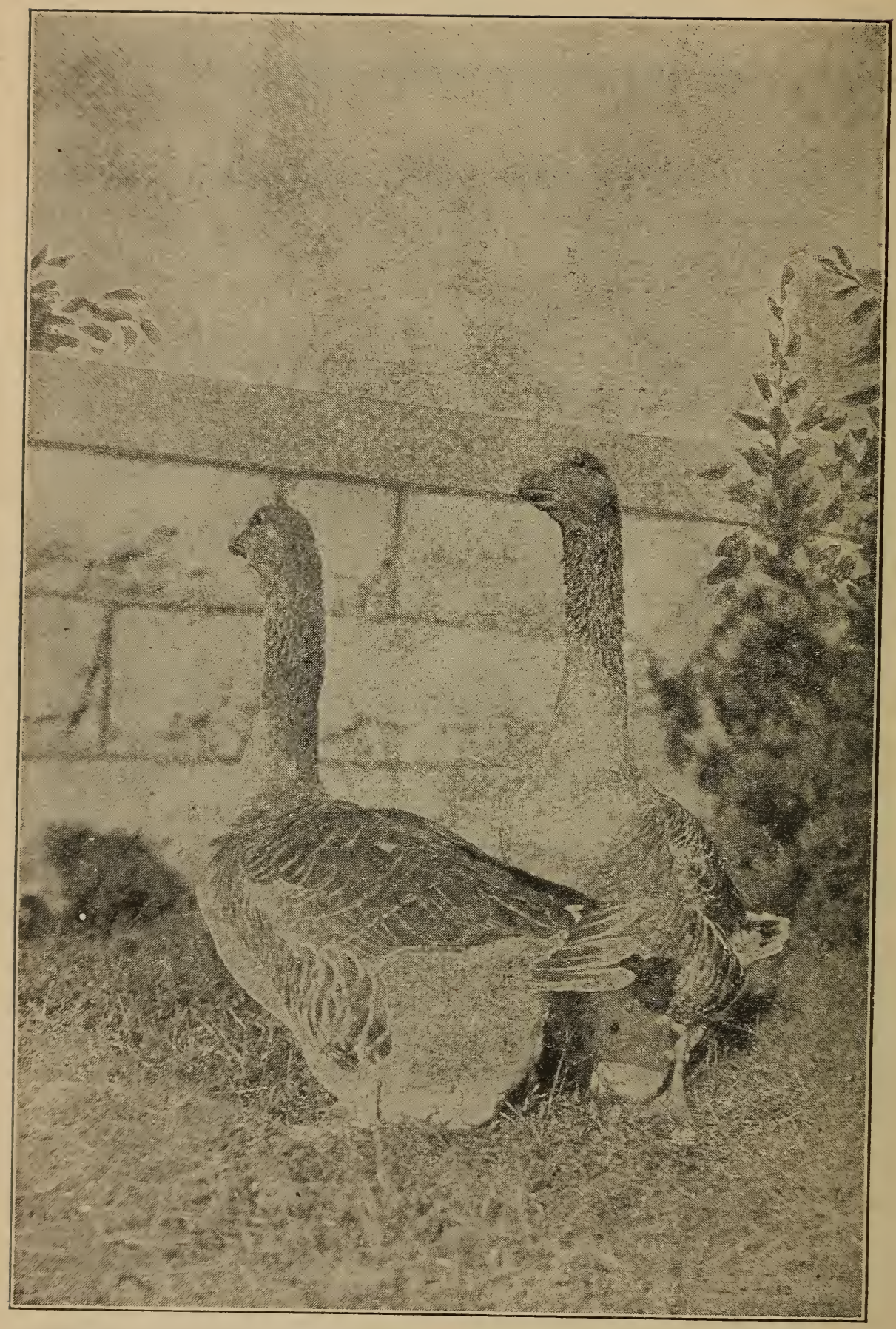

'The Pride of the Flock. 


\title{
SUCGESS WITH GEESE.
}

\author{
Goose Culture Requires Neither Large Capital Nor Expensive \\ Equipment-The Leading Breeds-Selecting, Mat- \\ ing and Feeding the Breeders-Hatching, \\ Brooding and Care of the \\ Young.
}

\section{By Geo. H. Pollard.}

Under favorable conditions no poultry is more profitable than geese. Yet they are sadly neglected and the great bulk of those sold and consumed in the big cities and towns are produced in the West, and most of them are so produced that they are hardly calculated to inspire a decent respect for the good qualities of the goose family as a source of desirable food supply. The necessary requirements for successful goose culture are few and simple and are readily prorided on most farms, and on a good many village places. The most essential is a good grass range sufficient in extent to furnish plenty of green grass for the geese and goslings. The breeding geese will do best where there is more or less low, wet land and where pools or streams are accessible.

Thousands of acres of swale, marsh or meadow land, now unused and returning no profit, could be made one of the best paying parts of the farm if stocked. with breeding geese, and the drier parts used in pasturing and feeding the young. Geese graze about as freely as cattle and will eat a surprising quantity of grass and soft roots. Where the range is sufficient they keep the grass "cut", but do not rlestroy the roots. On tno limited range they eat both root and blade and leave the ground bare. This fact has undoubtedly given rise to the somewhat common notion that 
geese are injurious to grass and vegetation, than which nothing could be further from the truth. No other birds or animals more quickly renew or fertilize worn-out land than properly fed geese or ducks.

In a limited way, geese may be raised in a city yard, and cut green food may be fed while a bucket of water imitates the swimming pool; but they are naturally noisy at times and their habits are so untidy that to persons at all fastidious in taste they will soon become a nuisance to both eye and ear. A few goslings may be raised on a limited area and no other young poultry is so interesting or so quaint in style and motion.

Mature geese are extremely hardy and will endure any degree of cold without apparent harm, yet it pays to provide some rough shelter from wind and storm. An open shed or the crudest of shacks will answer. Unless the geese are shut in, the chances are they will seldom use it; but it is available and gives them a home point where feeding may occasionally be done and if suitable litter is supplied they will most likely choose nesting places within the shelter. Nest boxes are unnecessary. The goose will hollow out a nest, line it with down and lay her eggs therein. The eggs will be carefully covered with litter and generally well out of sight.

Breeding geese should be selected for the object in view. While there are some who handle them only for show purposes, the fancier is less widely interested in geese than most other poultry and the bulk of those marketed are produced only for market and little attention is paid to good breeding or special color or marking. This neglect is a mistake even from a market point of view and costs the producer a percentage of his possible profits which is well worth considering.

The three breeds, which cover practically all the desirable qualities of practical worth, are the African, Toulouse and Embden. To these, perhaps, may be added the 
Canada or wild goose which is often used for crossing and the product of which in the good old days used to water the mouth of the epicure with joyful anticipation or pleasant retrospect. These cross-bred birds, from wild ganders and domesticated geese, were known as mongrels and are not so highly esteemed as some twenty years ago when they frequently sold in the big markets for from eight to fifteen dollars a pair and were never in sufficient supply.

The African goose, in general terms, is a dark gray, with considerable black and has a black bill with a pronounced knob or projection at the base of the bill. They are exceedingly strong and active and naturally quite quarrelsome. The ganders are vicious fighters, and sometimes hard to handle. The geese are good layers, perhaps the best of the three breeds named, though there is so much variation in families and individuals that probably on the whole one breed about equals the other in respect to egg production.

The Toulouse is lighter in color than the African, has a light colored bill, and is stouter and deeper in body and coarser and heavier in under lines. Grade Toulouse and outcroppings of Toulouse blood in scrub geese of dubious ancestry are rery common.

Embden geese are pure white in plumage and have pink or flesh colored legs and bills. Unlike white ducks and most other white poultry, their plumage is not creamy, but is clear, snow white. In size they are somewliat below the Toulouse and about on an average with the African, though of rather closer build than the latter. They supply the white in the pied geese so common in the most. disreputable puddle squads of the back alleys and of careless producers. When dressed at the best age the Emden vields the cleanest carcass, as there are no black pin feathers nor tattoo marks. Feathers, produced in dressing for market are an appreciable item and clear white often sell as high as sixty cents per pound wholesale, while colored feathers are worth ten to thirty cents less. We always protest 
against the picking of live geese as a practice permissable only in dark ages and among cruel, heedless and thoughtless people. The breeds run near enough in practical value to allow of the selection of whichever best suits the fancy of the breeder.

If an old field is available, and there is considerable range, very little in the way of fencing will keep them in. If the feed is poor and good grass is in sight they will sometimes, with the aid of their wings, scramble over a stone wall or low wire fence. Otherwise, a two-foot wire netting, or at most three-foot, will restrain their wanderings. African geese are sometimes fairly good flyers, but we have never seen Toulouse or Embden geese fly.

\section{Mating for Breeding.}

According to the individuals, from two to four geese should be mated with each gander. While mating separate, and where convenient, seclude each mating for a week or two just as the breeding season is beginning, which time will readily be determined by the cries and actions of the birds. After the birds are rightly mated they may be allowed to run together for they will not remate nor mix. In case of the death or disability of a male go through the same process of mating with a fresh male and when a mating is satisfactory, continue it as long as the geese prove prolific, which will usually be several years. Indeed, many breeders consider geese of five years and up preferable to younger birds, but we have found so much difference in individuals that we counsel a selection made from the best producers regardless of age.

\section{Feeding the Breeding Flocks.}

In order that fertile eggs and strong germs may be had, the breeding geese must be properly fed. The natural food of the goose is grasses, water plants and roots and some of the lower forms of animal life. They are easily thrown out of good breeding condition by too heavy feed- 
ing of corn and fattening food, and a large proportion of their winter ration should be of vegetables or roots, such as cabbage, beets, turnips, etc. They are very fond of green corn and if it is not too well matured will eat the stock completely up. As the breeding season approaches, which in New England is generally in February, the ration

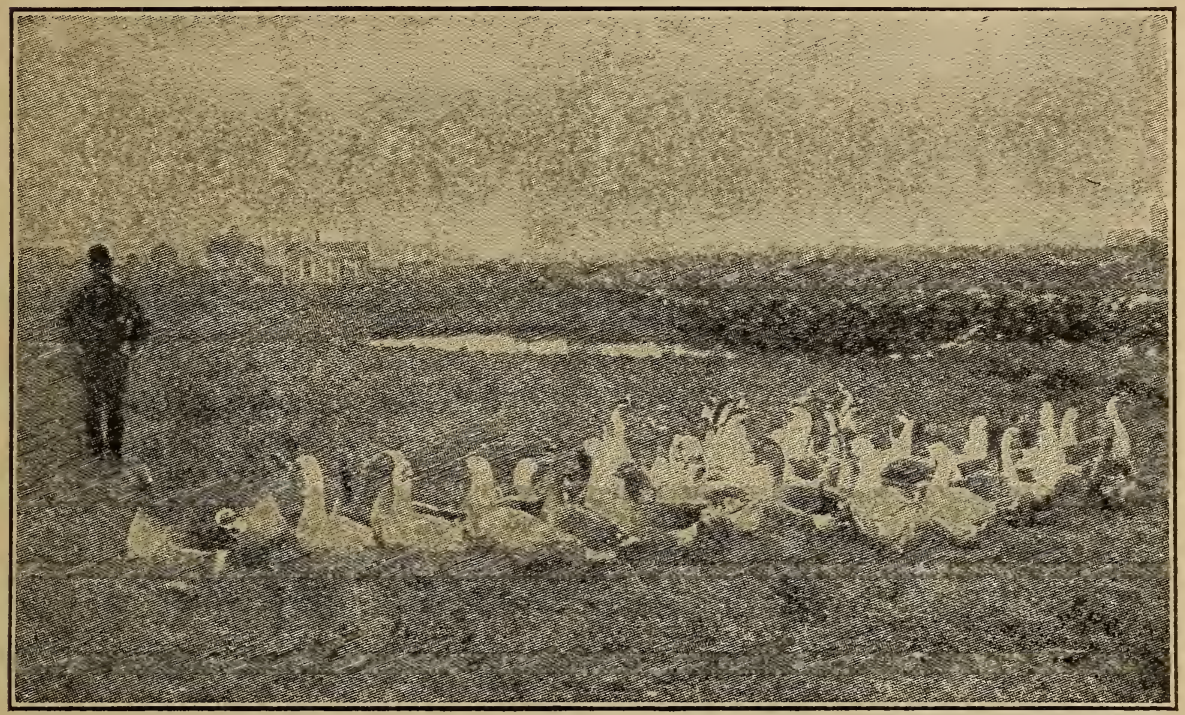

Cross-Ered Geese on a Rhode Island Goose Farm.

should be gradually increased and an allowance of good beef scraps or other meat food will help toward egg production, and in their hatching quality.

It should not be understood that the breeding stock is to be starved through the winter but that they are to be kept in good flesh but not fattened. Twice a day is often enough to feed at any season. If on good grass range, they will pick up their own living but will lay more and better eggs if helped out with some grain and scraps. If $\because$ arded or on insufficient range they should have plentiful feeds of green stuff and a grain ration of wheat bran, Indian meal and ground beef scrap in the proportions of four, three, one, or a dry mash, commercial or home mixed, 
may be kept within reach. They will appreciate some form of grit and oyster shell as much as fowl or ducks. Always keep a supply of drinking water within reach and even in winter see that they have as much as they need to drink. Feed with some regularity and in the same place and the geese will always be on hand and vociferously greet the feecier. They are naturally tame and readily respond to friendly advances.

\section{Hatching the Goslings.}

Most geese lay two litters in a season and the usual number laid totals from twenty-five to forty. It is well to set the first eggs under hens and to break up the goose, not permitting her to sit until the last litter is laid-if at all. Sitting geese are sometimes very ugly and should not be disturbed. A blow from the wing of an angry goose or gander may be severe enough to break an arm or seriously injure a leg, and one who has felt the force of the nasty flap they can give is pretty sure to be prudent ever after. Hatching geese eggs in incubators has seldom been very successful, and hens generally give better results. The єggs seem to need more moisture than hen or duck eggs when run in incubators, and the goslings don't get out of the shell as well as they should. Hens will hatch them if they are hatchable. Not more than four or five should be put under an ordinary sized hen and no special preparation is required. Set the hen in the same manner as for hens' eggrs. We have sprinkled eggs liberally with lukewarm water the last few days of the incubation, but got no better results than when we let the hen do the whole job.

As soon as the goslings are out of the shell, and well dried off we take them from the hen and put them in a warm place, leaving only one or two with the hen until ail are rcady to be taken from the nest. The little goslings are largely neck and head, and hens have a habit of walking on them and often they are killed before leaving the nest. Removing them as they hatch and giving the hen a chance 
to accustom herself to her new "offspring" saves many that otherwise would be lost.

When the goslings are all hatched and ready to go out for their start in the world, confine the hen in a convenient coop and let the little fellows run out on the fresh, tender grass. The hen may also be on grass, but should not be permitted to roam at will, as the goslings are not built for road work and need to be nursed along for a time before entering Marathon races.

\section{A "Growing Ration."}

A great many have been raised on little but the grass they grazed, but to get a quick, profitable growth they should be liberally fed on a growing ration of wheat bran, corn meal and scrap, similar to the laving ration before given, or on some of the commercial dry feeds. They are wonderful growers and may be made ready for market by twelve or fourteen weeks of good feeding and made to weigh from ten to fourteen pounds each. Don't forget that they need a plentiful supply of water for drinking and when old enough to reach into the vessel give them enough so they can run their heads and necks under the surface. Be careful that the pail or tub has slats across the top for many an awkward gosling has met death by losing balance and standing on his head in a water pail.

Before feathering goslings are easily chilled and during: cold rains should be looked after. If one is found chilled or cast on his back in the mud, put him at once in a very warm spot, and keep him there until the chill is past and he is steady on his pins. Often they may be brought around after becoming stiff and apparently dead. They must have shade, good grass, plenty of water and full feeding if they are to meet the demand of the producer for profit and of the market for high class poultry.

When properly grown, nothing in the poultry line is more toothsome. When grown, as too many are, on wiry 
128 TURKEIS, DUCKS AND GELSE

grass and fresh air, one goes a good ways and hurts the demand more than ten good ones can help it.

There is some market for goose eggs for table use. Most of these come from the West and South and are used more by people of foreign birth than by the natives. At Easter time there is a special demand, and many are held in cold storage for sale at that time. It will not pay to raise or keep geese for the eggs alone, but under some conditions they may add considerable to the revenue to be derived from goose culture.

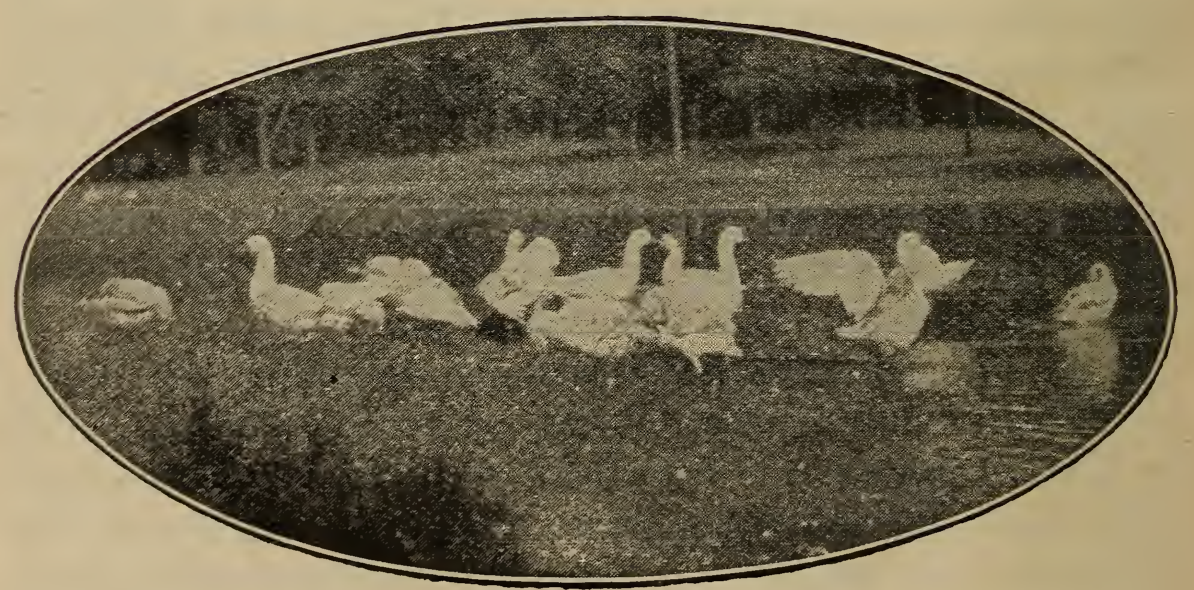




$$
\text { - }
$$





1

• 
LIBRARY OF CONGRESS

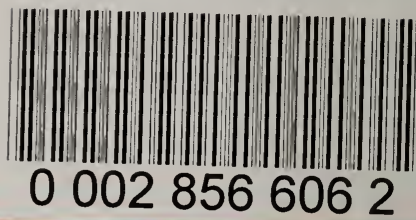

